A Characterization of Land Use Trends Around the Perimeter of Military Ranges

Elisabeth M. Jenicek, Donald F. Fournier,

Natalie R.D. Myers, and Brad Boesdorfer

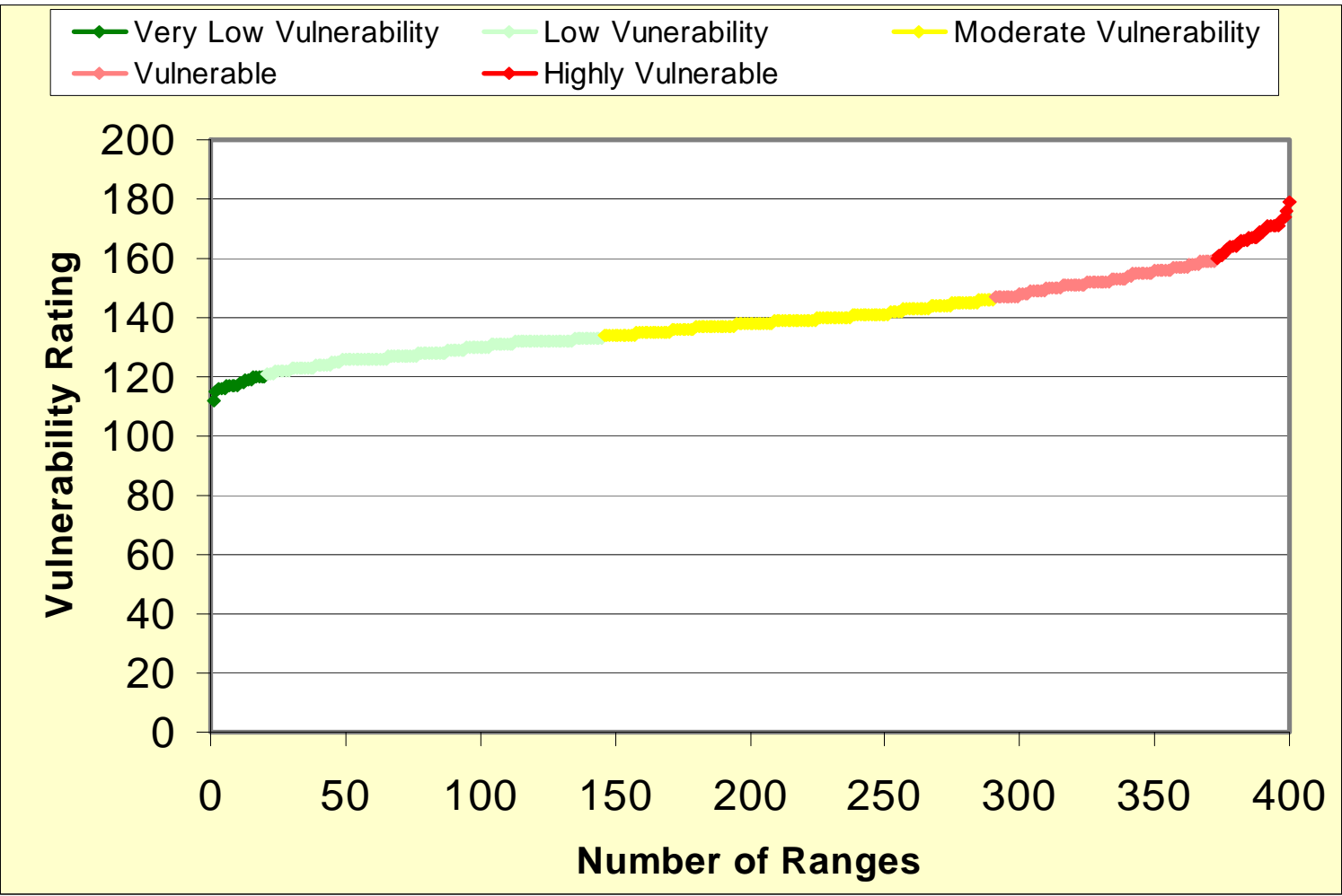




\title{
A Characterization of Land Use Trends Around the Perimeter of Military Ranges
}

\author{
Elisabeth M. Jenicek \\ Construction Engineering Research Laboratory \\ PO Box 9005 \\ Champaign, IL 61826-9005 \\ Donald F. Fournier \\ Building Research Council, University of Illinois at Urbana-Champaign \\ Natalie R.D. Myers and Brad Boesdorfer \\ The PERTAN Group, Champaign, IL
}

Final Report

Approved for public release; distribution is unlimited.

Prepared for U.S. Army Corps of Engineers

Washington, DC 20314-1000 


\begin{abstract}
A key concern for the Department of Defense (DOD) is the impact of urban encroachment on military installations and ranges. Regional competition for land, transportation, energy, water, and other resources may put the ability to use a range for essential activities at risk. The optimal use of ranges in the face of such urban encroachment, as well as changing missions, closures, and realignments requires an understanding of each range's capabilities. This research adapted the Sustainable Installations Regional Resource Assessment (SIRRA) methodology to provide a scientific, quantifiable, reliable, and datasourced system of determining vulnerability to a set of sustainability issues based on data from the surrounding regions. This methodology can be used to identify range installations most vulnerable to encroachment issues identified by the DOD Senior Readiness Oversight Committee (SROC). The region surrounding each range installation is rated based on individual indicators organized by sustainability issue areas. Planners can then review those areas to identify ranges that would benefit from further study, intervention, and planning, and to develop strategic interventions to ensure the DOD's ability to sustain, change, or expand mission activities at the studied sites.
\end{abstract}

DISCLAIMER: The contents of this report arenot to beused for advertising, publication, or promotional purposes. Citation of trade names does not constitutean official endorsement or approval of the use of such commercial products. All product names and trademarks cited are the property of their respective owners. The findings of this report are not to be construed as an official Department of the Army position unless so designated by other authorized documents. 


\section{Contents}

Figures and Tables............................................................................................................................iv

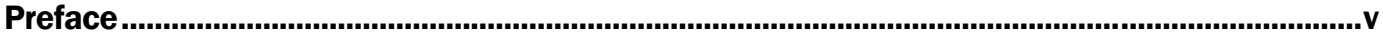

1 Introduction....................................................................................................................... 1

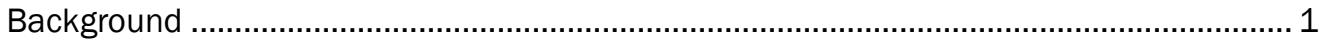

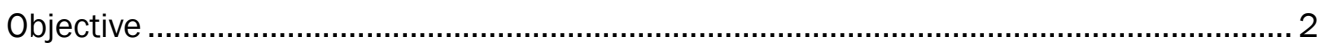

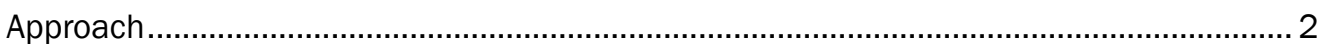

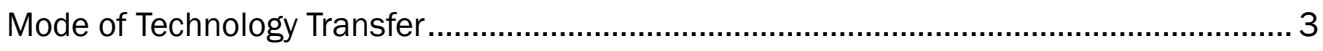

2 Sustainable Installations Regional Resource Assessment ............................................. 4

Regional Resource Assessment Framework and Metrics ................................................ 5

Overview of Indicator Development

SIRRA Indicator Framework 9

Sustainability Issues $\quad 9$

Assessing Endogenous Sustainability ..................................................................... 10

The SIRRA Set of Indicators ........................................................................... 11

3 Methodology ...............................................................................................................13

Analysis Concept .................................................................................................. 13

Analysis Methodology.......................................................................................... 14

4 Results ......................................................................................................................................16

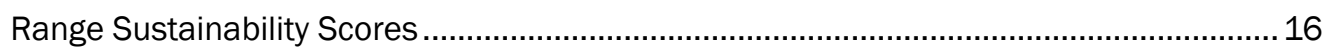

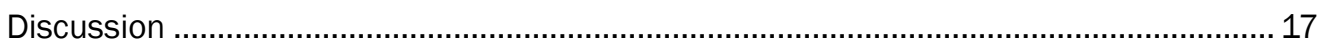

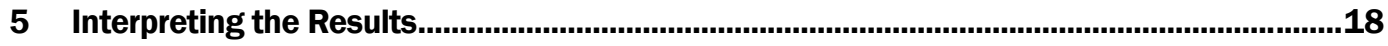

Scoring Implications............................................................................................ 18

Understanding Options for Vulnerability Mitigation ................................................. 19

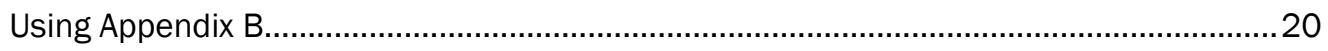

$\begin{array}{ll}\text { Scenario } 1 & 21\end{array}$

Scenario 2

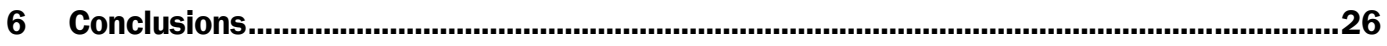

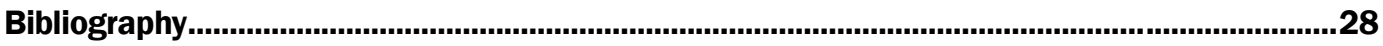

Acronyms and Abbreviations .............................................................................................29

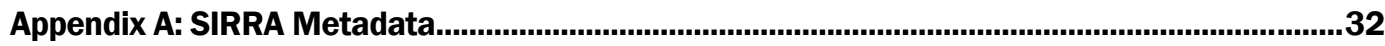

Appendix B: Range Indicator Data ......................................................................................... 166

Report Documentation Page ........................................................................................ 167 


\section{Figures and Tables}

\section{Figures}

1 Regional resource assessment framework with example

$2 \quad$ Range vulnerability scores

3 Screen capture of Appendix B resulting from Step 1 of Scenario 1. Army range installations located in the state of Alabama have been

highlighted

4 Screen capture of Appendix B resulting from Step 1 of Scenario 2. Fort Bliss has been highlighted

5 Screen Capture of Appendix B resulting from Step 4 of Scenario 2. Fort Bliss has been highlighted and water indicators are displayed.

\section{Tables}

1 Matrix of SIRRA indicators by issue area ..........................................................................12

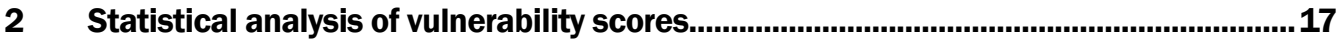

3 Vulnerability classifications based on statistics.......................................................... 17

$4 \quad$ Vulnerability class and mitigation options...................................................................19

A1 Regional data .................................................................................................................53

A2 NERC regional data ...................................................................................................55

A3 Wind power density limits for each wind power class....................................................56

A4 List of railroad crossings in the state of Hawaii (USDoT. FRA 2003) ........................ 155

A5 Annual freeway vehicle-miles traveled, by state (USDoT. FHA 2002)........................ 160

A6 Annual rural principal arterial vehicle-miles traveled, by state (USDoT. FHA 2002).

A7 Annual urban principal arterial vehicle-miles traveled, by state (USDoT. FHA 2002). 


\section{Preface}

This study was conducted for the Office of Secretary of Defense, Installations and Environment under project 83J 949, "J oint Training Range." The technical monitors were Michael Case, Fort Future Program Manager, and William Goran, Special Projects Officer, Construction Engineering Research Laboratory (CERL).

The work was performed by the Energy Branch (CF-E) and the Engineering Processes Branch (CF-N) of the CF Division, Construction Engineering Research Laboratory (CERL). The CERL Principal Investigator was Elisabeth M. J enicek. The associated Technical Directors are Michael Case and William Goran. Part of this work was done by Donald F. Fournier of the University of Illinois at Urbana-Champaign under contract and by Natalie R.D. Myers and Brad Boesdorfer of the PERTAN Corporation under contract. Donald Hicks is Chief, CEERD-CF-N, Thomas Hartranft is Chief, CEERD-CF-E, and Michael Golish is Chief, CEERD-CF. The Acting Director of CERL is Dr. Ilker R. Adiguzel.

CERL is an element of the U.S. Army Engineer Research and Development Center (ERDC), U.S. Army Corps of Engineers. The Commander and Executive Director of ERDC is COLJ ames R. Rowan, and the Director of ERDC is Dr. J ames R. Houston. 


\section{Introduction}

\section{Background}

One of the key concerns for Department of Defense (DoD) installations and ranges is their ability to sustain, and sometimes change or expand, their mission activities. Optimal use of installations and ranges in the face of changing missions, closures, and realignments requires an understanding of each installation's capabilities. Regional competition for land, transportation, energy, water, and other resources may put an installation's ability to perform essential activities at risk. It is critical to understand the factors that impact an installation's or range's ability to maintain its mission.

Over the past several decades, the population and amount of developed land around most U.S. cities and military installations and ranges have grown significantly. Economic expansion driven by the presence of DoD installations spurs development of new suburban communities while services such as utilities and housing offered by cities attract population to urban areas. As a result, many installations and ranges now find themselves at the fringe (or in the midst) of large urbanized or urbanizing areas.

DoD is required to deliver, in early 2006, a report to congress outlining the impacts of urban encroachment on military installations and ranges along with a plan to deal with that encroachment throughout 2010 (Sections 320 and 366). This will be followed by reports to congress 2007-2010 on progress dealing with encroachment. The Engineer Research and Development Center (ERDC) has developed a series of databases and analysis tools that have been successfully used to identify regions experiencing encroachment, analyze recent trends in urban development, identify where residential development is likely to occur, and predict future training opportunities that will be lost as a consequence of urban development.

One of these tools is The Sustainable Installations Regional Resource Assessment (SIRRA). SIRRA is a National level screening tool for assessing relative sustainability of regions and contains many indicators related to encroachment of military installations. The SIRRA framework contains 54 indicators in 10 issue areas: (1) air quality, (2) airspace, (3) energy, (4) urban development, (5) threatened and endangered species, (6) locational, (7) water, (8) economic, (9) quality of life, and (10) transportation. Several 
SIRRA indicators directly relate to the Senior Readiness and Oversight Council (SROC) identified encroachment issues of urban growth, air quality, endangered species, and airspace restrictions. SIRRA indicators such as energy and water are also impacted by encroachment, though not listed by SROC.

Most recently, in a research project sponsored by the Strategic Environmental Research and Development Program (SERDP), SIRRA was adapted to provide relative rankings for the 308 military installations contained in the database. Weighting factors were applied to indicators according to the impact each would have on the installation based on primary mission or function. For example, a training range would be impacted by clean air non-attainment more than would a depot. An index of overall sustainability was created by adding the scores for each individual indicator. Installations were then ranked by service and mission. Results of this work are contained in the draft technical report ERDC/ CERL TR-05-DRAFT Using the Sustainable Installations Regional Resource Assessment (SIRRA) Methodology to Evaluate Regional Vulnerability of Department of Defense (DOD) Installations. This report is currently under review.

Another recent application of SIRRA, funded by the System-Wide Water Resources Program (SWWRP), developed relative rankings for the 2,250 HUC8 watersheds. This analysis used 23 of the SIRRA indicators that impact watershed health. The full complement of 54 SIRRA indicators (six more than were available for the SERDP study) were applied, without weighting, to the watersheds in this analysis.

\section{Objective}

The objective of this work was to characterize the regions surrounding DOD CONUS ranges in relation to issues related to encroachment using indicators from the Sustainable Installations Regional Resource Assessment (SIRRA) tool. Through the use of environmental research and sustainment indices, this work aims to develop a methodology to identify ranges with potential sustainment problems and to rank the ranges by their relative vulnerability to such problems.

\section{Approach}

This project initially characterized sustainment issues using the indicators of the SIRRA tool. The SIRRA tool provides a scientific, quantifiable, and 
reliable data-sourced methodology for evaluating encroachment impacts. These assessments were then used as a screening tool to assess ranges and associated installations for potential encroachment vulnerability for which additional studies, planning, and actions may be recommended to ensure continued viability and sustainability.

\section{Mode of Technology Transfer}

This report will be made accessible through the World Wide Web (WWW) at URL:

http://www.cecer.army.mil 


\section{Sustainable Installations Regional Resource Assessment}

Planners for Department of Defense (DOD) installations and ranges face increasingly complex challenges, due to rapid land use changes, stakeholder involvement in planning processes, and the transformation of $\mathrm{De}$ fense forces, technologies, and global circumstances. In response to these issues, the U.S. Army Corps of Engineers Engineer Research and Development Center, Construction Engineering Research Laboratory (ERDCCERL) in Champaign, IL initiated several projects that are included in a project grouping entitled Sustainability, Encroachment, and Room to Maneuver (SERM). These research efforts are all designed to provide tools, data, expertise, and processes that help the DOD sustain and evolve mission operations, both military and civil works. The concept for SERM emerged from exploratory research initiated at CERL during the 19971998 timeframe. The purpose of SERM is to provide Defense planners with greater flexibility and ability to evaluate complex issues, and to access "the right information at the right time" to enhance their planning outcomes, while addressing current and future planning problems. SIRRA is one of the analysis tools developed under SERM.

Regional resource assessment provides the opportunity to incorporate the broader perspective of regional issues into the concept of installation sustainability and its implications to mission sustainment. SIRRA is a process of characterizing regions surrounding installations based on a set of indicators grouped into several issues (J enicek, Fournier et al. 2004). SIRRA uses uniform assessments with a broad set of indicators covering the range of issues that may affect military installations and their locality. The determined indicator(s) may be used to express the relative ranking of installations or ranges based on single measures (or groups of measures) that define an issue. This standardized approach enables the use of National level data to evaluate the regional aspects of the installation setting. This provides a heightened awareness of long-term issues that could threaten mission sustainment, and allows an evaluator the choice to determine whether an issue or group of indicators is germane to the question at hand concerning a range or installation's future viability. 
This methodology was first developed and presented in the ERDC/ CERL TR-02-27, An Assessment of Encroachment Mitigation Techniques for Army Lands (Deal et al. 2002), and further developed in the ERDC/ CERL SR-02-12, Sustainable Installation Risk Assessment and Stationing Implications (Fournier et al. 2002). SIRRA version 1 was documented in ERDC/ CERL TR-04-9, The Sustainable Installations Regional Resource Assessment (SIRRA) Capability: Version 1 (J enicek et al. 2004). SIRRA Version F1a is currently on line in the web-based analysis tool and contains enhancements beyond the documented version.

\section{Regional Resource Assessment Framework and Metrics}

Assessing installation or range sustainability is a complex activity that requires the evaluation of a combination of indicators related to both exogenous and endogenous factors. These factors may not really lend themselves to prioritization, but may simply present an indication of issues that may need to be addressed in installation or range planning and management. The effects of demographic change, community growth and sprawl, and regional economic vitality present levels of exogenous resource issues that may be a threat to continued mission sustainment or range utility. Issues associated with installation or range mission, management, and cultural and natural histories define endogenous risk. The framework developed in this work looks outside the installation or range and is based on exogenous indicators that could be determined with data sets available nation-wide. Some indicators were deemed so critical that they were retained despite the lack of a National data set. Assessing levels of regional resource and environmental stress or demands entails developing a set of indicators or indices that can provide reliable information about the level and type of a given resource. The resource can vary from availability of clean water to the amount of vehicular traffic congestion in the region (the latter being an indicator of potential air and water pollution from non-point sources as well as the capacity of the existing road networks).

\section{Overview of Indicator Development}

An "indicator" is a piece of information that reflects what is happening in a larger system. It allows observers to see the big picture by looking at a smaller part of it. Indicators are often quantitative measures such as physical or economic data. For example, traditional indicators such as inflation and unemployment rates are used for making economic decisions. Indicators are widely used as a tools for monitoring progress and to simplify, quantify, and communicate complex issues. Multiple indicators are 
sometimes aggregated into an index, usually for comparison across locations or to indicate change over time. Indicators are often used as the feedback mechanism to inform policy changes intended to improve the situation being measured. Their intent in the SERM analysis cycle is to provide the baseline information about the region in which the installation resides and illuminate key issues which may be a current or future threat to mission sustainment, mission realignments, or regional environmental health. These provide the starting point for regional planning and impact amelioration.

Because the process of measuring focuses attention on the impact, it makes a great deal of difference what is measured and how it relates to what we wish to measure. Developing indicators is a six-step process (MacLaren 1996):

1. Define and conceptualize the goals for which indicators are needed.

2. Identify the target audience, the associated purpose for which indicators will be used, and the relative number of indicators needed.

3. Choose an appropriate indicator framework.

4. Define indicator selection criteria.

5. Identify a set of potential indicators and evaluate them against the selection criteria.

6. Choose a final set of indicators and test their effectiveness.

The goal of the use of indicators as described here is to define and highlight regional issues that may define current or future encroachment and resource issues or potential future impacts. The encroachment and mission sustainment issue areas defined by the Senior Readiness Oversight Council are:

- endangered species and critical habitat

- unexploded ordinance and munitions

- frequency encroachment

- maritime sustainability

- airspace restrictions

- air quality

- airborne noise

- urban growth.

Many of these issues are associated with external aspects, what is located and what happens outside the installation or range boundaries. Incompatible residential and commercial development of land close to military installations can affect the ability of an installation to carry out its mission. 
Such development also threatens public safety because accidents sometimes occur in areas surrounding an installation. The economic health of a community is affected if urban encroachment forces military operations and missions to relocate.

The target audience for the indicators and the regional resource assessment are decisionmakers and planners who need broadly based information to inform their processes that determine future stationing, base realignments, and installation or range sustainability actions.

A framework for developing a set of indicators is necessary for every indicator effort. The choice of framework must meet users' needs and priorities. A number of frameworks have been identified and used. These frameworks provide a starting point for any organization embarking on a sustainability effort.

Virginia MacLaren (1996) reviewed four general frameworks for use in organizing sustainability indicators: domain-based, goal-based, sectoral, or causal frameworks. To the original four, MacLaren added a fifth type, known as "issue-based," and a combination framework, which uses two or more of the other frameworks:

- A domain-based framework is based on the three key dimensions of sustainability: environment, economy, and society. Indicators are identified for each dimension. This framework is effective at ensuring that the key dimensions of sustainability are covered. A weakness of this framework is that indicators are not linked to sustainability goals. An example of the domain-based framework is the Sustainable Seattle effort.

- A goal-based framework is predicated on the development of community sustainability goals. Indicators are then created for each goal. A benefit of this framework is it uses fewer indicators. A weakness is that it does not capture linkages among the dimensions of sustainability. Examples of goals are basic human needs, social well-being, economic prosperity, and carrying capacity. The United Kingdom's Local Government Management Board (LGMB) employed this kind of framework.

- A sectoral framework may tie indicators to different sectors of a governing entity. This framework makes it easier to assign responsibilities for problems or results revealed by indicators. A drawback to using this framework is the resulting compartmentalization that often masks linkages between domains.

- A causal framework is useful in explaining changes in indicators or whether policy interventions are effective. A drawback to this framework is that it implies simple linkages between stressors and condi- 
tions that may be very complex. This oversimplification can confuse the issues and lead to erroneous perceptions.

- An issue-based framework may be popular because it addresses visible problems. A weakness of this framework is that it lacks explicit linkages to policy and presents a "shotgun" approach to developing indicators. Some examples of issues are urban sprawl, solid waste management, crime and safety, job creation, and industrial pollution.

The difficulty in selecting indicators is not a lack of measures, but rather the overwhelming number of potentially useful indicators. The InterNational Institute for Sustainable Development selected the following criteria based on indicator literature and practical experience with performance measurement (IISD 2000):

- Relevance. Can the indicator be associated with one or several issues around which key policies are formulated? The indicator must be linked to critical decisions and policies.

- Simplicity. Can the information be presented in an easily understandable, appealing way to the target audience? Complex issues and calculations should yield clearly presentable and understandable information.

- Validity. Is the indicator a true reflection of the facts? Were the data collected using scientifically defensible measurement techniques? Is the indicator verifiable and reproducible? Methodological rigor is needed to make the data credible.

- Temporality. Are time-series data available, reflecting the trend of the indicator over time? Several data points are needed to visualize the direction the community or region may be going in the near future.

- Measurability. Are the data quantifiable-something that can be measured directly or can be counted? Data must be based on tangible information.

- Availability and Affordability of Data. Are good quality data available at a reasonable cost or is it feasible to initiate a monitoring process that will make it available in the future?

- Expansiveness. Is the indicator about a narrow or broad issue? Indicators that aggregate information on broader issues are preferred, e.g., forest canopy temperature is a useful indicator of forest health and is preferable to other indicators that yield the same conclusion.

- Sensitivity. Can the indicator detect a small change in the system? Determine whether small or large changes are relevant for monitoring.

- Reliability. Will you arrive at the same result if you make two or more measurements of the same indicator? Others should reach the same conclusions based on the indicator. 


\section{SIRRA Indicator Framework}

The research team developed a SIRRA framework based on the process, framework, and criteria considerations described above. The SIRRA Indicator Framework is a combination of issue-based and domain-based frameworks. It addresses many aspects of installation range sustainability from a regional perspective. Using a combination framework has the advantage of being able to draw on the strengths of the two frameworks while downplaying their weaknesses (MacLaren 1996). This framework enables a relatively easy assessment of the potential resource issues in a region and highlights the issues within that region that an installation or range may be experiencing. The indicators show where the issues lie and highlight potential long-term sustainability implications.

Figure 1 shows the regional resource assessment framework of issues and indicators, including an example issue-indicator-data relationship. Each indicator measures a different dimension of potential risk or stress. Comparing values for an individual indicator across installations can give a measure of relative stress along one dimension. Each issue has several indicators and sometimes a combination of several indicators or indices. Organizing the indicators by sustainability issue area allows users to determine and consider only those issues relevant for their particular analysis.

\section{Sustainability Issues}

The selected sustainability issues are based on regional resource concerns outside the installation boundaries. The associated indicators were developed based on criteria previously discussed. Community grouth increases the contiguity between outside development and the installation or range. This contiguity increases the likelihood of incompatibility of land use between military missions and nearby urban development resulting in conflicts. The issues to apply to military installations, but a subset of these issues and indicators would also apply to watersheds, political boundaries, energy grids, etc. Water and energy resources are impacted by regional growth and related consumption and contamination. Regional types of energy use and their sources affect energy security and availability. Based on the criteria, the research team developed a set of 10 sustainability issue areas with 54 indicators. The sustainability issue areas are: Air Quality, Airspace, Energy, Urban Development, Threatened and Endangered Species, Locational, Water, Economic, Quality of Life, and Transportation. 


\begin{tabular}{|c|c|c|}
\hline \multicolumn{3}{|l|}{ Issue } \\
\hline & Indicator & Data \\
\hline & Indicator & Data \\
\hline & Indicator & Data \\
\hline \multicolumn{3}{|c|}{ Threatened and Endangered Species } \\
\hline & Number of TES in state & Fish and Wildlife Service \\
\hline & Species at Risk & Journal of American Water Resources Association \\
\hline & Federally listed TES by Ecoregion & NatureServe \\
\hline & TES of Concern & NatureServe \\
\hline
\end{tabular}

Figure 1. Regional resource assessment framework with example.

\section{Assessing Endogenous Sustainability}

The SIRRA methodology was developed to address exogenous sustainability, that is, conditions and stressors that occur outside the military fence line. Other sustainability assessment systems have been developed to evaluate endogenous sustainability - that directly related to activities onpost. One such example is the U.S. Army Environmental Center's (USAEC's) Encroachment Condition Model (ECM) (USAEC 2005). ECM is an indicator-based model used to assess demographic and environmental conditions in support of the Office of the Deputy Chief of Staff for Operations and Plans (DAMO-TR), Headquarters, Department of the Army, task to analyze the relative training value of a variety of active component Army installations. The umbrella effort is the Installation Training Capacity (ITC). The ITC is used to determine installations' relative capability to support live training by Active and Reserve Component units stationed at, or habitually training on those installations as well as live training requirements of Service Schools on those installations. ITC focuses on land, ranges, training facilities, and demographic/ environmental factors affecting training. The study did not consider other installation capabilities such as cantonment area facilities, infrastructure, housing, etc.

The ECM is a process to identify and evaluate:

- environmental regulatory issues

- environmental issues that impact training

- encroachment issues that impact training

- impact of costs to maintain land for training

- environmental ability of the land to support and sustain training

- the installation's capability to expand or reconfigure to support training.

The ECM Methodology is a coordinated effort with USAEC and the major army commands and is continuing to be refined to ensure accuracy of in- 
formation and pertinence of the criteria. ECM has been combined with CERL's exogenous indicator framework to develop a list of environmental factors to consider prior to stationing of forces (Tomich 2002). ITC and SERM complement one another and provide independent approaches to similar issues.

\section{The SIRRA Set of Indicators}

Indicators with the potential for assessing these regional resources within the 10 issue areas were selected based on these requirements:

- the availability of data at a uniform scale nation-wide to ensure consistency in comparisons

- the availability of data recorded for multiple time periods to enable the evaluation of change

- the preparation of data by a reputable source, such as a government agency or professional data vendor, and accompanied by metadata for quality assurance

- the availability of data in a digital format, to accelerate data gathering and preparation for analysis

- the ability of data to be converted to GIS format.

The 10 sustainability issue areas with their corresponding indicators represent a broad spectrum of topics related to resource availability and development. The 54 indicators provide a wide variety of information about population, economics, land development and usage, water availability and watershed health, natural disasters, infrastructure, air pollution, airspace availability, regional energy, and regional quality of life. Indicator data is from a variety of sources such as the U.S. Geological Survey for seismicity information, the U.S. Environmental Protection Agency for air quality data and water supply characterization, the U.S. Fish and Wildlife Service and NatureServe for endangered species data, the U.S. Census Bureau for population statistics, and the U.S. Department of Energy for energy-related data.

Appendix A includes the metadata documentation for each indicator, and provides the logic for indicator selection along with data sources, method of calculation, and assessment criteria. Since most of these are National data sets and were chosen due to their availability at the National level, incorporating them into GIS format for mapping provided a ready pictorial view of the sustainability issues. Table 1 lists the SIRRA indicators broken out by sustainability issue area and also the data source and the data resolution level. All 54 indicators were used in this study. 
Table 1. Matrix of SIRRA indicators by issue area. Indicator Data Source

Data Level

\begin{tabular}{|c|c|c|c|}
\hline \multicolumn{4}{|c|}{ Air Quality Sustainability } \\
\hline AQ1 & Criteria Pollutant Non-Attainment & EPA & county \\
\hline AQ2 & Noise Sensitivity & USCB & installation \\
\hline \multicolumn{4}{|c|}{ Airspace Sustainability } \\
\hline AS1 & SUA, Fighter Range & FAA & installation \\
\hline AS2 & SUA, Bomber Range & FAA & installation \\
\hline AS3 & Terminal Airspace & FAA & installation \\
\hline AS4 & MTR, Fighter Range & FAA & installation \\
\hline AS5 & MTR, Bomber Range & FAA & installation \\
\hline \multicolumn{4}{|c|}{ Energy Sustainability } \\
\hline EN1 & Electrical Grid Congestion & NERC & NERCSub \\
\hline EN2 & Electrical Reserve Margin & NERC & NERCReg \\
\hline EN3 & Renewable Energy - Wind & NREL & Windgridunit \\
\hline EN4 & Renewable Energy - Solar & NREL & Solargridunit \\
\hline EN5 & Renewable Energy - Biomass & NREL & state \\
\hline EN6 & Electrical Price Structure (Dereg) & EIA & state \\
\hline EN7 & Net metering & Green Power network & state \\
\hline \multicolumn{4}{|c|}{ Urban Development } \\
\hline UD1 & Regional population density & USCB - 10 yrs & county \\
\hline UD2 & Incr. Regional Growth Rate & USCB - 10 yrs & county \\
\hline UD3 & Regional population growth & USCB - 10 yrs & county \\
\hline UD4 & Regional Land Urbanization & NLCD - 5 yrs & installation \\
\hline UD5 & State smart growth plans & APA web site & state \\
\hline UD6 & Joint Land Use Study (JLUS) & DoD & installation \\
\hline UD7 & Proximity to MSA & USCB & installation \\
\hline \multicolumn{4}{|c|}{ TES Sustainability } \\
\hline TE1 & Number of TES per State & \multirow{2}{*}{$\begin{array}{c}\text { USFWS } \\
\text { EPA }\end{array}$} & state \\
\hline TE2 & Species at Risk & & watershed \\
\hline TE3 & Federally Listed TES by Ecoregion & NatureServe & ecoregion \\
\hline TE4 & Species of Concern & NatureServe & ecoregion \\
\hline \multicolumn{4}{|c|}{ Locational Sustainability } \\
\hline LO1 & Federally declared floods & FEMA database & county \\
\hline LO2 & Seismic Zones & USGS maps & zone \\
\hline LO3 & Weather-related damage & NWS/NOAA - annual & state \\
\hline LO4 & Federally declared disasters & FEMA database & county \\
\hline LO5 & Tornadoes & NOAA & county \\
\hline \multicolumn{4}{|c|}{ Water Sustainability } \\
\hline WA1 & Level of Development & JAWRA & watershed \\
\hline WA2 & Ground Water Depletion & JAWRA & watershed \\
\hline WA3 & Flood Risk & JAWRA & watershed \\
\hline WA4 & Low Flow Sensitivity & JAWRA & watershed \\
\hline WA5 & Water Quality & JAWRA & watershed \\
\hline \multicolumn{4}{|c|}{ Economic Sustainability } \\
\hline EC1 & DoD Local Employment & www.bea.gov (REIS) & county \\
\hline EC2 & Job Availability/unemployment & BLS - annual & county \\
\hline EC3 & Housing Affordability & USCB - 10 yrs & county \\
\hline EC4 & Poverty & USCB - 10 yrs & county \\
\hline EC5 & Avg Hsg Value of New Construction & USCB & county \\
\hline EC6 & Housing Permits Issued & USCB & county \\
\hline \multicolumn{4}{|c|}{ Quality of Life Sustainability } \\
\hline QL1 & Crime Rate & NACJD & county \\
\hline QL2 & Housing Availability & USCB - 10 yrs & county \\
\hline QL3 & Rental Availability & USCB - $10 \mathrm{yrs}$ & county \\
\hline QL4 & Healthcare Availability & $\mathrm{HHS}$ & zipcode \\
\hline QL5 & Educational Attainment & USCB - 10 yrs & county \\
\hline QL6 & Commute Times & USCB - 10 yrs & county \\
\hline \multicolumn{4}{|c|}{ Transportation Sustainability } \\
\hline TR1 & Capacity of Comml Airports & TAF System & installation \\
\hline TR2 & Airport Suitability-C5 & FAA & installation \\
\hline TR3 & Airport Suitability-C141 & FAA & installation \\
\hline TR4 & Railroad Capacity & FRA & county \\
\hline TR5 & Proximity to Interstate & IRRIS & installation \\
\hline TR6 & Roadway Congestion & 2002 Urban Mobility \& FHWA & state \\
\hline TR7 & Traffic Volume & TTI \& FHWA & state \\
\hline
\end{tabular}




\section{Methodology}

\section{Analysis Concept}

SIRRA has proven to be a useful and successful sustainability screening tool and has been used to assess installations in a decision support function (Fournier, Deal et al. 2002). SIRRA version la was released in J uly 2004 using National data sets organized in a web-based analysis tool. The SIRRA methodology was reviewed by the individual DOD services before release. SIRRA data is derived from validated National sources, compiled in a consistent format, and covers a wide array of sustainability topics. SIRRA quantifies the state or condition of sustainability indicators and provides sustainability ratings for single indicators. However, it does not currently provide sustainability ratings based on an index, that is, a group of indicators. To meet the objective of this task and rank the general sustainability of all the ranges included in the Appendix of the February 2004 320/ 366 Report, this report generates a set of sustainability ratings based on multiple indicators with the capability to illustrate minor differences between range installations and regions of the country.

The SIRRA sustainment ratings contained in version 1a, categorize indicator measures in three ratings as follows: sustainable, moderately sustainable, or unsustainable. The current SIRRA sustainment ratings were adjusted to have a finer resolution to highlight differences between a large number of installations and ranges within various regional settings. These ratings are not yet available on the SIRRA web site. This study categorizes indicator measures in five sustainment ratings:

- Very low vulnerability

- Low vulnerability

- Moderate vulnerability

- Vulnerable

- High vulnerability.

The process of setting the thresholds for the categories is described in step 4 of the next section. Note that these ratings are not absolute in all cases as some are relative to a norm or mean. Note that not all indicators are broken out into five categories; some remain with three as the data did not lend itself to the finer scale. 
Some vulnerability "ratings" for indicators are not germane to some categories of range installations in this study. The interpretation of an indicator presumes the most common use of ranges (active military training and/ or testing operations).

\section{Analysis Methodology}

The analysis methodology consists of initially characterizing sustainment issues at all the range installations using the SIRRA system. The full set of the original 48 indicators from SIRRA 1a, plus an additional 6 indicators, were used for this evaluation. The set of indicators is listed in Table 1 and also contained in Appendix A with metadata documentation. The full set of indicators is used for completeness and the user may choose to ignore certain indicators or issue areas.

An additional product of this research project will be inclusion of the analyzed ranges in the next release of the SIRRA web-based analysis tool. This will allow users to conduct sustainability queries of ranges through the SIRRA web site.

The following steps were used to accomplish the range assessment:

1. Obtain Installation Boundary Files for the range installations that are not currently in SIRRA or in possession of ERDC/CERL. The total number of ranges contained in this analysis are broken out by services as follows:

$\begin{array}{ll}\text { Army } & 365 \text { boundary files } \\ \text { USMC } & 13 \text { boundary files } \\ \text { Navy } & 8 \text { boundary files } \\ \text { USAF } & 14 \text { boundary files }\end{array}$

Review files and rate accuracy of the information.

2. Create GIS Coverage of the 400 range boundary files for this analysis. Ranges that are not included in this study are all OCONUS ranges and those CONUS ranges whose boundary files were not available to the research team.

3. Create Relational Database of Boundaries and SIRRA GIS data layers. This requires overlapping 400 range boundary files with 54 indicator data layers. Final data points must be checked for "weighted averages" where boundaries overlap and "null" data calculations where data is unavailable.

4. Establish Indicator Thresholds for SIRRA indicators where these are not set by data providers or regulation and divide them into the 5 sus- 
tainability categories where possible. This requires statistical analysis of each indicator data set and preparation of GIS National map of data. 5. Develop SIRRA Data Matrix and Evaluate Results. Give the data a "reality check."

Indicator data values were extracted directly from the updated SIRRA relational database, not yet contained in the online version 1a. The query results in several "not-available" data values-specifically for water sustainment indicators in Alaska and Hawaii-where the data source does not report conditions in these areas. To ensure that these "not-available" data values neither hurt nor help watersheds, these values were either entered as "moderately sustainable." In other cases, where enough data was available, the rating was interpolated from the surrounding nearby regions.

The indicator characterizations for each range were then summed to arrive at an overall sustainability score that characterizes a level of encroachment potential or vulnerability of the site for sustainability issues. Indicator ratings were also averaged by sustainability issue area to provide additional insight into the results.

Appendix B (contained in a separate Excel file AppedixB.xls) provides the indicator vulnerability scores and final sustainment scores for each range. The higher the score, the more vulnerable the range is considered or the more stress it incurs due to development and encroachment issues. The lower the score, the less vulnerable the range is to environmental and key issue stresses. The indicators are not weighted and each is treated equally. There could be some locational weighting applied for certain indicators, but this was not attempted for the current study. The user may want to discount certain indicators or issue areas as they deem appropriate to obtain revised ratings. For example, vulnerability to noise may not be a valid encroachment issue if the range does not house noise generating activities or the energy issue area may not be appropriate if there are no large energy consuming activities on the range. Warning! Users are advised to review the indicators that led to a high or low sustainability score and judge the score based on local knowledge. 


\section{Results}

\section{Range Sustainability Scores}

Figure 2 shows the resulting rankings of all 400 range sustainability scores. The sustainability scores for the ranges varied from 112 to 179. Overall range vulnerability ratings were determined by subjecting the data to statistical analysis.

Possible overall sustainability scores varied from 54 to 270 , where the lowest score represents the lowest potential vulnerability and the highest score represents the highest potential vulnerability. Table 2 provides the score statistics and Table 3 lists the overall data spread for the various vulnerability classifications.

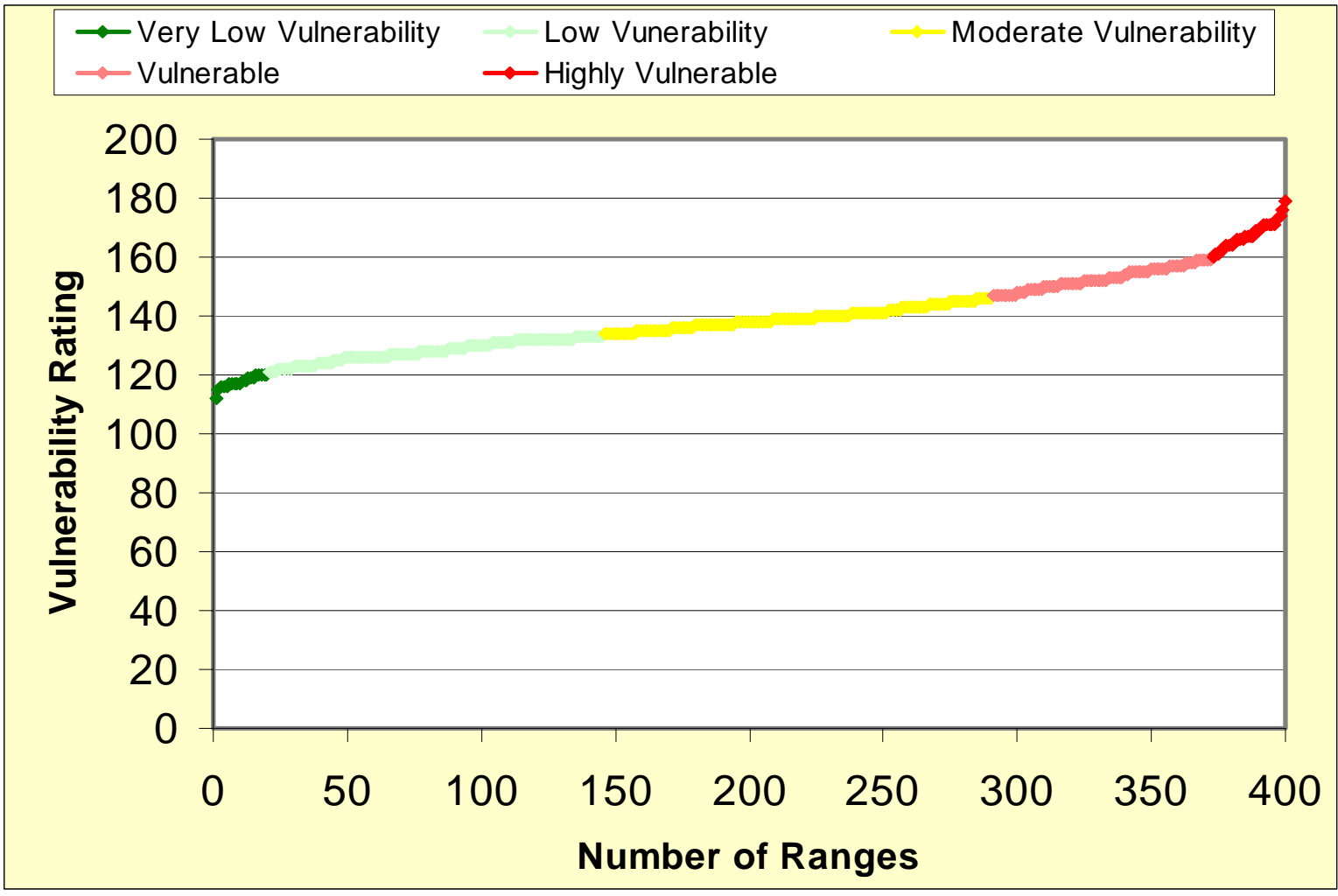

Figure 2. Range vulnerability scores. 
Table 2. Statistical analysis of vulnerability scores.

\begin{tabular}{|l|l|}
\hline Median & 138 \\
\hline Mean & 140 \\
\hline Standard Deviation & 13 \\
\hline Lowest Score & 112 \\
\hline Highest Score & 179 \\
\hline
\end{tabular}

Table 3. Vulnerability classifications based on statistics.

\begin{tabular}{|l|l|}
\hline Very Low Vulnerability & Less that 1 Std Dev below Mean $(<120.5)$ \\
\hline Low Vulnerability & Between 1 Std Dev below Mean and Mean $(120.5-133.5)$ \\
\hline Moderate Vulnerability & Between 1 Std Dev above Mean and Mean $(133.5-146.5)$ \\
\hline Vulnerable & Between 1 and 1.5 Std Dev above Mean $(146.5-159.5)$ \\
\hline High Vulnerability & Above 1.5 Std Dev above Mean $(>159.5)$ \\
\hline
\end{tabular}

\section{Discussion}

Ranges with the highest vulnerability tended to be in areas with high levels of urban development or near large metropolitan areas. Regions showing the highest vulnerability were in Hawaii, California, and the mid-Atlantic coastal states. Ranges in areas rated the least vulnerable tended to be located in rural areas or settings with low population. Appendix B provides overall ranking by installation. This can be sorted by installation, state, service, score, issue area, or indicator.

All locations have some vulnerabilities or sustainability concerns, as evidenced by the fact that the lowest rating score was still significantly higher than the lowest possible score. However, the highest scored range was still a good deal lower than the highest possible score. This shows that indicators vary considerably with region and that not all of the indicators are low for any given location. This is somewhat due to the large set of indicators applied and how they relate to the various encroachment issues. As noted in Chapter 3, not all indicators are relevant to all ranges.

It should also be noted that the range of scores was fairly linear through the middle three categories of vulnerability with significant change at either extreme. The range installations with the highest vulnerability scores have a fairly steep rise in the number of indicators scoring high. This shows that vulnerabilities and encroachment factors tend to worsen as a group. The same is true for regions rated least vulnerable; the indicators tended to get much lower or better as a group. 


\section{Interpreting the Results}

\section{Scoring Implications}

The vulnerability scores presented here represent a generic evaluation of the potential for environmental problems and general sustainability of any given setting for a range or installation. The ranking methodology is meant to be a screening tool -not a final, definitive evaluation of the vulnerability to encroachment or the overall sustainability of a range's location and region. The screened information requires further detailed studies specific to a range and its region. In other words, this methodology screens for certain issues and identifies ranges considered to have potential problems as determined by the chosen set of indicators. A range may score high on an indicator that is state-wide in scope, yet the score could be inapplicable for that particular location or ecoregion.

For example, a range may show poor water quality within its region and thus be rated high in terms of vulnerability. However, in practice, the range may use its own potable water system with its own sources or use no water-making its actual vulnerability rating to this issue of sustainability "low" instead of "high." The methodology of this report is exogenous to a range and does not factor in site-specific conditions. This is a National level screening tool and the information represents entire counties, watersheds, or states; therefore this data will not always agree with local data sources for specific locations or managed units within a state, county, watershed, or ecoregion.

There are trade-offs between using this standardized approach, which allows the use of National-level data to evaluate regional aspects of the installation setting, and one that uses range-specific data. The best recommendation is to examine the indicators that are most important and to seek additional information to better understand the rating. Any decision relevant to a specific range or location should always be informed by more than SIRRA. This report is a helpful screening tool that uses reliable data and scientifically organizes these numerous external (to the range) sustainability data to provide relative characterizations of ranges based on that information. 


\section{Understanding Options for Vulnerability Mitigation}

The characterization process results in a list of ranges and installations with ranges that may soon be experiencing or are already experiencing impacts on mission and readiness due to outside forces in the region. Any decision on how to proceed should be based on the characterization and any known additional sustainability issues for the range or installation. An installation or range facing sustainability encroachment issues has essentially five courses of action. Table 4 lists general guidelines for determining which overall option is best for a given installation or range.

Table 4. Vulnerability class and mitigation options.

\begin{tabular}{|l|l|l|}
\hline Class & Vulnerability Score & Scoring Implications \\
\hline 1 & $54-120$ & Limited concerns; continue to monitor \\
\hline 2 & $121-133$ & Concerns may require mitigation \\
\hline 3 & $134-146$ & $\begin{array}{l}\text { Concerns likely to require mitigation and proactive coordination } \\
\text { with regional stakeholders }\end{array}$ \\
\hline 4 & $147-159$ & Significant concern(s) to address and resolve \\
\hline 5 & $160-270$ & Many significant concerns to address and resolve \\
\hline
\end{tabular}

Each progressive step of action includes the previous step; therefore, if step 5 is recommended, so are the actions in steps 2 through 4 . Ranges in all categories should be engaging stakeholders in planning and coordination of various regional issues. The best sustainment mitigation strategy is often a combination of these options:

- Class 1. There are limited concerns. However, continuous monitoring is the recommended action for those ranges rated as having a very low vulnerability. Indicators illustrate that the region and the range mission are currently in fairly good harmony. This action includes a need to continue monitoring the range and updating the sustainment assessment as new information is made available. Temporal changes in indicators will provide a measure of how the situation is evolving and eventually identify when "no action" is no longer viable.

- Class 2. Ranges that are experiencing select pressures and need immediate action in a selected sustainment issue may require mitigation in that particular issue. Examples of select pressures are U.S. Endangered Species Act (USESA) compliance, local community concerns, or a private landowner lawsuits.

- Class 3. Ranges characterized with moderate vulnerability may be struggling with some sustainability issues. They may require long-term efforts in regional planning that rely on external jurisdictions for enabling real change within the region. This action is valuable for building connections with neighbors, exposing positive installation efforts to the public, establishing zoning to ensure military compatible land uses, and awakening local area responsibility for ecosystem sustainability. 
Programs that support this action include J oint Land Use Studies (J LUS), USDA programs that keep farm land actively farming, and regional transportation studies and plans. In other words, moderately vulnerable ranges should collaborate with local governments to ensure a future for both the installation and local communities.

- Class 4. Ranges considered vulnerable should initiate an assessment of on-site activities for how they reach beyond the fence line, maximizing effective use of existing lands, and ensuring long-term sustainability. These are accomplished by characterizing the range land assets, understanding how those assets meet the current mission, and predicting what might be needed in the future. This action should generally be implemented at all installations.

- Class 5. Ranges classified as highly vulnerable should actively work with local governments to develop sustainable solutions for their region. This refers to controlling land use actions outside the fence through mechanisms such as conservation easements and land purchase. It assumes the potential for short-term, concrete action to mitigate severe on-site issues while the longer-term efforts are being negotiated. It should not be assumed that pursuing this option will de facto be beneficial; success depends on sufficient understanding of the issues and the availability of appropriate off-installation partners. It also depends on the ability to identify suitable land for easement acquisition, buffer zones, or other land control options and that these options are affordable.

\section{Using Appendix B}

Appendix B is attached as a Microsoft Excel workspace (AppendixB.xls). The workspace provides the 54 individual indicator vulnerability scores, an average issue area vulnerability score for the 10 issues, and the final sustainment scores for all 400 range installations. As previously stated, the higher the score the more vulnerable the range is considered or the more stress it incurs due to development and encroachment issues. The lower the score, the less vulnerable the range is to environmental and key issue stresses. When opening Appendix B workspace, be certain that all macros are enabled. Once open, the workspace contains two worksheetsMAIN Page and SIRRA Indicators. These are identifiable by tabs located in the bottom, left corner of the workspace. MAIN Page holds all vulnerability and final sustainment scores. SIRRA Indicators is a reference worksheet. Users may refer to this worksheet for a quick reference of indicator identifiers, source, and data level (i.e., users may recollect that AQ1 represents Criteria Pollutant Non-Attainment data from the U.S. Environmental Protection Agency at the county level). 
Appendix B provides users the ability to analytically identify potential environmental problems for any given range installation as well as view vulnerability ratings in relation to other range installations. Data columns include Installation name, State, and Branch; Final Sustainment Score; and individual Issue Area Average Vulnerability Score. Check boxes located above the issue area column headings may be checked to reveal or unchecked to hide a break-down of individual indicator vulnerability scores. For example, checking the "AQ" box reveals AQ1 and AQ2 rating columns. Removing the checkmark collapses these columns. Users may sort the MAIN Page columns using the Microsoft Excel sort function for several analyses including a ranking of all range installations by sustainment score and a ranking of range installations by branch, state, issue area, or indicator.

The final sustainment scores are the sum of all 54 indicator vulnerability scores. Indicators are not weighted and each is treated equally. There could be some locational weighting applied for certain indicators as users customize the data for their specific purposes. For example, a user may want to discount noise indicators of a particular installation if the range does not house noise generating activities. Overall, these sustainability assessments are intended to be used as a screening tool to assess ranges and associated installations for which additional studies, planning, and actions may be recommended to ensure continued viability and sustainability. To go beyond this initial screening, users are advised to review the indicators that led to a high or low sustainability score and judge the score based on local knowledge. Example applications of the data follow.

\section{Scenario 1}

As an Army Forces Command planner, you are curious as to the viability of adding a training range to an existing installation located within the southeast region of the United States (the southeast region is defined by Alabama, Georgia, Florida, North Carolina, and South Carolina). You wish to identify Army installations in the southeast capable of supporting an additional training range.

Step 1: Using the Microsoft Excel sorting function, sort the "MAIN Page" data by Service Branch (column C), then by State (column B), and then by Final Sustainment Score (column E), in ascending order (Figure 3). 
This results in a grouping of Army range installations by state and ranked by Final Sustainment Scores. In other words, it becomes clear which Army installations have the lowest vulnerability ratings in each respective state.

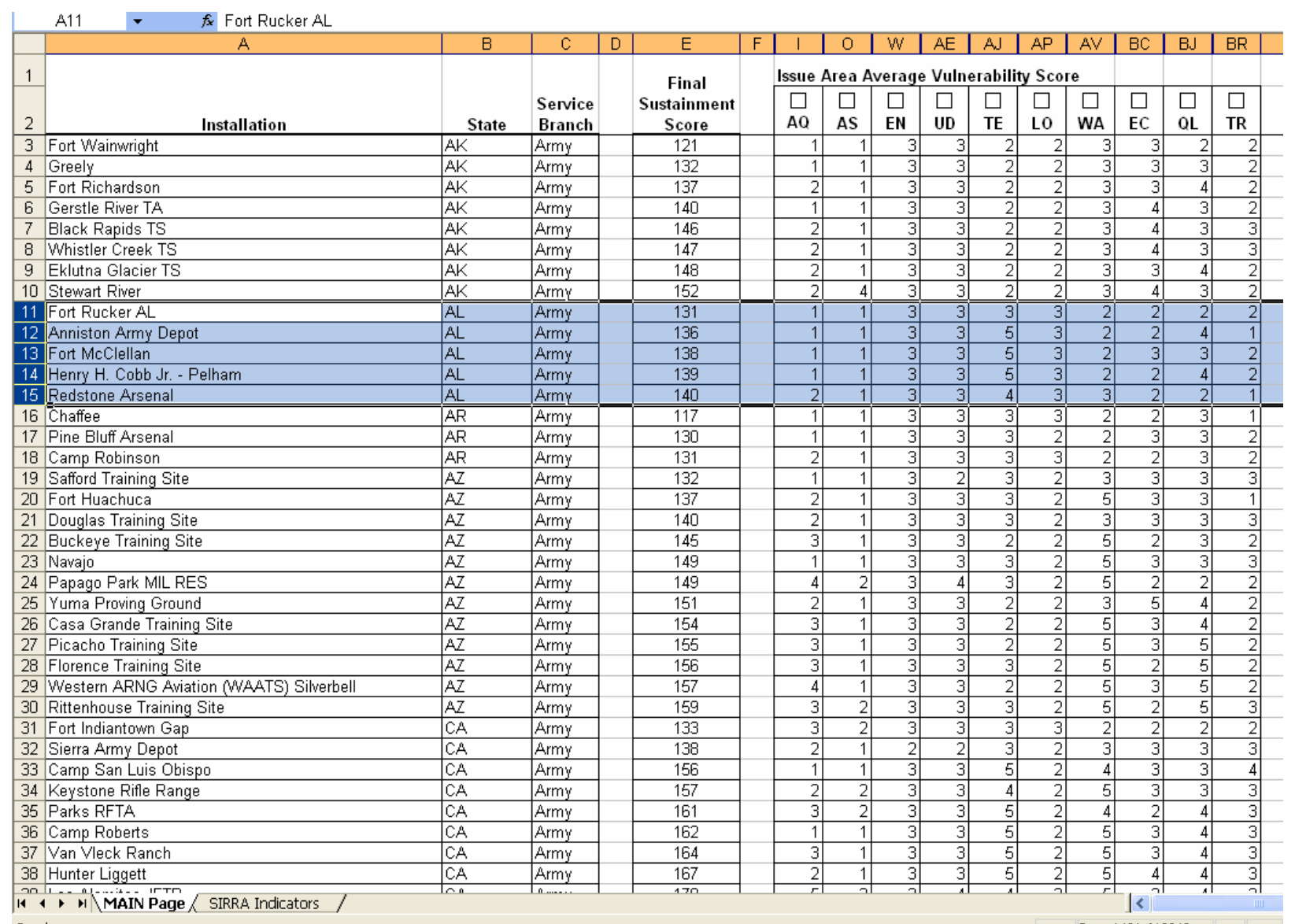

Figure 3. Screen capture of Appendix B resulting from Step 1 of Scenario 1. Army range installations located in the state of Alabama have been highlighted.

Step 2: Identify sustainability issue areas critical to a training mission.

The vulnerability rating is based on 10 issue areas, yet, the relevance of an issue changes depending on the specific missions or functions of an installation. For example, a storage depot facility is less concerned with soldier quality of life issues and more concerned with transportation availability for the movement of its goods; while a radar bomb scoring range is highly concerned with air space And noise indicators and minimally concerned with energy and water availability. We shall assume for the type of training being added, critical issue areas include AQ, UD, TE, WA, and QL (air quality, urban development, threatened and endangered species, water, and quality of life, respectively). 
Step 3: Highlight installations within the southeast region-Alabama, Georgia, Florida, North Carolina, and South Carolina-rating 3 (Moderate Vulnerability) or better in all critical issue areas.

These installations include Fort Rucker, AL; Fort Gordon, GA; Camp Mackall, NC; Fort Bragg, NC; Military Ocean TML Sunny Point, NC; Fountain Inn TS, SC; McCrady Training Center, SC; Fort J ackson, SC; Pickens TS, SC; and Hodges TS, SC.

Step 4: Review the indicators that led to a high or low sustainability score and judge the score based on local knowledge.

The results of Step 3 identified viable installations for the addition of a training range in the southeast United States. However, users are advised to review this result and judge scores based on local knowledge. For example, Fort Benning, GA rated moderate to low vulnerable in every issue area except threatened and endangered species (TE). Due to the poor TE rating, the installation was eliminated. However, local knowledge reveals that Fort Benning is currently proactively addressing threatened and endangered species issues through participation in the SERDP Ecosystem Management Program (SEMP). In this instance the high TE vulnerability rating would be of less concern and the installation could be considered viable.

\section{Scenario 2}

A realignment proposal has been made at Fort Bliss, TX, to relocate the $1^{\text {st }}$ Armored Division, Artillery Brigade, Maneuver Battalion, Support Battalion, and Aviation Unit to Fort Bliss. You wish to ensure Fort Bliss region has sufficient infrastructure to support this proposal. You want to know if Fort Bliss can sustain the additional missions and if not, what actions need to be taken to ensure sustainability.

Step 1: Using Microsoft Excel sorting function, sort the MAIN Page data by Installation (column A) ascending alphabetically (Figure 4).

Fort Bliss should appear in row 138 and show a final sustainment score of 135. A sustainment score of 135 indicates that Fort Bliss is currently moderately vulnerable to encroachment issues. 


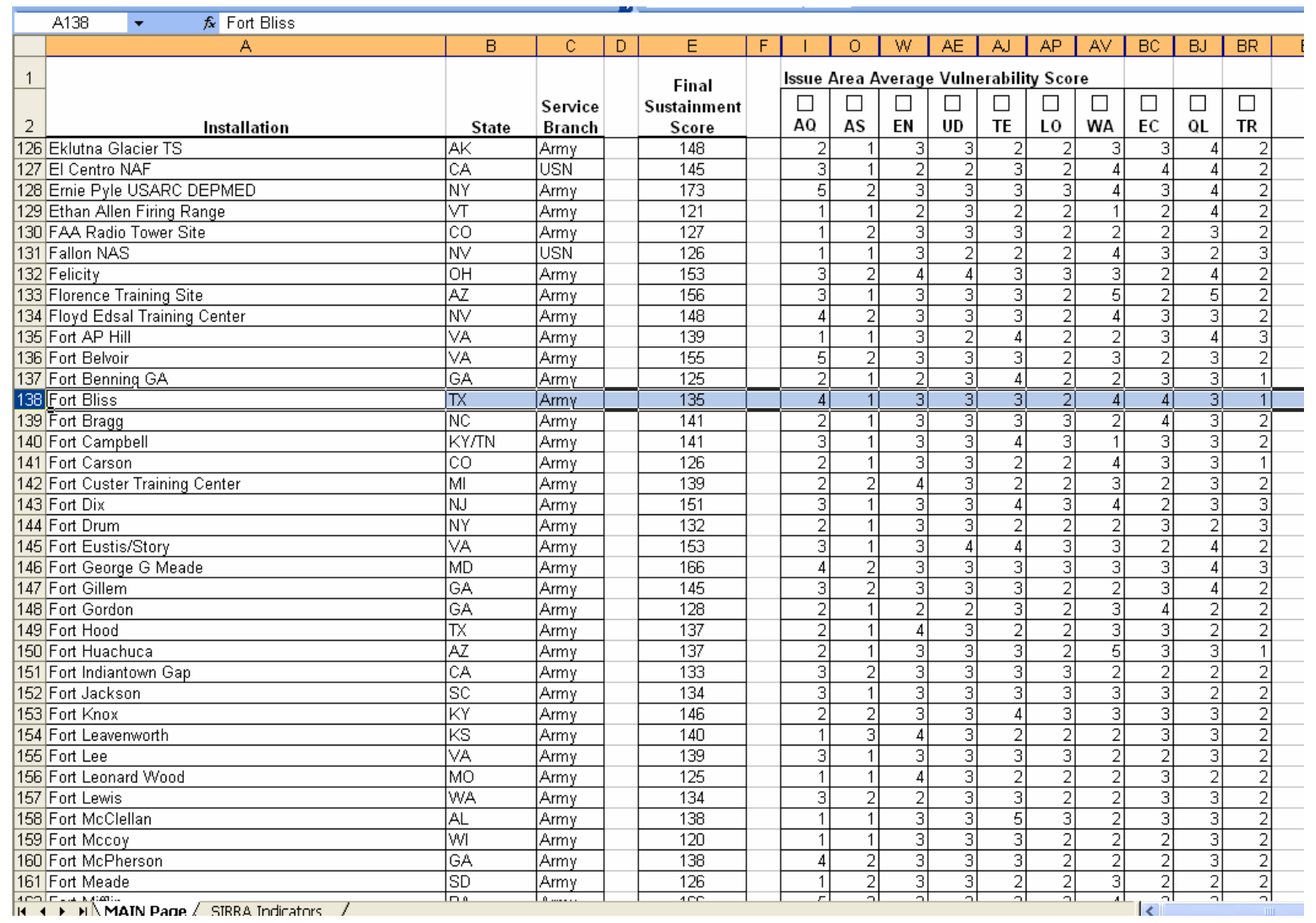

Figure 4. Screen capture of Appendix B resulting from Step 1 of Scenario 2. Fort Bliss has been highlighted.

Step 2: Identify sustainability issues critical to the 1st Armored Division, Artillery Brigade, Maneuver Battalion, Support Battalion, and Aviation Unit missions.

Overall, Fort Bliss is moderately vulnerable to encroachment issues. However, its most vulnerable issues may not be relevant to the proposed missions. It is necessary to assess whether "moderately sustainable" is the proper designation for Fort Bliss given its functions. We shall assume for the missions being added, critical issue areas include AS, EN, TE, WA, and TR (airspace, energy, threatened and endangered species, water, and transportation respectively).

Step 3: Highlight which of the critical issues has a vulnerability rating of 4 or 5 (High Vulnerability or Very High Vulnerability).

High vulnerability issue areas include water (WA). 
Step 4: Check the column heading of WA issues. This opens individual indicator ratings for water issues. Next, highlight indicators having a vulnerability rating of 4 or 5 (Figure 5 )

High vulnerability indicators include WA1, WA2, and WA4 (level of development, groundwater depletion, and low flow sensitivity respectively).

Step 5: Review the indicators that led to a high or low sustainability score and judge the score based on local knowledge.

The results of Step 4 identified water availability problems in the region that may conflict with the proposed additional missions and accompanying personnel. To ensure sustainability, actions addressing water availability need to be taken. However, further analysis will be required to determine the extent of vulnerability that these indicators pose to Fort Bliss sustainability under the proposed realignment. This analysis results in identifying possible conflicts. It does not provide installation-specific assessments. For example, the scenario identifies ground water sources within the watershed as insufficient. However, it does not know if Fort Bliss uses its own water source; that would decrease the relevance of this rating. Use of local knowledge and understanding of indicator measures (found in indicator metadata) are critical to the application of this report.

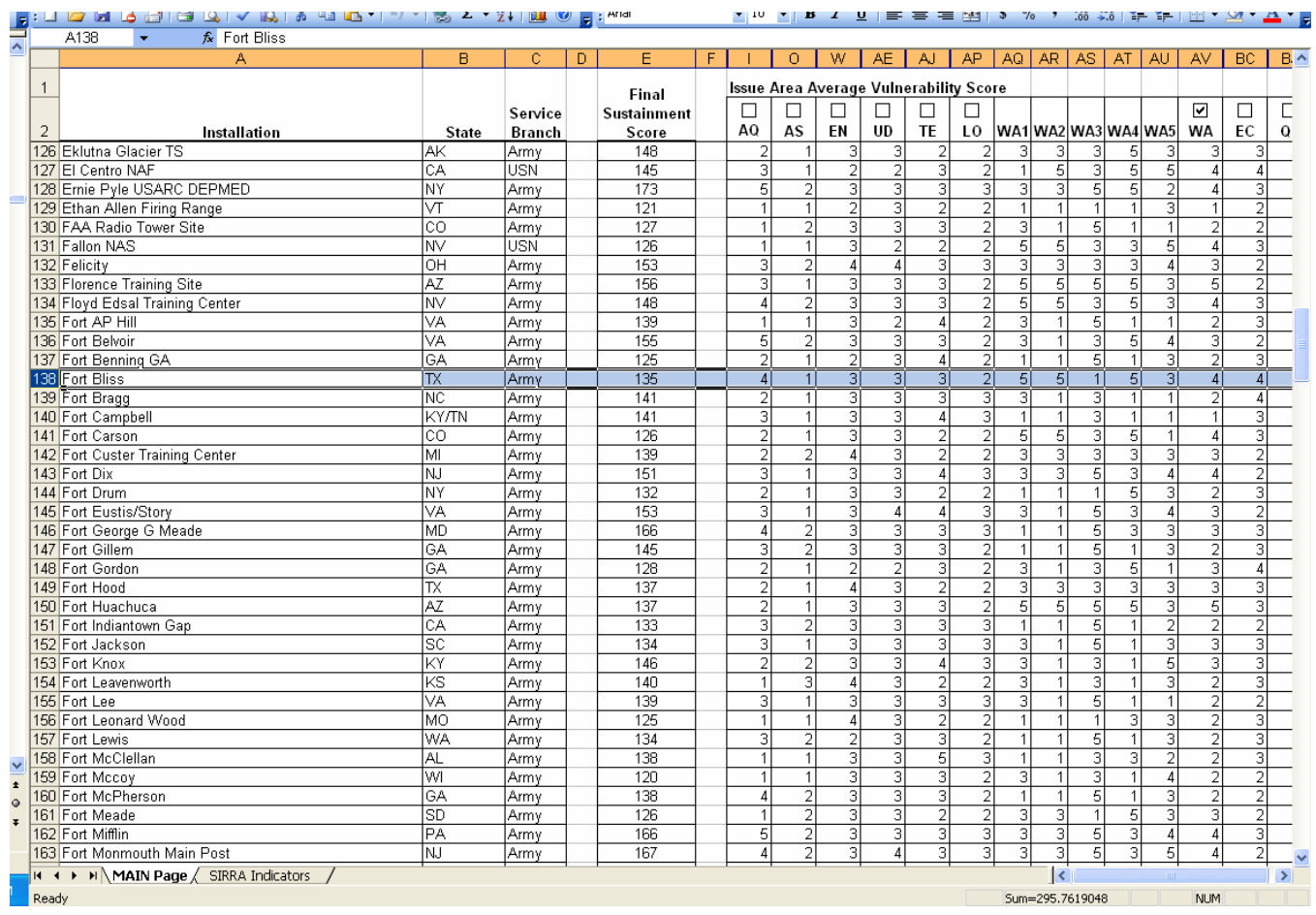

Figure 5. Screen Capture of Appendix B resulting from Step 4 of Scenario 2. Fort Bliss has been highlighted and water indicators are displayed. 


\section{Conclusions}

The results of using the SIRRA indicators to rank DOD range installations has provided a list of ranges that may be vulnerable to encroachment issues and require further analysis and evaluation. Of the 400 ranges and installations contained in the analysis, the results indicate that 110 (about 28 percent) of the range installations are vulnerable or have high vulnerability. Another 145 of the range installations were rated as moderately vulnerable. The remaining 145 ( 36 percent) of the range installations were rated as having low or very low vulnerability.

The percentage of installations rated vulnerable or highly vulnerable is not a surprising result considering that sustainability threats occur throughout the Nation as population shifts and urban growth are proceeding rapidly and sustainability concerns involve a large number of issues. The most vulnerable installations tend to be located in areas of high growth and urbanization. The least vulnerable installations tend to be located in nonurbanized areas where population growth and development have not reached levels where encroachment issues have become a concern.

The adaptation of the SIRRA methodology in this analysis demonstrates how a web-based decision support framework can be applied to regions surrounding installations and ranges. This approach used the SIRRA information, databases, and index models coupled with GIS capabilities for regional assessments. This analysis added several new airspace indicators to the SIRRA methodology and updated the relational database contained in the web-based analysis tool, though it is not yet resident on-line. This report represents the first tier of a multi-tiered approach that allows the use of various levels of models and tools based on scientific needs, user ability, and available resources. The framework supports flexible decisionmaking, allowing individual applications of the information.

SIRRA allows planners and project managers, regulators, and operation and maintenance managers involved with installation and range management studies, ecosystem restoration, and resource reallocation studies to obtain a first-cut evaluation of range installations using National data sets. This methodology gives the DOD an assessment tool that provides a significant new capability to apply National data sets in a range or installation context to address environmental mission needs on a regional scale; it 
will encourage sustainable management of our National resources. The SIRRA-based installation and range analysis capability provides an information link that increases the effectiveness of partnering with other agencies and private stakeholders. The regionally-based screening tool may also reduce costs associated with determining which installations or ranges need further study and interventions to cope with encroachment issues. 


\section{Bibliography}

Deal, Brian M., Donald F. Fournier, Diane M. Timlin, and Elisabeth M. J enicek. October 2002. ERDC/ CERL Technical Report TR-02-27. An Assessment of Encroachment Mitigation Techniques for Army Lands. Champaign, IL: Engineer Research and Development Center, Construction Engineering Research Laboratory (ERDC-CERL).

Fournier, Donald F., Brian M. Deal, Elisabeth M. J enicek, and Adam J . Sagert. September 2002. ERDC/CERL Special Report SR-02-12 Sustainable Installation Risk Assessment and Stationing Implications. ERDC-CERL.

IISD. 2002. Measurement and Indicators for SD. Manitoba, Canada: InterNational Institute for Sustainable Development.

J enicek, Elisabeth M., Donald F. Fournier, William D. Goran, Natalie R. Downs, and Adam J . Sagert. J uly 2004. ERDC/ CERL TR-04-9, The Sustainable Installations Regional Resource Assessment (SIRRA) Capability. ERDC-CERL.

J enicek, Elisabeth M. N. Downs, B. Boesdorfer, D. Fournier. 2005. ERDC/CERL TR-05Draft, A Comparison of Regional Vulnerability Factors for DoD Installations. ERDC-CERL.

J enicek, Elisabeth M., Donald F. Fournier, Natalie R. Downs, and Brad Boesdorfer. September 2005. ERDC/CERL TR-05-24, Watershed Application of the Sustainable Installations Regional Resource Assessment Tool. ERDC-CERL.

MacLaren, V.W. 1996. Developing Indicators of Sustainability: A Focus on the Canadian Experience. Toronto, Canada: Intergovernmental Committee on Urban and Regional Research Press.

MacLaren, V.W. Spring 1996. “Urban Sustainability Reporting.” Chicago, IL: APA Journal. pp 184-202.

SERDP Program Office. 2004. Annual Report to Congress-Fiscal Year 2003. Arlington, VA: Department of Defense (DOD). p 324.

Tomich, K., and B. Deal. 2002. Environmental Factors to Consider Prior to Restationing Forces. Alexandria, VA: Center for Army Analysis.

U.S. Army Environmental Center (USAEC). 2005. Encroachment Condition Model. Aberdeen Proving Ground, MD: USAEC. 


\section{Acronyms and Abbreviations}

\begin{tabular}{|c|c|}
\hline Term & Spellout \\
\hline AADT & Annual Average Daily Traffic per Lane \\
\hline AEC & U.S. Army Environmental Center \\
\hline AFB & Air Force Base \\
\hline ANSI & American National Standards Institute \\
\hline APA & American Planning Association \\
\hline AVMT & annual vehicle miles traveled \\
\hline CERL & Construction Engineering Research Laboratory \\
\hline $\mathrm{CO}$ & carbon monoxide \\
\hline $\mathrm{DA}$ & Department of the Army \\
\hline $\mathrm{DC}$ & direct current \\
\hline DO & Dissolved Oxygen \\
\hline DOD & Department of Defense \\
\hline $\mathrm{DOI}$ & Department of Interior \\
\hline EIA & Energy Information Administration \\
\hline EO & Executive Order \\
\hline EPA & Environmental Protection Agency \\
\hline ERDC & Engineer Research and Development Center \\
\hline ES & Electrical System \\
\hline ESRI & Environmental Systems Research Institute, Inc. \\
\hline FAA & Federal Aviation Administration \\
\hline FEMA & Federal Emergency Management Agency \\
\hline FHA & Federal Housing Authority \\
\hline FHWA & Federal Highway Administration \\
\hline $\mathrm{FY}$ & fiscal year \\
\hline GIS & geographic information system \\
\hline $\mathrm{HQ}$ & headquarters \\
\hline HQUSACE & Headquarters, U.S. Army Corps of Engineers \\
\hline HUC & hydrologic unit code \\
\hline ID & Identification \\
\hline IRRIS & Intelligent Road/Rail Information Server \\
\hline ITC & Installation Training Capacity \\
\hline JAWRA & Journal of American Water Resources Association \\
\hline JLUS & Joint Land Use Study \\
\hline MSA & Metropolitan Statistical Areas \\
\hline NAAQS & National Attainment Air Quality Standards \\
\hline NACJD & National Archive of Criminal Justice Data \\
\hline
\end{tabular}




\begin{tabular}{|c|c|}
\hline Term & Spellout \\
\hline NAVFAC & Naval Facilities Engineering Command \\
\hline NEMIS & National Emergency Management Information System \\
\hline NERC & North American Electricity Reliability Council \\
\hline NLCD & National Land Use Data \\
\hline NOAA & National Oceanic and Atmospheric Administration \\
\hline NREL & National Renewable Energy Laboratory \\
\hline NWS & National Weather Service \\
\hline OCE & Office of the Chief of Engineers \\
\hline OMB & Office of Management and Budget \\
\hline ORD & Operational Requirements Document \\
\hline PDF & Portable Document Format \\
\hline PM & particulate matter \\
\hline PO & purchase order \\
\hline QOL & Quality of Life \\
\hline $\mathrm{RCl}$ & Roadway Congestion Index \\
\hline RDTE & Research, Development, Test, and Evaluation \\
\hline REIS & U.S. Department of Commerce, Bureau of Economic Analysis \\
\hline SAR & Search and Rescue \\
\hline SERM & Sustainability, Environment, and Room to Maneuver \\
\hline $\mathrm{SI}$ & Systeme InterNationale \\
\hline SIRRA & Sustainable Installations Regional Resource Assessment \\
\hline SR & Special Report \\
\hline SWWRP & System-Wide Water Resources Program \\
\hline TAF & Terminal Aerodrome Forecasts \\
\hline TES & threatened and endangered species \\
\hline TNC & The Nature Conservancy \\
\hline TR & Technical Report \\
\hline TTI & Travel Time Index \\
\hline URL & Universal Resource Locator \\
\hline USACE & U.S. Army Corps of Engineers \\
\hline USAEC & U.S. Army Environmental Center \\
\hline USC & United States Code \\
\hline USCB & U.S. Census Bureau \\
\hline USDOA & U.S. Department of Agriculture \\
\hline USDOC & U.S. Department of Commerce \\
\hline USDOE & U.S. Department of Energy \\
\hline USDOI & U.S. Department of the Interior \\
\hline USDOJ & U.S. Department of Justice \\
\hline USDOL & U.S. Department of Labor \\
\hline USDOT & U.S. Department of Transportation \\
\hline
\end{tabular}




\begin{tabular}{|l|l|}
\hline Term & Spellout \\
\hline USEPA & U.S. Environmental Protection Agency \\
\hline USESA & U.S. Endangered Species Act \\
\hline USFWS & U.S. Fish and Wildlife Service \\
\hline USGS & U.S. Geological Survey \\
\hline WWW & World Wide Web \\
\hline
\end{tabular}




\section{Appendix A: SIRRA Metadata}

\section{Sustainability Issue: Air Quality}

Indicator: Criteria Pollutant Non-Attainment (AQ1)

Variables

Six Principal Air Pollutants (also referred to as criteria pollutants): Nitrogen Dioxide $\left(\mathrm{NO}_{2}\right)$, Ozone $\left(\mathrm{O}_{3}\right)$, Sulfur Dioxide $\left(\mathrm{SO}_{2}\right)$, Particulate

Matter (PM), Carbon Monoxide (CO), and Lead (Pb)

Scale

County

Year

2004

Data Sources

U.S. Environmental Protection Agency (USEPA). 2005. Green Book Nonattainment Areas for Criteria Pollutants. Office of Air and Radiation/ Office of Air Quality Planning and Standards. Washington, DC: USEPA. (Nonattainment Status for Each County by Year). Accessible through URL:

http://www.epa.gov/oar/oaqps/greenbk/anay.html

USEPA. 2004. The Particle Pollution Report: Current Understanding of Air Quality and Emissions through 2003. Washington, DC: Office of Air Quality Planning and Standards. Emissions, Monitoring, and Analysis Division, USEPA. Accessible through URL: http://www.epa.gov/airtrends/

Logic

The Clean Air Act provides the principal framework for National, state, tribal, and local efforts to protect air quality. Under the Clean Air Act, the USEPA establishes air quality standards to protect public health by setting National Attainment Air Quality Standards (NAAQS) for the six principal pollutants that are considered harmful to public health and the environment and ensuring that these air quality standards are met (in cooperation with the state, tribal, and local governments) through National standards and strategies to control air pollutant emissions from vehicles, factories, and other sources (USEPA 2004). The USEPA has set National air quality standards for six principal air pollutants (also referred to as criteria pollutants): nitrogen dioxide $\left(\mathrm{NO}_{2}\right)$, ozone $\left(\mathrm{O}_{3}\right)$, sulfur dioxide $\left(\mathrm{SO}_{2}\right)$, particulate matter $(\mathrm{PM})$, carbon monoxide $(\mathrm{CO})$, and lead $(\mathrm{Pb})$. Four of these pol- 
lutants $\left(\mathrm{CO}, \mathrm{Pb}, \mathrm{NO}_{2}\right.$, and $\left.\mathrm{SO}_{2}\right)$ result primarily from direct emissions from a variety of sources. PM results from direct emissions, but is also commonly formed when emissions of nitrogen oxides (NOx), sulfur oxides (SOx), ammonia, organic compounds, and other gases react in the atmosphere. Ozone is not directly emitted but is formed when NOx and volatile organic compounds (VOCs) react in the presence of sunlight (USEPA 2004).

The USEPA tracks trends in air quality based on actual measurements of pollutant concentrations in the ambient (outside) air at monitoring sites across the country. State, tribal, and local government agencies as well as some Federal agencies, including the USEPA, operate monitoring stations.

Air quality is important to military operations in non-attainment areas of USEPA ambient air quality. The standards for the six criterion pollutants will have added restrictions on emissions from military operations. Gaining compliance for these regulations may cause financial strain on the DoD. Being located in a nonattainment zone is a strong indicator that the military may face restrictions on the amounts of certain emissions they can release (including mobility emissions) as part of the region's plan for coming into attainment. Information concerning what affects each criterion is available from the USEPA through URL: http://www.epa.gov. In summary, each criterion is vulnerable to change. Thus, the data should be updated regularly and the age of the data should be carefully noted in any analysis.

Additionally, the data reflects county level data where different values are reported for the same county in the same year in some cases. Thus, knowledge of the local area and its efforts need to be considered especially in large acreage counties.

\section{Replicable}

Each year the USEPA examines changes in levels of these ambient pollutants and their precursor emissions over time and summarizes the current air pollution status (USEPA 2005). The updates are available for download through URL: http://www.epa.gov/air/oaqps/greenbk/anay.html. 


\section{Directions}

Download NonAttainment Status for Each County by Year for all U.S. counties from the USEPA Green Book (USEPA 2005) through URL: http://www.epa.gov/airloaqps/greenbklanay.html

Import the Classification data into a GIS program and join it with county boundary files to create a GIS air quality attainment status indicator layer.

\section{Indicator Measure}

Emission status indicates whether a U.S. County is in attainment of USEPA air quality emission standards for the six criteria pollutants. The USEPA designates a classification rating for each criterion depending on the non-attainment status - extreme, severe, serious, moderate, marginal, primary, subpart 1, and section 185A (USEPA 2005). Different values may be reported for the same county in the same year in some cases. In this case, the worst value is indicated (USEPA 2004). The emission ratings were grouped into the following classifications:

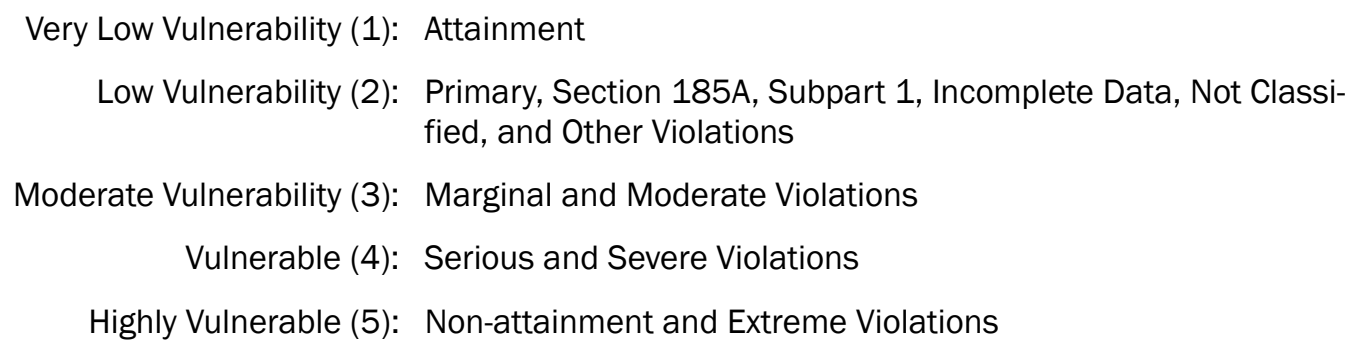

Rules

Installations are often in two or more counties. Therefore, the region around an installation is classified by a weighted average. The weighted average calculation determines what percentage of the installation is in each county and multiplies that percentage for each county by that county's classification value. The values for each county are then totaled to arrive at a value for the region around the installation. This value is subjected to the same metric that determined the classification for the individual counties. 
For example:

Indicator Value for the Region Around Installation = (Percentage of Installation in County A* Indicator Value for County A) + (Percentage of Installation in County $B *$ Indicator Value for County $B$ )...etc.

\section{Indicator: Noise Sensitivity (AQ2)}

Variables

Environmental Noise Sensitivity

Scale

Installation

Year

2000

\section{Data Sources}

Headquarters, Department of the Army (HQDA). 2002. FY03 Army Well-Being Action Plan. Washington, DC: Deputy Chief of Staff for Personnel, HQDA. Accessible through URL: http://www.odcsper.army.mil/Directorates/wb/FY03 WBAP Vol 1.pdf

U.S. Bureau of the Census, U.S. Department of Commerce. 2000. Incorporated Places/Census Designated Places. Washington, DC: Geography Division, Bureau of the Census. Accessible through URL: http://www.census.gov/geo/www/cob/pl2000.html

Westervelt, J ames. 2004. Champaign, IL: Engineer Research and Development Center, Construction Engineering Research Laboratory (ERDC-CERL).

Logic

Lower noise levels will result in improved quality of life for both military personnel and the residents of the region surrounding military installations. Fewer noise problems helps to ensure that military personnel are well-trained, will remain in the military, and will be able to carry out missions with greater effectiveness and reduced losses. The training and testing capability impacts include loss of training hours, rescheduling training and testing, modifying training procedures, and the consequences of inadequate training. An effective and proactive noise management program greatly improves effective military operations as well as relations with the surrounding community (USDoA 2002).

The U.S. military has articulated goals of: (1) protecting the ability of personnel to train as they fight by working to limit civilian encroachment into areas exposed to high levels of military noise; (2) protecting people who 
live near military training areas from unhealthy levels of noise from military operations; and (3) protecting military families.

Every installation has its own style of keeping noise complaint logs, and there is no central repository - making it difficult to track noise complaints by installation. Noise researchers often generate noise contours surrounding a noise source to spatially represent noise levels (Westervelt 2004). A method similar to this is used to characterize noise sensitivity. Yet, this method may not easily be used to explore circumstance patterns. Missing from this data is the situational patterns that affect noise. For instance, topography, climate, community activity, and community value all impact noise-large mountains or buildings absorb sounds, high humidity slows the travel of sound, additional noises tend to go unnoticed or are "blockedout" in high sound areas, social contexts react differently to differing sound types, etc. Therefore small noises may generate a big impact and large noises may generate no complaints depending on the surrounding environment. Because of these concerns, it is important to use local knowledge and applicable supplemental analysis in interpreting the noise sensitivity classifications for a particular environment.

\section{Replicable}

It is recognized that noise complaints have a direct relationship with population concentrations. Theoretically, noise complaints have a greater chance of occurring near civilian development. Any section of an installation located within or near a civilian population is considered sensitive or vulnerable to noise complaints. Therefore, this indicator may be updated every 10 years as the U.S. Census updates the Incorporated Places/Census Designated Places GIS compatible maps available online through URL: http://www.census.gov/geo/www/cob/pl2000.html

\section{Directions}

Download Incorporated Places/Census Designated Places GIS compatible shapefile for all of the United States from the U.S. Census Bureau through URL: http://www.census.gov/geo/www/cob/pl2000.html. Note, the U.S. Census makes no population requirements for incorporated or designated placesall populations are indicated within the shapefile. Make sure the average population per square mile is attached in the attribute table of each place. Import the data into a GIS program and create 3-mile buffers around all places. J oin the place and buffer shapefiles with installation boundary files to create a GIS noise sensitivity indicator layer. 
Indicator Measure

Because military installations are often of a significant size, what goes on within one area of the installation may not affect what goes on within another area. Thus, only the area of the installation located in or within 3 miles of an incorporated or designated place is classified as noise sensitive. As noted earlier, the size of the population affected also makes a difference. Therefore, the installation area in or within 3 miles of an incorporated or designated place is multiplied by the population per square mile of the specified place. The result is an estimated population affected by possible installation generated noise. The following vulnerability thresholds were defined under expert guidance from Army Corps of Engineers, Construction Engineering Research Laboratory (CERL):

\author{
Very Low Vulnerability (1): $<=50,000$ affected persons \\ Low Vulnerability (2): $>50,000-<=100,000$ affected persons \\ Moderate Vulnerability (3): $>100,000-<=150,000$ affected persons \\ Vulnerable (4): $>150,000-<=200,000$ affected persons \\ Highly Vulnerable (5): >200,000 affected persons
}

\title{
Rules
}

Installations are possibly located within 3 miles of two or more incorporated or designated places. Therefore, the estimated population sensitive to noise is calculated on each place and summed to establish a total estimated population sensitive to noise. The total estimated population sensitive to noise is then subject to the same metric noted above. 


\section{Sustainability Issue: Airspace}

Indicator: Proximity to Special Use Airspace, Fighter Range (AS1)

Variables

Warning Area, Military Operations Area, Restricted Area, and Controlled Firing Area Special Use Airspace (SUA)

Scale

Installation

Year

2005

Data Sources

Aircraft Owners and Pilots Association (AOPA) Air Safety Foundation. 2002. Safety Advisor, Regulation No. 1. Frederick, MD: AOPA. Accessible through URL: http://www.aopa.org/asf/publications/sa02.pdf

Digital Aeronautical Flight Information File (DAFIF), National Imagery and Mapping Agency. 2005. DAFIF Edition 6. Bethesda, MD: DAFIF. Accessible through URL: https://164.214.2.62/products/digitalaero/index.cfm

U.S. Air Force (USAF). 2005. Air Force Link. Fact Sheets: Aircraft. Washington, DC: USAF. Accessible through URL: http://www.af.mil/Fact Sheets/

Logic

Airspace structure is complex. The Federal Aviation Administration regulates aircraft based on altitudes as well as through the development of special use airspace (SUA). SUAs were developed to advise pilots of an activity or surface area that dictates special rules or notices and may possibly be hazardous. There are five main types of SUAs (prohibited areas, restricted areas, warning areas, military operations areas, and alert areas) and several secondary types (National security areas, military training routes, air defense identification zones, controlled firing areas, local airport advisory areas, and parachute jump areas). Descriptions of commonly referred to SUAs follow (AOPA 2002).

Prohibited areas are established for security reasons or for National welfare. They are permanently "off limits." An example of a prohibited area is the White House, or Camp David.

Restricted areas, though not entirely prohibited to flight activity, are areas in which unauthorized penetration is not only illegal, but also extremely 
dangerous. Restricted areas generally contain operations that do not mix well with aircraft such as artillery firing, guided missiles, or aerial gunnery.

Warning areas are airspace over domestic or international water that extend beyond shore. Warning areas are advisory in nature and alert pilots that they may be entering areas of hazardous activity.

Military operations areas (MOA) separate high-speed military traffic from other traffic. Although no one is prohibited from entering MOAs, they are cautioned to keep a watchful eye out for military operations such as aerial refueling, air combat training, and formation flying.

Alert areas are airspace in which an unusual type of aerial activity or dense pilot training takes place. They advise pilots of possible aerial conflicts, but have no special rules.

National security areas are established over areas that require increase security.

Military training routes are one-way high-speed routes for military traffic.

Controlled firing areas allow military activity such as artillery fire that is suspended when radar detects approaching aircraft.

SUAs primarily used by the military include warning areas, MOAs, restricted areas, and controlled firing areas. This indicator provides a measurement of special use airspace available to fighter aircraft. Availability is measured by the aircrafts un-refueling range as defined by the U.S. Air Force (Air Force 2005). Having available airspace is typically a necessity for military training. If access is inadequate, then it is a strong indicator of pressures on the future use and vulnerability of airspace, leading to greater demands and limitations on military development and missions. This would then place the military installation in a vulnerable state, affecting the type and intensity of training that could take place on the installation.

It is important to note that although this indicator describes availability of fighter aircraft training airspace, not all installations make use of training airspace. Ideally, installations are prepared for transformations to any mission. However, it may not be realistic. It is important to use local knowledge of an installation's current and future mission requirements when interpreting this indicator. 


\section{Replicable}

This indicator could be replicated annually based on information updated in the DAFIF System (DAFIF 2005).

\section{Directions}

Download the DAFIF System SUA file (2005) through URL: https://164.214.2.62/products/digitalaero/index.cfm.

This file includes boundary files for six SUA designations-warning (W), military operation $(\mathrm{M})$, alert $(\mathrm{A})$, restricted $(\mathrm{R})$, prohibited $(\mathrm{P})$, controlled firing area, and National security ( $\mathrm{T}$ ). Delete prohibited, alert, and National security SUAs for the purposes of this indicator. Import the remaining SUA boundary files into a GIS program to create a Proximity to Special Use Airspace, Fighter Range indicator layer. Create buffers at 35, 70, 105, and 140 mile intervals around the SUAs to form vulnerability-rating classifications.

\section{Indicator Measure}

This indicator provides insight into an installation's fighter aircraft SUA access. Classifications were defined based on fighter aircraft capabilities as recommended by Air Force Headquarters (Air Force 2005):

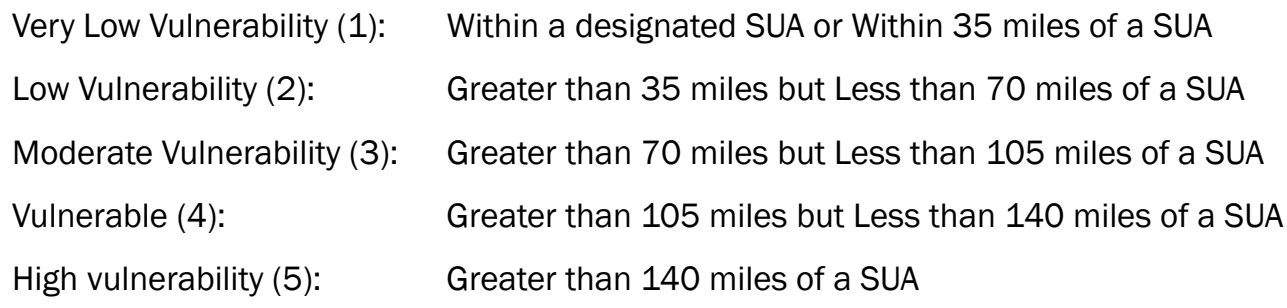

\section{Rules}

Installations typically have only one SUA located within 35 to 140 miles. However, several installations do have two or more SUAs located within 35 to 140 miles. In this instance, the region around an installation takes on the SUA classification of the lowest vulnerability. For instance, if an installation has an SUA located within 35 miles and another SUA located within 105 miles, the region would be classified as very low vulnerability. 


\section{Indicator: Proximity to Special Use Airspace, Bomber Range (AS2)}

Variables

Warning Areas, Military Operations Areas, Restricted Areas, and Controlled Firing Area Special Use Airspace (SUA)

Scale

Installation

Year

2005

Data Sources

AOPA Air Safety Foundation. 2002. Safety Advisor, Regulation No. 1. Frederick, MD: AOPA. Accessible through URL: http://www.aopa.org/asf/publications/sa02.pdf

DAFIF, National Imagery and Mapping Agency. 2005. DAFIF Edition 6. Bethesda, MD: Accessible through URL: https://164.214.2.62/products/digitalaero/index.cfm

USAF. 2005. Air Force Link. Fact Sheets: Aircraft. Washington, DC: USAF. Accessible through URL: http://www.af.mil/Fact Sheets/

Logic

Airspace structure is complex. The Federal Aviation Administration regulates aircraft based on altitudes as well as through the development of special use airspace (SUA). SUAs were developed to advise pilots of an activity or surface area that dictates special rules or notices and may possibly be hazardous. There are five main types of SUAs (prohibited areas, restricted areas, warning areas, military operations areas, and alert areas) and several secondary types (National security areas, military training routes, air defense identification zones, controlled firing areas, local airport advisory areas, and parachute jump areas). Descriptions of commonly referred to SUAs follow (AOPA 2002).

Prohibited areas are established for security reasons or for National welfare. They are permanently "off limits." An example of a prohibited area is the White House, or Camp David.

Restricted areas, though not entirely prohibited to flight activity, are areas in which unauthorized penetration is not only illegal, but also extremely dangerous. Restricted areas generally contain operations that do not mix well with aircraft such as artillery firing, guided missiles, or aerial gunnery. 
Warning areas are airspace over domestic or international water that extend beyond shore. Warning areas are advisory in nature and alert pilots that they may be entering areas of hazardous activity.

Military operations areas (MOA) separate high-speed military traffic from other traffic. Although no one is prohibited from entering MOAs, they are cautioned to keep a watchful eye out for military operations such as aerial refueling, air combat training, and formation flying.

Alert areas are airspace in which an unusual type of aerial activity or dense pilot training takes place. They advise pilots of possible aerial conflicts, but have no special rules.

National security areas are established over areas that require increase security.

Military training routes are one-way high-speed routes for military traffic.

Controlled firing areas allow military activity such as artillery fire that is suspended when radar detects approaching aircraft.

SUAs primarily used by the military include warning areas, MOAs, restricted areas, and controlled firing areas. This indicator provides a measurement of special use airspace available to bomber aircraft. Availability is measured by the aircrafts un-refueling range as defined by the U.S. Air Force (Air Force 2005). Having available airspace is typically a necessity for military training. If access is inadequate, then it is a strong indicator of pressures on the future use and vulnerability of airspace, leading to greater demands and limitations on military development and missions. This would then place the military installation in a vulnerable state, affecting the type and intensity of training that could take place on the installation.

It is important to note that although this indicator describes availability of bomber aircraft training airspace, not all installations make use of training airspace. Ideally, installations are prepared for transformations to any mission. However, this may not be realistic. It is important to use local knowledge of an installation's current and future mission requirements when interpreting this indicator. 
Replicable

This indicator could be replicated annually based on information updated in the DAFIF System (DAFIF 2005).

\section{Directions}

Download the SUA file from the DAFIF System through URL: https://164.214.2.62/products/digitalaero/index.cfm (DAFIF 2005). This file includes boundary files for six SUA designations-warning (W), military operation (M), alert (A), restricted (R), prohibited (P), controlled firing area, and National security $(\mathrm{T})$. Delete prohibited, alert, and National security SUAs for the purposes of this indicator. Import the remaining SUA boundary files into a GIS program to create a Proximity to Special Use Airspace, Bomber Range indicator layer. Create buffers at 70, 140, 210, and 280 mile intervals around the SUAs to form vulnerability-rating classifications.

Indicator Measure

This indicator provides insight into an installation's bomber aircraft SUA access. Classifications were defined based on bomber aircraft capabilities as recommended by Air Force Headquarters (Air Force 2005):

\footnotetext{
Very Low Vulnerability (1): Within a designated SUA or Within 70 miles of a SUA

Low Vulnerability (2): Greater than 70 miles but Less than 140 miles of a SUA

Moderate Vulnerability (3): Greater than 140 miles but Less than 210 miles of a SUA

Vulnerable (4): Greater than 210 miles but Less than 280 miles of a SUA

High vulnerability (5): Greater than 280 miles of a SUA
}

Rules

Installations typically have only one SUA located within 70 to 280 miles. However, several installations do have two or more SUAs located within 70 to 280 miles. In this instance, the region around an installation takes on the SUA classification of the lowest vulnerability. For instance, if an installation has an SUA located within 70 miles and another SUA located within 210 miles, the region would be classified as very low vulnerability.

\section{Indicator: Terminal Airspace (AS3)}

Variables

Terminal Airspace 
Scale

Installation

Year

2005

Data Source

DAFIF, National Imagery and Mapping Agency. 2005. DAFIF Edition 6. Bethesda, MD: DAFIF. Accessible through URL:

https://164.214.2.62/products/digitalaero/index.cfm

Logic

This indicator provides a measurement of the quantity of terminal airspace within 20 miles of a military installation. Terminal airspace is airspace in which approach-control service or airport traffic control service regulates all traffic. In addition to the burden of coordinating traffic routes with one or more traffic controller, terminal airspaces are increasingly experiencing congestion problems due to increased traffic demands induced, for example, by the deregulation of the air transport industry. Congestion problems may arise from arrival/departure overloads, frequency of en route aircraft, or simply inadequate coordination.

Having available airspace is typically a necessity for military shipments, mobilization, and training. Inadequate access places the installation in a vulnerable state, affecting mobilization or, possibly, the type and intensity of training that could take place. Therefore, terminal airspace is considered an important encroachment indicator.

Although travel through any terminal airspace requires approval, not all terminal airspaces will impose restrictions on an installations desired traffic route. Depending on the time and altitude of military aircraft as well as the time and altitude of airport operations, the two may rarely conflict. Thus, it is important to use local knowledge when interpreting the impact of terminal airspace.

\section{Replicable}

This indicator could be replicated annually based on information updated in the DAFIF System (DAFIF 2005). 


\section{Directions}

Download the DAFIF System Airspace Boundary file through URL: https://164.214.2.62/products/digitalaerolindex.cfm (DAFIF 2005). This file includes boundary files for airspace designations. Import the terminal airspace boundary files into a GIS program. In the same GIS workspace, create 20-mile buffers around each installation. Intersect the terminal airspace boundaries with the installation buffers. Calculate the percentage of terminal airspace located within 20 miles of each installation. Use this percentage to form vulnerability-rating classifications.

\section{Indicator Measure}

This indicator provides insight into an installation's airspace accessibility. It is assumed that an installation's proximity to terminal airspace may restrict military shipments, mobilization, and training. One hundred thirtyfive of the 402 installations analyzed had no terminal airspace within 20 miles of the installation. Classifications were defined based on statistical analysis of the standard deviation (23.06) around the National average (15.34 percent):

$$
\begin{aligned}
& \text { Very Low Vulnerability (1): } 0 \text { percent Terminal Airspace within } 20 \text { miles of the installa- } \\
& \text { Low Vulnerability (2): }>0-<=15.34 \text { percent Terminal Airspace within } 20 \text { miles of } \\
& \text { the installation boundary } \\
& \text { Moderate Vulnerability (3): } \begin{array}{l}
>15.34-<=38.4 \text { percent Term } \\
\text { of the installation boundary }
\end{array} \\
& \text { Vulnerable (4): }>38.4-<=61.46 \text { percent Terminal Airspace within } 20 \text { miles } \\
& \text { of the installation boundary }
\end{aligned}
$$

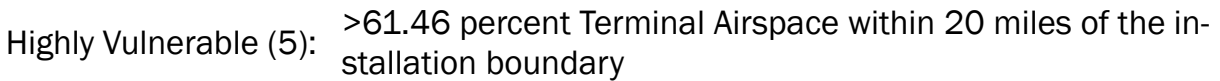

Rules

Since this data is collected by installation, there is no calculation to determine installation risk ratings.

\section{Indicator: Proximity to Military Training Routes, Fighter Range (AS4)}

Variables

Military Training Routes (MTR) Primary and Alternate Entry and Exit points

Scale

Installation 
Year

2005

Data Sources

DAFIF, National Imagery and Mapping Agency. 2005. DAFIF Edition 6. Bethesda, MD: Accessible through URL:

https://164.214.2.62/products/digitalaero/index.cfm

USAF. 2005. Air Force Link. Fact Sheets: Aircraft. Washington, DC: USAF. Accessible through URL:

http://www.af.mil/Fact Sheets/

USAF. 2005. Air Force Link. Fact Sheets: Low-Altitude Flying Training. Washington, DC: USAF. Accessible through URL:

http://www.af.mil/Fact Sheets/factsheet.asp?fsID=183

Logic

National security depends largely on the deterrent effect of our airborne military forces. To be proficient, the military services must train in a wide range of airborne tactics. One phase of this training involves "low level" combat tactics. The required maneuvers and high speeds are such that they may occasionally make the avoid aspect of flight more difficult without increased vigilance in areas containing such operations. In an effort to ensure the greatest practical level of safety for all flight operations, the Military Training Route (MTR) was conceived.

The MTR program is a joint venture by the Federal Aviation Administration and the Department of Defense. MTRs are mutually developed for use by the military for the purpose of conducting low-altitude, high-speed training. Generally, MTRs are established below 10,000 ft (mean sea level) for operations at speeds in excess of 250 knots (Air Force 2005). However, route segments may be defined at higher altitudes for purposes of route continuity. For example, route segments may be defined for descent, climb-out, and mountainous terrain.

This indicator provides a measurement of MTR airspace available to fighter aircraft. Availability is measured by the aircrafts un-refueling range as defined by the U.S. Air Force (Air Force 2005). Having available airspace is typically a necessity for military training. Inadequate access is a strong indicator of limitations on military development and missions. This would then place the military installation in a vulnerable state, affecting the type and intensity of training that could take place on the installation. 
It is important to note that although this indicator describes availability of fighter aircraft MTRs, not all installations make use of training airspace. Ideally, installations are prepared for transformations to any mission. However, it may not be realistic. It is important to use local knowledge of an installation's current and future mission requirements when interpreting this indicator.

\section{Replicable}

This indicator could be replicated annually based on information updated in the DAFIF System (DAFIF 2005).

\section{Directions}

Download the MTR: Routes, Polylines, Entry/ Exit Points, and Points file from the DAFIF System through URL (DAFIF 2005):

https://164.214.2.62/products/digitalaero/index.cfm.

Import all points designated as "A" Alternate Entry Point, "B' Alternate Exit Point, "C" Alternate Entry/ Exit Point, "S" Primary Entry Point, and " $\mathrm{X}$ " Primary Exit Point for all kinds of flying routes ("VR" Visual Route, "IR" Instrument Route, and "SR" Slow Route) into a GIS program to create a Proximity to Military Training Routes, Fighter Range indicator layer. Create buffers at 35, 70, 105, and 140 mile intervals around all points to form vulnerability-rating classifications.

Indicator Measure

This indicator provides insight into an installation's fighter aircraft MTR access. Classifications were defined based on fighter aircraft capabilities as recommended by Air Force Headquarters (Air Force 2005):

\footnotetext{
Very Low Vulnerability (1): Within a designated MTR or Within 35 miles of a MTR

Low Vulnerability (2): Greater than 35 miles but Less than 70 miles of a MTR

Moderate Vulnerability (3): Greater than 70 miles but Less than 105 miles of a MTR

Vulnerable (4): Greater than 105 miles but Less than 140 miles of a MTR

High vulnerability (5): Greater than 140 miles of a MTR
}

\section{Rules}

Installations typically have only one MTR located within 35 to 140 miles. However, several installations do have two or more MTRs located within 35 to 140 miles. In this instance, the region around an installation takes on the MTR classification of the lowest vulnerability. For instance, if an in- 
stallation has an MTR located within 35 miles and another MTR located within 105 miles, the region would be classified as very low vulnerability.

\section{Indicator: Proximity to Military Training Routes, Bomber Range (AS5)}

Variables

Military Training Routes (MTR) Primary and Alternate Entry and Exit points

Scale

Installation

Year

2005

Data Sources

DAFIF, National Imagery and Mapping Agency. 2005. DAFIF Edition 6. Bethesda, MD: DAFIF. Accessible through URL: https://164.214.2.62/products/digitalaero/index.cfm

USAF. 2005. Air Force Link. Fact Sheets: Aircraft. Washington, DC: USAF. http://www.af.mil/Fact Sheets/

USAF. 2005. Air Force Link. Fact Sheets: Low-Altitude Flying Training. Washington, DC: USAF. Accessible through URL:

http://www.af.mil/Fact Sheets/factsheet.asp?fsID=183

Logic

National security depends largely on the deterrent effect of our airborne military forces. To be proficient, the military services must train in a wide range of airborne tactics. One phase of this training involves "low level" combat tactics. The required maneuvers and high speeds are such that they may occasionally make the avoid aspect of flight more difficult without increased vigilance in areas containing such operations. In an effort to ensure the greatest practical level of safety for all flight operations, the Military Training Route (MTR) was conceived.

The MTR program is a joint venture by the Federal Aviation Administration and the Department of Defense. MTRs are mutually developed for use by the military for the purpose of conducting low-altitude, high-speed training. Generally, MTRs are established below 10,000 ft (mean sea level) for operations at speeds in excess of 250 knots (Air Force 2005). However, route segments may be defined at higher altitudes for purposes of route 
continuity. For example, route segments may be defined for descent, climb-out, and mountainous terrain.

This indicator provides a measurement of MTR airspace available to bomber aircraft. Availability is measured by the aircrafts un-refueling range as defined by the U.S. Air Force (Air Force 2005). Having available airspace is typically a necessity for military training. Inadequate access is a strong indicator of greater demands and limitations on military development and missions. This would then place the military installation in a vulnerable state, affecting the type and intensity of training that could take place on the installation.

It is important to note that although this indicator describes availability of bomber aircraft MTRs, not all installations make use of training airspace. Ideally, installations are prepared for transformations to any mission. However, it may not be realistic. It is important to use local knowledge of installation's current and future mission requirements when interpreting this indicator.

\section{Replicable}

This indicator could be replicated annually based on information updated in the DAFIF System (DAFIF 2005).

\section{Directions}

Download the MTR: Routes, Polylines, entry/ Exit Points, and Points file from the DAFIF System through URL(DAFIF 2005):

https:/1164.214.2.62/products/digitalaero/index.cfm

Import all "A" Alternate Entry Point, "B" Alternate Exit Point, "C" Alternate Entry/ Exit Point, "S" Primary Entry Point, and “ $\mathrm{X}$ " Primary Exit Point for all kinds of flying routes ( "VR" Visual Route, "IR" Instrument Route, and "SR" Slow Route) into a GIS program to create a Proximity to Military Training Routes, Bomber Range indicator layer. Create buffers at $70,140,210$, and 280 mile intervals around all points to form vulnerability-rating classifications.

\section{Indicator Measure}

This indicator provides insight into an installation's bomber aircraft MTR access. Classifications were defined based on bomber aircraft capabilities as recommended by Air Force Headquarters (Air Force 2005): 
Very Low Vulnerability (1): Within a designated MTR or Within 70 miles of a MTR

Low Vulnerability (2): Greater than 70 miles but Less than 140 miles of a MTR

Moderate Vulnerability (3): Greater than 140 miles but Less than 210 miles of a MTR

Vulnerable (4): Greater than 210 miles but Less than 280 miles of a MTR

High vulnerability (5): Greater than 280 miles of a MTR

Rules

Installations typically have only one MTR located within 70 to 280 miles. However, several installations do have two or more MTRs located within 70 to 280 miles. In this instance, the region around an installation takes on the MTR classification of the lowest vulnerability. For instance, if an installation has an MTR located within 70 miles and another MTR located within 210 miles, the region would be classified as very low vulnerability. 


\section{Sustainability Issue: Energy}

\section{Indicator: Electrical Grid Congestion (EN1)}

Variables

Number of Transmission Loading Relief (TLR) Procedures and Regional Self-Assessments

Scale

NERC Regional Reliability Councils and Sub-Regions Year

2004

Data Sources

NERC TLR Trend Logs.2004. Accessible through URL: http://www.nerc.com/ filez/Logs/index.html

North American Electricity Reliability Council (NERC). 2004. Long-Term Reliability Assessment: The Reliability of Bulk Electric Systems in North America. Princeton, NJ , North American Electric Reliability Council. Vol. 88.

Logic

Portions of the transmission systems are reaching their limits as customer demand increases and the systems are subjected to new loading patterns resulting from increased power transfers caused by market conditions and weather patterns. Operating procedures, market-based congestion management procedures, and transmission loading relief procedures (TLRs) are used to control the flow on the system within operating reliability limits.

Some well-known transmission constraints are recurring and new constraints are appearing as electricity flow patterns change with installation generation capacity. The transmission system is being subjected to flows in magnitudes and directions that were not contemplated when it was designed or for which there is minimal operating experience. These new flow patterns result in an increasing number of facilities being identified as limits to transfers, and market-based congestion management procedures and TLR procedures are required in areas not previously subject to overloads to maintain the transmission facilities within operating limits.

In some areas, market operators employ locational marginal pricing (LMP) to effect a generation redispatch through economic incentives. In other areas of the Eastern Interconnection, reliability coordinators invoke 
NERC TLRs to maintain reliability by managing transactions within transmission operating reliability constraints. In effect, TLRs cause generation redispatch by restricting or curtailing scheduled transfers. As such, the number of TLRs is an indication of the grid reaching its capacity in a certain region. Since several other methods in addition to TLRs are used to control grid traffic and some regions do not report, NERC regional selfassessments also provide insight into the grid capacity and operation in the given regions and sub-regions.

The current operating paradigm for almost all defense installations is to obtain their electrical power from the grid. Therefore, grid congestion is an indicator of potential shortfalls in power availability and price volatility in a given region.

\section{Replicable}

This indicator could be replicated every year based on information updated in annual NERC reliability assessments. TLR data is continuously reported and updated.

\section{Directions}

The TLR data for the past 2 years is averaged to provide a preliminary assessment. This assessment is further tempered and adjusted based on the regional self-assessments in the annual long-term report. Data is from trend analysis of TLR logs on the NERC web-site through URL:

\section{http://www.nerc.com/ filez/Logs/index.html}

There is no TLR data for the Western Electricity Coordinating Council, Alaska, or Hawaii. Simply import the final data into a GIS program with NERC boundary files to create an Electrical Grid Congestion indicator layer.

Indicator Measure

Electrical Grid Congestion ranges were defined as follows based on natural breaks and implications in the data (where TLR data was not available or incomplete, regional self-assessment data was used to generate or amplify the rating): 


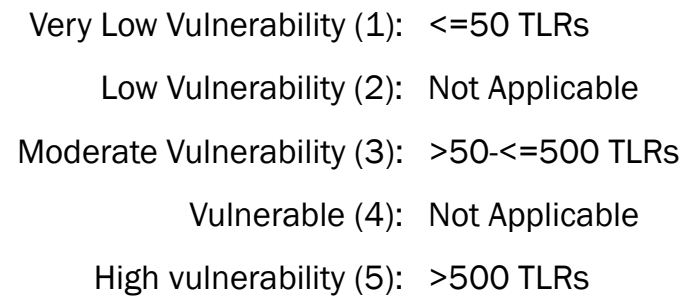

Rules

Every installation is located primarily in one reliability region, although several installations may cross regional boundaries. An area around an installation takes on the classification of the region in which the installation is primarily located (Table A1).

Table A1. Regional data.

\begin{tabular}{|l|l|l|}
\hline Reliability Region/Sub Region & TLRs & Encroachment Vulnerability Classification \\
\hline ECAR & 82.5 & Moderate (Michigan \& WV) \\
\hline ERCOT & Market & Moderate (Dallas, Houston, West Texas) \\
\hline FRCC & 0 & Low \\
\hline MAAC & 188 & Moderate \\
\hline MAIN & 47.5 & Moderate (Wisconsin and delayed upgrades) \\
\hline MAPP & 1000 & High (Twin Cities area and interties) \\
\hline NPCC/New England & 0 & Low \\
\hline NPCC/New York & 0 & Moderate (NYC and Long Island) \\
\hline SERC/Entergy & 65 & Moderate \\
\hline SERC/TVA & 51 & Moderate \\
\hline SERC/SoCo & 1 & Low \\
\hline SERC/VACAR & 4 & Low \\
\hline SPP & 193 & Moderate \\
\hline WECC/AZMNSV & & Moderate \\
\hline WECC/CA & & Moderate \\
\hline WECC/NWPP & & Low \\
\hline WECC/RMPA & & Low \\
\hline
\end{tabular}

\section{Indicator: Electrical Grid Reserve Capacity in 2010 (EN2)}

Variables

Capacity Margins (\% of Capacity Resources) Summer 2010 Scale

NERC Regional Reliability Councils

Year 


\section{Data Source}

NERC. 2005. Long-Term Reliability Assessment: The Reliability of Bulk Electric Systems in North America. Princeton, NJ : North American Electric Reliability Council. Vol. 88.

\section{Logic}

The Electrical Grid Reserve Capacity indicator shows the percentage of capacity margin for the NERC regions for the summer of 2010. This indicator is important because it shows how well the region is planning to meet electrical demand growth in the future. Reduced capacity margins indicate the possibility of future electric shortages in a region in times of high electrical demand.

\section{Replicable}

This indicator could be replicated every year based on the annual updates in NERC reliability assessments.

\section{Directions}

There are no calculations for this indicator. Data is from tables in the periodic reliability report. There is no data for Alaska or Hawaii, only the continental United States. Simply import the final data into a GIS program with NERC boundary files to create an Electrical Grid Reserve Capacity indicator layer.

\section{Indicator Measure}

Electrical Grid Reserve Capacity ranges were defined as follows based on natural breaks in the data:

$$
\begin{aligned}
& \text { Very Low Vulnerability (1): }>20-<=30 \text { percent margin } \\
& \text { Low Vulnerability (2): }>17.5-<=20 \text { percent margin } \\
& \text { Moderate Vulnerability (3): }>15-<=17.5 \text { percent margin } \\
& \text { Vulnerable (4): }>12.5-<=15 \text { percent margin } \\
& \text { High vulnerability (5): } \quad<=12.5 \text { percent margin }
\end{aligned}
$$

\section{Rules}

Every installation is located primarily in one reliability region, although several installations may cross regional boundaries. The area around an installation takes on the rating of the NERC region where the installation is primarily located, on an area basis (Table A2). 
Table A2. NERC regional data.

\begin{tabular}{|c|c|l|}
\hline Reliability Region & Reserve Margin (\%) & \multicolumn{1}{|c|}{ Rating } \\
\hline ECAR & 12.6 & Vulnerability \\
\hline ERCOT & 11.9 & High Vulnerability \\
\hline FRCC & 16.3 & Moderate Vulnerability \\
\hline MAAC & 13.0 & Vulnerable \\
\hline MAIN & 12.9 & Vulnerable \\
\hline MRO & 12.8 & Vulnerable \\
\hline NPCC & 11.9 & High Vulnerability \\
\hline SERC & 7.8 & High Vulnerability \\
\hline SPP & 13.0 & Vulnerable \\
\hline WECC & 20.7 & Very Low Vulnerability \\
\hline
\end{tabular}

\section{Indicator: Wind Resources (EN3)}

Variables

Wind Power Density

Scale

1/4 degree of latitude by $1 / 3$ degree of longitude Grid Cells

Year

1986

Data Source

Pacific Northwest Laboratory 2003. Wind Energy Resource Atlas of the United States.

Washington, DC: U.S. Department of Energy. Accessible through URL:

http://rredc.nrel.gov/wind/

Logic

The Wind Resource indicator provides wind power class classifications ranging from 1 to 6 , with 6 being the windiest. The assigned wind power class is representative of the range of wind power densities likely to occur at exposed sites within the grid cell. This indicator is important because it shows how well equipped the region is to provide renewable energy sources to meet future energy requirements once fossil fuel becomes unavailable or too expensive.

The wind resource assessment was based on surface wind data, coastal marine area data, and upper-air data, where applicable. In data-sparse areas, three qualitative indicators of wind speed or power were used when applicable: topographic/ meteorological indicators (e.g., gorges, mountain summits, sheltered valleys); wind deformed vegetation; and eolian land- 
forms (e.g., playas, sand dunes). The data was evaluated at a regional level to produce 12 regional wind resource assessments; the regional assessments were then incorporated into the National wind resource assessment.

The conterminous United States was divided into grid cells $1 / 4$ degree of latitude by $1 / 3$ degree of longitude. Each grid cell was assigned a wind power class ranging from 1 to 6 . The wind power density limits for each wind power class is shown in Table A3.

Table A3. Wind power density limits for each wind power class.

\begin{tabular}{|c|c|c|c|c|}
\hline \multirow{2}{*}{$\begin{array}{l}\text { Wind } \\
\text { Power } \\
\text { Class }\end{array}$} & \multicolumn{2}{|c|}{$10 \mathrm{~m}$ (33 ft) } & \multicolumn{2}{|c|}{$50 \mathrm{~m}(164 \mathrm{ft})$} \\
\hline & $\begin{array}{c}\text { Wind Power Density } \\
\left(\mathrm{W} / \mathrm{m}^{2}\right)\end{array}$ & $\begin{array}{l}\text { Speed }{ }^{(\mathrm{b})} \mathrm{m} / \mathrm{s} \\
(\mathrm{mph})\end{array}$ & $\begin{array}{c}\text { Wind Power Density } \\
\left(\mathrm{W} / \mathrm{m}^{2}\right)\end{array}$ & $\begin{array}{c}\text { Speed }^{(b)} \mathrm{m} / \mathrm{s} \\
(\mathrm{mph})\end{array}$ \\
\hline \multirow{2}{*}{1} & 0 & 0 & 0 & \\
\hline & \multirow{2}{*}{100} & \multirow{2}{*}{$4.4(9.8)$} & \multirow{2}{*}{200} & \multirow{2}{*}{$5.6(12.5)$} \\
\hline \multirow[t]{2}{*}{2} & & & & \\
\hline & 150 & 5.1 (11.5) & 300 & $6.4(14.3)$ \\
\hline 3 & \multirow[t]{2}{*}{200} & \multirow[t]{2}{*}{$5.6(12.5)$} & \multirow[t]{2}{*}{400} & \multirow[t]{2}{*}{$7.0(15.7)$} \\
\hline \multirow[t]{2}{*}{4} & & & & \\
\hline & 250 & $6.0(13.4)$ & 500 & 7.5 (16.8) \\
\hline 5 & 300 & 6.4 (14.3) & 600 & $8.0(17.9)$ \\
\hline 6 & 400 & $7.0(15.7)$ & 800 & 8.8 (19.7) \\
\hline 7 & 1000 & $9.4(21.1)$ & 2000 & 11.9 (26.6) \\
\hline
\end{tabular}

Where possible, existing ground measurement stations are used to validate the model. The degree of certainty with which the wind power class can be specified depends on three factors: the abundance and quality of wind data; the complexity of the terrain; and the geographical variability of the resource. Hilltops, ridge crests, mountain summits, large clearings, and other locations free of local obstruction to the wind are expected to be well exposed to the wind. In contrast, locations in narrow valleys and canyons, downwind of hills or obstructions, or in forested or urban areas are likely to have poor wind exposure. A certainty rating was assigned to each grid cell based on these three factors, and is included in the Wind Energy Resource Atlas of the United States available online through URL: http://rredc.nrel.gov/windl

Furthermore, it is also recognized that there are several additional alternative sources of energy such as solar and biomass. For regions that lack wind resources, these additional resources may be prevalent and ample to 
meet future energy requirements. Given these recognitions, local knowledge of the region and its additional resources needs to be taken in consideration.

\title{
Replicable
}

The Pacific Northwest Laboratory typically updates the data annually. However, it is dependent on changes in the data. It is recommended to contact the Laboratory to inquire about the latest available data.

\section{Directions}

There are no calculations for this indicator. Data is downloaded directly from the Pacific Northwest Laboratory website located through URL:

\section{http://rredc.nrel.gov/wind/}

Simply import the data into a GIS program to create the Wind Resource indicator layer. Note, there is no data for Alaska or Hawaii-only the continental United States.

\section{Indicator Measure}

Areas designated class 4 or greater are suitable for most utility-scale wind turbine applications, whereas class 3 areas are marginal for utility-scale applications but may be suitable for rural applications. Class 2 and 1 areas are generally not suitable, although a few locations (e.g., exposed hilltops) with adequate wind resource for wind turbine applications may exist in some class 1 areas (Pacific Northwest Laboratory 2003). Therefore, it is important to use local knowledge to interpret wind power classifications. Wind Resource ranges were defined as follows based on Pacific Northwest Laboratory literature:

\author{
Very Low Vulnerability (1): Wind Power Class of 6 \\ Low Vulnerability (2): Wind Power Class of 5 \\ Moderate Vulnerability (3): Wind Power Class of 4 \\ Vulnerable (4): Wind Power Class of 3 \\ High vulnerability (5): Wind Power Class of 1 or 2
}

\section{Rules}

Every installation is located primarily in one grid cell, although several installations may cross cell boundaries. The area around an installation takes on the rating of the grid cell where the installation is primarily located (area basis). 


\section{Indicator: Solar Resources (EN4)}

Variables

Solar Resources for Flat Plate Collectors

Scale

$40 \mathrm{~km}$ by $40 \mathrm{~km}$ Grid Cells

Year

1985-1992

Data Source

National Renewable Energy Laboratory (NREL) 2003. Climatologically Solar Radiation Model. Washington, DC: U.S. Department of Energy. Accessible through URL: http://rredc.nrel.gov/solarl

Logic

The Solar Resource indicator is based on the monthly average daily total solar resource information on grid cells of approximately $40 \mathrm{~km}$ by $40 \mathrm{~km}$ in size. The insolation values represent the resource available to a flat plate collector, such as a photovoltaic panel, oriented due south at an angle from horizontal equal to the latitude of the collector location. This is typical practice for PV system installation, although other orientations are also used (NREL 2003). This indicator is important because it shows how well equipped the region is to provide renewable energy sources to meet increasing demand in the future. The availability of renewable energy in a region is an indicator of future sustainability once transition away from fossil fuels is required due to resource limitations and cost.

Indicator data was developed from the Climatological Solar Radiation (CSR) Model. The CSR model was developed by the NREL for the U.S. Department of Energy. This model uses information on cloud cover, atmospheric water vapor and trace gases, and the amount of aerosols in the atmosphere, to calculate the monthly average daily total insolation (sun and sky) falling on a horizontal surface. The cloud cover data used as input to the CSR model are an 8-year histogram (1985 - 1992) of monthly average cloud fraction provided for grid cells of approximately $40 \mathrm{~km} \mathrm{x} 40 \mathrm{~km}$ in size. Thus, the spatial resolution of the CSR model output is defined by this database. The data are obtained from the National Climatic Data Center in Asheville, NC, and were developed from the U.S. Air Force Real Time Nephanalysis (RTNEPH) program. Atmospheric water vapor, trace gases, and aerosols are derived from a variety of sources, as summarized in the references. 
Where possible, existing ground measurement stations are used to validate the model. Nevertheless, there is uncertainty associated with the meteorological input to the model, since some of the input parameters are not available at a $40 \mathrm{~km}$ resolution. As a result, it is believed that the modeled values are accurate to approximately 10 percent of a true measured value within the grid cell. Due to terrain effects and other microclimate influences, the local cloud cover can vary significantly even within a single grid cell. Furthermore, the uncertainty of the modeled estimates increases with distance from reliable measurement sources and with the complexity of the terrain.

It is also recognized that there are several additional alternative sources of energy such as wind and biomass. For regions that lack solar resources, these additional resources may be prevalent and available to meet future energy requirements. Therefore, local knowledge of the region and its additional resources needs to be taken in consideration.

Replicable

NREL typically updates the data annually. However, it is dependent on changes in the data. It is recommended to contact the Laboratory to inquire about the latest available data.

\section{Directions}

There are no calculations for this indicator. Data is downloaded directly from the NREL website located through URL:

\section{http://rredc.nrel.gov/solarl}

Simply import the data into a GIS program to create the Solar Resource indicator layer. Note, there is no data for Alaska or Hawaii, only the continental United States. It is assumed that Hawaii is very low vulnerability and Alaska is high vulnerability.

Indicator Measure

Solar Resource ranges were defined by NREL (NREL 2003): 


$$
\begin{aligned}
\text { Very Low Vulnerability (1): } & >=7 \text { insolation value } \\
\text { Low Vulnerability (2): } & >=6-<7 \text { insolation value } \\
\text { Moderate Vulnerability (3): } & >=5-<6 \text { insolation value } \\
\text { Vulnerable (4): } & >=4-<5 \text { insolation value } \\
\text { High vulnerability (5): } & <4 \text { insolation value }
\end{aligned}
$$

Rules

Every installation is located primarily in one grid cell, although several installations may cross cell boundaries. The area around an installation takes on the rating of the grid cell where the installation is primarily located (area basis).

\section{Indicator: Biomass Resources (EN5)}

Variables

Total Annual Biomass Available (in dry tons) at $\$ 30 /$ dry ton Scale

State

Year

1999

\section{Data Sources}

The White House. 1999. Executive Order13134 Developing and Promoting Biobased Products and Bioenergy. Washington, DC: The White House, Office of the Press Secretary. Accessible through URL: http://ceq.eh.doe.gov/nepa/regs/eos/eo13134.html

Walsh, Mary. 2000. Bioenergy Feedstock Development Program. Washington, DC: Oak Ridge National Laboratory, U.S Department of Energy. Accessible through URL: http://bioenergy.ornl.gov/resourcedata/index.html

Logic

Current biobased product and bioenergy technology has the potential to make renewable farm and forestry resources major sources of affordable electricity, fuel, chemicals, pharmaceuticals, and other materials. These technologies can create new markets for farm and forest waste products, new economic opportunities for underused land, and new value-added business opportunities. They also have the potential to reduce our Nation's dependence on foreign oil, improve air quality, water quality, and flood control, decrease erosion, and help minimize net production of greenhouse gases. Executive Order 13134 of 1. 12 August 1999 set the goal to develop a 
comprehensive National strategy, including research, development, and private sector incentives, to stimulate the creation and early adoption of technologies needed to make biobased products and bioenergy costcompetitive in large National and international markets (USA 1999). This indicator is important in assuring an affordable supply of energy for today and the future to a military installation. Thus, available biomass resources serves as an energy sustainability indicator.

Since Executive Order 13134, interest in using biomass feedstocks to produce power, liquid fuels, and chemicals in the United States is increasing. Central to determining the potential for these industries to develop is an understanding of the location, quantities, and prices of biomass resources. This indicator contains estimates of biomass quantities potentially available in five categories: mill wastes, urban wastes, forest residues, agricultural residues, and energy crops, and at an anticipated delivered price of $\$ 30$ per dry ton. A presentation that explains how this information was used to support the goal of increasing biobased products and bioenergy three times by 2010 expressed in Executive Order 13134 is Accessible through URL:

\section{http://bioenergy.ornl.gov/resourcedata/index.html}

Furthermore, it is also recognized that there are several additional alternative sources of energy such as solar and wind. For regions that lack biomass resources at an affordable rate, these additional resources may be highly prevalent and ample to meet increasing demand growth in the future. Given these recognitions, local knowledge of the region and its additional resources need to be taken in consideration.

\section{Replicable}

The Oak Ridge National Laboratory typically updates the data every 2 to 4 years. However, it is dependent on changes in the data. It is recommended to contact the Laboratory to inquire about the latest available data.

\section{Directions}

Download total dry tons delivered at or below $\$ 30$ per dry ton directly from the Oak Ridge National Laboratory website located through URL: http://bioenergy.ornl.gov/resourcedata/index.html 
Simply import the data into a GIS program to create the Biomass Resource indicator layer. Note, there is no data for Alaska or Hawaii-only the continental United States.

Indicator Measure

Biomass resources are available at a delivered price ranging from $\$ 20$ to over $\$ 50$ per dry ton. Research conducted by the Oak Ridge National Laboratory reveals $\$ 30$ per dry ton or less is considered an affordable delivery price (Oak Ridge National Laboratory 2000). Therefore, total dry tons delivered at or below $\$ 30$ per dry ton were used to classify biomass resource availability.

The quantity of biomass resources delivered per state was divided by its respective state area (square miles) resulting in available biomass resources by state per square mile. This distributes the data by area. Distributing the data by area allows for an equal comparison between large and small-area states. In other words, it protects against a small-area state from a more vulnerable classification because it naturally has less resources compared to a large-area state. Biomass Resources per square mile were statistically classified based on the mean (50.6) and standard deviation (39.6) values. Using this logic, the following classifications were defined:

$$
\begin{aligned}
\text { Very Low Vulnerability (1): } & >60 \text { tons per square mile } \\
\text { Low Vulnerability }(2): & >50-<=60 \text { tons per square mile } \\
\text { Moderate Vulnerability }(3): & >40-<=50 \text { tons per square mile } \\
\text { Vulnerable }(4): & >30-<=40 \text { tons per square mile } \\
\text { High vulnerability }(5): & <=30 \text { tons per square mile }
\end{aligned}
$$

Rules

Every installation is located primarily in one state, although several installations do cross state boundaries. A region takes on the rating of the state the nearby installation is primarily located within.

\section{Indicator: Electrical Price Structure (Deregulation) (EN6)}

Variables

Electric Utility Deregulation Status

Scale

State 
Year

2003

Data Source

U.S. Department of Energy (USDOE), Energy Information Administration. 2003. Status of State Electric Industry Restructuring Activity. Washington, DC: USDOE Office of Electricity. Accessible through URL: http://www.eia.doe.gov/cneaf/electricity/chg str/regmap.html

Logic

The price structure for electricity demand and delivery indicates whether the commodity has been deregulated and is thus more susceptible to market distortion such as price instability and availability fluctuations (EIA 2003). Deregulation of electrical markets in the United States is still very much a "work in progress," and the market has not normalized. This indicator will affect the availability and price of electricity to a military installation, and is thus highly sought after as an energy sustainability indicator. Also, utilities in states that have been deregulated have not made the needed investments into the grid because return on investment is ill defined and thus these are more susceptible to outages as seen in the August 2003 blackout. Virtually all areas affected by the blackout were in deregulated markets.

\section{Replicable}

This indicator could be replicated every year based on events that occur from states that are in the process of going to electric industry restructuring. February 2003 was the last update made by the EIA.

\section{Directions}

The EIA website for electric utility deregulation contains a map showing the states that: (1) have active deregulation, (2) have deregulation activity delayed/suspended, and (3) have no deregulation activity (EIA 2003), through URL:

http://www.eia.doe.gov/cneaf/electricity/chg_str/regmap.html

Details on the deregulation status of each state can be found by clicking on the desired state on the map located on the EIA website listed above. Download this data. Import it into a GIS program and join it with state boundary files to create an Electrical Price Structure indicator layer. 
Indicator Measure

Electrical Price Structure classifications were defined as follows based on the definitions of the EIA (EIA 2003):

\author{
Very Low Vulnerability (1): No Regulation \\ Low Vulnerability (2): Not Applicable \\ Moderate Vulnerability (3): Delayed/suspended \\ Vulnerable (4): Not Applicable \\ High vulnerability (5): Active
}

Rules

Every installation is located primarily in one state, although several installations do cross state boundaries. The area surrounding an installation takes on the classification of the state the installation is primarily located within.

\title{
Indicator: Net Metering (EN7)
}

Variables

Net Metering Actions

Scale

State

Year

2003

Data Source

Database of State Incentives for Renewable Energy (DSIRE). 2004. Green Power

Network. Interstate Renewable Energy Council, North Carolina State University Solar Center. (Summary of State Net Metering Programs; Map of Net Metering Programs). Accessible through URLs:

http://www.dsireusa.orgl http://www.eere.energy.gov/greenpower/pdfs/metering 0603.pdf http://www.eere.energy.gov/greenpower/resources/maps/netmetering map. shtml

Logic

The availability of net metering indicates whether a state allows nonenergy producers, such as consumers, to sell excess electrical energy produced onsite back to the grid at the local rate. The implications of this indicator are whether the state is progressive in its approach to integrated resource planning and management. A progressive approach ensures elec- 
tricity availability and security in the future, while other approaches may not. The use of distributed generation adds to the robustness of the grid and its overall reliability (DSIRE 2004).

\section{Replicable}

This indicator could be replicated every year based on updated actions by states that do not currently have net metering regulations.

\section{Directions}

Determine if each state participates in net metering using the Green Power Network website, through URL:

\section{http://www.eere.energy.gov/greenpower/pdfs/metering 0603.pdf}

Determine if enactments for net metering regulations are either (a) complete, (b) underway, or (c) not considered for action. If enactments are complete, specify the year in which the state net metering rules are implemented (DSIRE 2004). Download the data into a GIS program and join it to state boundary files to create a Net Metering indicator layer.

\section{Indicator Measure}

Net Metering classifications were defined as follows based on information provided by the DSIRE (DSIRE 2004):

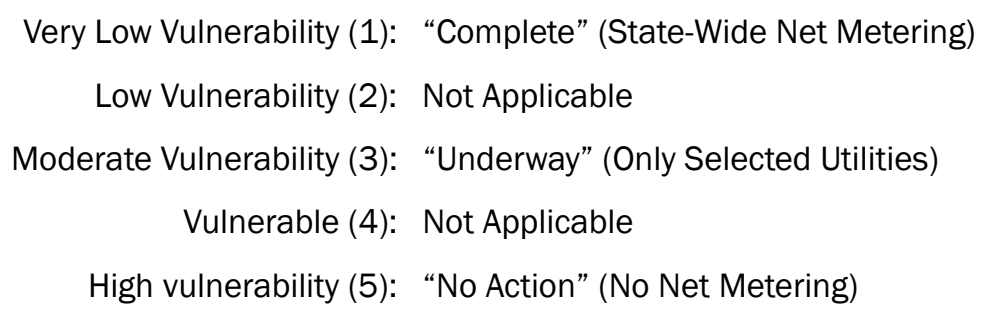

Rules

Every installation is located primarily in one state, although several installations do cross state boundaries. The region around an installation takes on the classification of the state the installation is primarily located within. 


\section{Sustainability Issue: Urban Development}

\section{Indicator: Regional Population Density (UD1)}

Variables

Population, Land Area (square mile)

Scale

County

Year

2004

Data Sources

Craig, J ohn. 1984. “Averaging Population Density.” Demography. Vol 21. No. 3. pp. 405412. Accessible through URL:

http://www.jstor.orgl

U.S. Bureau of the Census, U.S. Department of Commerce. 2000. Summary File 1: GCTPH1-R Population, Housing Units, Area, and Density. American FactFinder. Washington, DC: U.S. Bureau of the Census. Accessible through URL: http://factfinder.census.gov

U.S. Bureau of the Census, U.S. Department of Commerce. 2004. County Population Estimates and Estimated Components of Change, April 1, 2000 to J uly 1, 2004. Population Estimates Program. Washington, DC: U.S. Bureau of the Census. Accessible through URL: http://eire.census.gov/popest/estimates dataset.php

Logic

This indicator provides a measure of the population density of all counties in the United States. A high population density in the region surrounding an installation is a strong indicator of potential encroachment issues. This can affect the type and intensity of training that can take place on an installation.

Population density is a commonly quoted statistic. Almost no general descriptive summary of the population of an area is complete without a density listing, table, or map. As each such density statistic is an average, it is worth considering what kind of average is being used (Craig 1984). Additionally, it is important to note that this data is on the county level, not community or installation. Hence, it may be skewed by local "hotspots." In other words, if a county has one community with relatively high regional population density, the entire county data is skewed by that density and may be classified as high regional population density regardless of the characteristics of the remaining majority of the county. Because of these 
concerns, it is important to use local knowledge in interpreting the regional population density classifications.

\section{Replicable}

This indicator could be replicated every year based on Census population estimates, or every decade based on actual, verifiable counts.

\section{Directions}

Download county population from County Population Estimates and Estimated Components of Change, April 1, 2000 to J uly 1, 2004 through URL: http:/leire.census.gov/popest/estimates dataset.php (Bureau of the Census 2004). Download land area from Summary File 1: GCT-PH1-R Population, Housing Units, Area, and Density of the 2000 U.S. Census through URL: http:l/factfinder.census.gov (Bureau of the Census 2000). Divide the total population for each county in the United States by the land area (not total area, which includes water bodies) in that county to reach a population density figure:

Regional Population Density $=$ total population $/$ land area

Import the resulting math into a GIS program and join it with county boundary files to create a GIS Regional Population Density indicator layer.

\section{Indicator Measure}

The average population density for the entire United States is 79.6 people per square mile according to the 2000 U.S. Census. The mean density for U.S. counties is 267 people per square mile. The results were then subjected to a normal statistical distribution (19\%/62\%/ 19\%) to determine the following vulnerability classifications:

$$
\begin{aligned}
\text { Very Low Vulnerability (1): } & <6 \text { people per square mile } \\
\text { Low Vulnerability (2): } & >=6-<12 \text { people per square mile } \\
\text { Moderate Vulnerability (3): } & >=12-<247 \text { people per square mile } \\
\text { Vulnerable (4): } & >=247-<2,000 \text { people per square mile } \\
\text { High vulnerability (5): } & >=2,000 \text { people per square mile }
\end{aligned}
$$

\section{Rules}

Installations are often in two or more counties. Therefore, the region around an installation is classified by a weighted average. The weighted average calculation determines what percentage of the installation is in 
each county and multiplies that percentage for each county by that county's classification value. The values for each county are then totaled to arrive at a value for the region around the installation. This value is subjected to the same metric that determined the classification for the individual counties.

For example:

Indicator Value for the Region Around Installation =

(Percentage of Installation in County A* Indicator Value for County A) +

(Percentage of Installation in County $B *$ Indicator Value for County B)...etc.

\section{Indicator: Increasing Regional Growth Rate (UD2)}

Variables

Total Population 1995, 2000, and 2004

Scale

County

Year

2004

Data Sources

Bureau of the Census, U.S. Department of Commerce. (2004). Intercensal State and County Characteristics Population Estimates with 1990-Base Race Groups. Population Division. Washington, DC. Accessible through URL: http://eire.census.gov/popest/estimates dataset.php

Bureau of the Census, U.S. Department of Commerce. (2004). County Population Estimates and Estimated Components of Change, April 1, 2000 to J uly 1, 2004. Population Estimates Program. Washington, DC. Accessible through URL: http://eire.census.gov/popest/estimates_dataset.php

Logic

An increasing regional growth rate is a strong indicator of increased population pressures in the future, leading to greater demands for services, access, resources, and land in competition with the military installation. This can affect the type and intensity of training that can take place on the installation.

Additionally, it is important to note this data is on the county level, not community or installation. Hence, it may be skewed by local "hotspots." In other words, if a county has one community with relatively high regional growth rates, the entire county is classified as high regional growth regard- 
less of the characteristics of the remaining majority of the county. Because of this concern, it is important to use local knowledge in interpreting the increasing regional growth rate classifications.

\section{Replicable}

This indicator could be replicated every year based on Census population estimates, or every decade based on actual, verifiable counts.

\section{Directions}

Download population for all U.S. counties for 1995 and 2000 from the Intercensal State and County Characteristics Population Estimates with 1990-Base Race Groups database maintained by the U.S. Census Bureau (Bureau of the Census 2004). Sum total population per county. Download populations for all U.S. counties for 2004 from the County Population Estimates and Estimated Components of Change, April 1, 2000 to J uly 1, 2004 database maintained by the U.S. Census Bureau (Bureau of the Census 2004). Compare the population growth rate from 1995 to 2000 with the growth rate from 2000 to 2004 . The increasing regional grouth rate calculation used is as follows:

Increasing Regional Growth Rate $=$

(Population Growth Rate from 2000 to 2004) -

(Population Growth Rate from 1995 to 2000)

Population Growth Rate from 2000 to $2004=$

[(Population $2004-$ Population 2000)/ Population 2000] *100

Population Growth Rate from 1995 to $2000=$

[(Population 2000 - Population 1995)/ Population 1995] *100

Import the resulting math into a GIS program and join it with county boundary files to create a GIS Increasing Regional Growth Rate indicator layer.

\section{Indicator Measure}

Increasing Regional Growth Rate is a measure of how fast a county is growing in the past 5 years compared with data from the previous 5 years. The population growth rate from 2000 to 2004 is compared with the growth rate from 1995 to 2000 . This data is available from the U.S. Census through URL: http://eire.census.gov/popest/estimates dataset.php 
(Bureau of the Census 2004). The data illustrates a county average increasing growth rate of 3.13 percent. Range classifications were based on natural breaks:

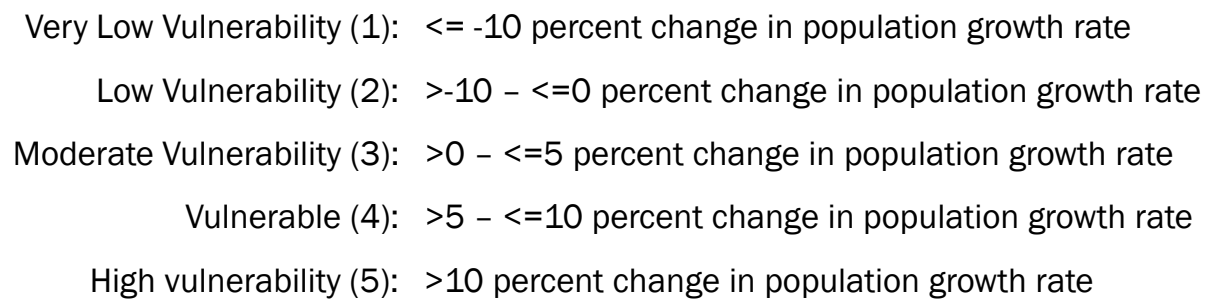

In random instances, the U.S. Census Bureau does not report population estimates for select counties. These instances are rare but do occur. Additionally, county boundaries are subject to change. Again, occurrence is rare but does occur. Drastic changes in population could reflect a division or merge of one or more counties.

\section{Rules}

Installations are often in two or more counties. Therefore, installation classifications are determined by a weighted average. The weighted average calculation determines what percentage of the installation is in each county and multiplies that percentage for each county by that county's classification value. Those values for each county of the installation are then totaled to arrive at a value for the region around an installation. This value is subjected to the same ranking metric that determined the classifications for the individual counties.

For example:

Indicator Value for the Installation =

(Percentage of Installation in County A* Indicator Value for County A) +

(Percentage of Installation in County $B *$ Indicator Value for County B)...etc.

\section{Indicator: Regional Population Growth (UD3)}

Variables

Total Population 1995 and 2004

Scale

County

Year 


\section{Data Sources}

Bureau of the Census, U.S. Department of Commerce. (2004). County Population

Estimates and Estimated Components of Change, April 1, 2000 to J uly 1, 2004.

Population Estimates Program. Washington, DC. Accessible through URL:

http:/leire.census.gov/popest/estimates dataset.php

Bureau of the Census, U.S. Department of Commerce. (2004). Intercensal State and County Characteristics Population Estimates with 1990-Base Race Groups. Population Division. Washington, DC. Accessible through URL:

http:/leire.census.gov/popest/estimates dataset.php

Logic

This indicator measures the population growth over the last decade of every county in the United States. Population growth is one of the leading causes of environmental degradation, because more people use more resources including water, energy, and waste disposal, and other problems. This indicator assumes that fast growing human populations are less sustainable.

The degree of regional population growth is a strong indicator of the demand for services, access, resources, and land in competition with the military installation. This can affect the type and intensity of training that can take place on the installation. This indicator was calculated based on population data from the U.S. Census Bureau.

Additionally, it is important to note this data is on the county level, not community or installation. Hence, it may be skewed by local "hotspots." In other words, if a county has one community with relatively high regional population growth, the entire county is classified as high regional population growth regardless of the characteristics of the remaining majority of the county. Because of this concern, it is important to use local knowledge in interpreting the regional population growth classifications.

\section{Replicable}

This indicator could be replicated every year based on Census population estimates, or every decade based on actual, verifiable counts.

\section{Directions}

Download population for all U.S. counties for 1995 from the Intercensal State and County Characteristics Population Estimates with 1990-Base Race Groups database maintained by the U.S. Census Bureau (Bureau of the Census 2004). Sum total population per county. Download popula- 
tions for all U.S. counties for 2004 from the County Population Estimates and Estimated Components of Change, April 1, 2000 to J uly 1, 2004 database maintained by the U.S. Census Bureau (Bureau of the Census 2004). Given the total population for each county in the United States for 1995 and 2004, the population growth rate from 1995 to 2004 was calculated as follows:

Regional Growth Rate $=$

[(Population $2004-$ Population 1995)/Population 1995]*100

Import the resulting math into a GIS program and join it with county boundary files to create a GIS Regional Growth Rate indicator layer.

\section{Indicator Measure}

Regional Growth Rate is a measure of how fast a county has grown during the previous decade. The population growth rate is measured from 1995 to 2004. This data is available from the U.S. Census (2004) through URL:

\section{http://eire.census.gov/popest/estimates dataset.php}

The data illustrates a county average growth rate of 8.5 percent. The results were statistically classified based on the mean (8.5) and standard deviation (56.3) values:

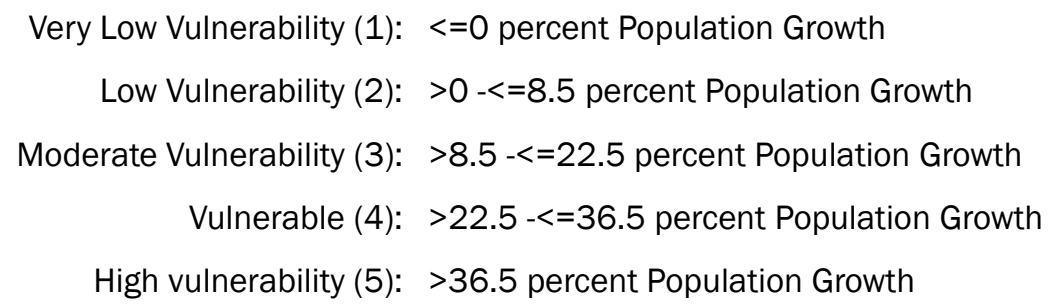

In random instances, the U.S. Census Bureau does not report population estimates for select counties. These instances are rare but do occur. Additionally, county boundaries are subject to change. Again, occurrence is rare but does occur. Drastic changes in population could reflect a division or merge of one or more counties.

\section{Rules}

Installations are often in two or more counties. Therefore, installation classifications are determined by a weighted average. The weighted average calculation determines what percentage of the installation is in each county and multiplies that percentage for each county by that county's classification value. Those values for each county of the installation are 
then totaled to arrive at a value for the region around an installation. This value is subjected to the same ranking that determined the ratings for the individual counties.

For example:

Indicator Value for the Installation =

(Percentage of Installation in County A* Indicator Value for County A) +

(Percentage of Installation in County $B *$ Indicator Value for County B)...etc.

\section{Indicator: Regional Land Urbanization (UD4)}

Variable

Urbanized Land Area, Total Land Area

Scale

Installation (30 Meter Cells)

Year

1992

Data Source

U.S. Geological Survey Bureau (USGS), U.S. Department of the Interior. (1992). Land Cover Characterization Program. (National Land Cover/ MRLC). Reston, VA: USGS. Accessible through URL: http://landcover.usgs.gov

Logic

This indicator provides a measure (in percent) of land urbanization within a 20-mile boundary surrounding the installation. The indicator value is found by dividing the amount of urbanized land by the total land area surrounding a given installation.

The degree of regional development is a strong indicator of potential encroachment problems that can affect the type and intensity of training that can take place on the installation.

\section{Replicable}

This indicator calculation was performed with GIS using the National Land Cover Characterization data available from the USGS online through URL: http://landcover.usgs.gov (USGS 1992). This website provides more about the data and the USGS's program for land characterization. Overall, the data set describes land use for the entire United States, for a 1992 timeframe, by 60 land use and vegetation types (USGS 1992). Currently 
only 1992 data is available, but the USGS is in the process of making 2000 Land Cover data available on the USGS website. It is recommended that this indicator be updated as new data is available.

\title{
Directions
}

Download land coverages for each state from the USGS Internet site through URL: http:/llandcover.usgs.gov or more directly through URL: http:/ledcww.cr.usgs.gov/pub/data/landcover/states in a geotiff format (USGS 1992). Convert these tiff image files to raster data.

Once the data is in a grid/raster format, the only information needed for the regional land urbanization analysis for risk assessment is developed land; all other land covers are irrelevant for this task. Thus to simplify processing, reduce storage requirements, and minimize display and processing times, reclassify the dataset to display urban or non-urban land. Classify cells originally labeled as attribute 21, 22, or 23 as urban (reclassify values to 1) and all other land covers (any other attribute value) as non-urban (reclassify values to 0 ).

Next, using the ArcGIS buffer wizard, create 20-mile buffers around each military installation. Finally, tabulate the percentage of urban and nonurban land areas within each 20-mile buffer. With the data simplified to two classifications ( $1=$ urban and $0=$ non-urban $)$ and a polygon file with the appropriate buffers for each installation, the ratio of urbanized land surrounding each installation was determined as follows:

Urbanization Ratio = value-1 area $/($ value-1 area + value-0 area $)$.

\section{Indicator Measure}

Regional Land Urbanization classifications are defined by the percent of land urbanization within a 20-mile boundary surrounding the installation. This value is found by dividing urbanized land by the total land area. The classifications were defined by natural breaks in the data as follows:

\author{
Very Low Vulnerability (1): <=29 percent Urbanized \\ Low Vulnerability (2): Not Applicable \\ Moderate Vulnerability (3): >29 $-<=35$ percent Urbanized \\ Vulnerable (4): Not Applicable \\ High vulnerability (5): >35 percent Urbanized
}


Rules

Since this data is collected by installation, there is no calculation to determine installation risk ratings.

\section{Indicator: State Smart Growth Plans (UD5)}

Variables

Presence of State Smart Growth Plan

Scale

State

Year

2002

Data Source

American Planning Association (APA). (2002). Planning for Smart Growth: 2002 State of the States. Smart Growth Network. Chicago, IL. Accessible through URL: http://www.planning.org/growingsmart/states2002.htm

Logic

This indicator shows the status of State Smart Growth Initiatives across the United States. Smart growth is the planning, design, development, and revitalization of cities, towns, suburbs, and rural areas to create and promote social equity, a sense of place and community, as well as to preserve natural and cultural resources. Smart growth enhances ecological integrity over both the short- and long-term, and improves quality of life for all by expanding -in a fiscally responsible manner-the range of transportation, employment, and housing choices available to a region (APA 2002).

The presence of a state smart growth plan is important because smart growth legislation can reduce sprawl and decrease the growth of urbanized land surrounding a military installation. The potential encroachment caused by sprawl and urban development can affect the type and intensity of training that can take place on the installation.

However, this indicator does not indicate whether the initiatives were successful. Typically, state smart growth initiatives have positive results, yet there is never a guarantee. Additionally, APA monitors smart growth initiatives at a state level. Local communities may have established local smart growth initiatives, yet here they are rated as high vulnerability be- 
cause of the state's status. Therefore, it is critical to use local knowledge in interpreting smart growth initiatives classifications.

\section{Replicable}

This indicator could be replicated regularly as long as the APA continues to monitor Smart Growth (which is likely considering that one of the main tenants of the APA currently is to get smart growth passed in every state). It is recommended that this indicator be updated annually. 2002 was the last update made by the APA.

\section{Directions}

APA constructed a map to chart the progress of smart growth reform, Accessible through URL: http://www.planning.org/growingsmart/states2002.htm, and was synthesized to create the map and scale used for this indicator (APA 2002). Download the map data, import it into a GIS program, and join it with state boundary files to create a GIS State Smart Growth Plans indicator layer.

\section{Indicator Measure}

Substantial Reforms means that smart growth legislation has been passed in the state; moderate reforms or pursuing additional reforms means that some form of land use laws resembling smart growth have been passed or legislation has been proposed; and no reforms mean that no legislation has been passed or proposed (APA 2002), as follows:

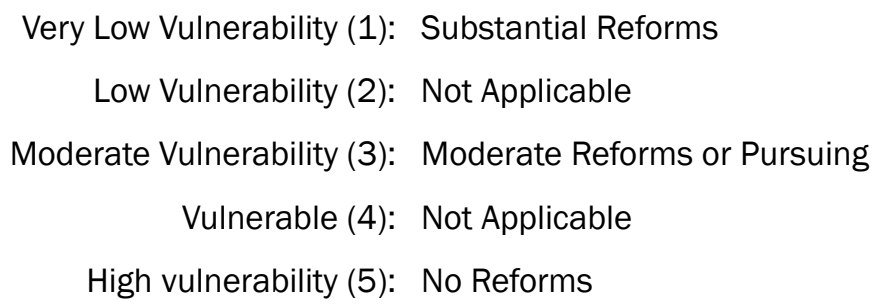

Rules

Every installation is located primarily in one state, although several installations do cross state boundaries. The region around an installation takes on the rating of the state in which the installation is primarily located.

\section{Indicator: Joint Land Use Study (JLUS) (UD6)}

Variables

J LUS Program Participation 
Scale

Installation

Year

1985-2003

Data Sources

J oint Land Use Study Assistance Grant. 1985. Title 10 U.S. C. Section 2391.

Office of Economic Adjustment (OEA), United States Department of Defense. 2003. J oint Land Use Study Program. Washington, DC. Accessible through URLs:

http://www.nga.org/cda/files/1002LANDUSESUMMARY.pdf http://www.ngms.state.ms.us/cfmo/joint land.html

Logic

Military operations can be loud and present safety concerns for nearby civilian communities. For example, low flying, high performance, military aircraft, create both noise and accident potential during landings, take-off, and training exercises. Likewise, ground-training exercises (e.g., artillery firing ranges, maneuver areas, and aerial bombing ranges) generate impact noise that can adversely affect the surrounding community if the civilian population chooses to locate too close. Conversely, civilian activities located adjacent to active military bases can impair the operational effectiveness, training, and readiness of the installations' mission (OEA 2003). In other words, urban encroachment near a military base, if allowed to go unregulated, can compromise the utility and effectiveness of the installation and its mission. Thus, in the mid-1970s, the Department of Defense (DoD) established the Air Installation Compatible Use Zone (AICUZ) and the Environmental Noise Management Program (ENMP) in response to existing and potential threats of incompatible land development compromising the defense missions at military installation (OEA 2003). The programs include noise propagation studies of military activities to delineate on- and off-base areas most likely to be affected by unacceptable noise levels. The programs also identify aircraft landing and take-off accident potential zones that often extend off a base into the neighboring community (OEA 2003).

Since then, Congress authorized the DoD to make community planning assistance grants ('J oint Land Use Study Assistance Grant," 1985) to state and local governments to help better understand and incorporate the AICUZ/ ENMP technical data into local planning programs (OEA 2003). This is done in the form of a J oint Land Use Study (J LUS). The OEA manages the J LUS program. A J LUS is a cooperative land use planning effort 
between affected local government and the military installation. The recommendations present a rationale and justification, and provide a policy framework to support adoption and implementation of compatible development measures designed to prevent urban encroachment; safeguard the military mission; and protect the public health, safety, and welfare (OEA 2003).

The presence of a J LUS indicates an effort between the local community and the military installation to work together. Thus, any form of a JLUS is viewed as a positive. Whether the installation has completed a JLUS, begun a J LUS, or is simply receiving technical assistance, the installation is classified as "very low vulnerability." If no effort is shown toward completing a J LUS, the installation is classified as "high vulnerability." However, this puts some limitations on the data. First, the classifications do not indicate whether the J LUS was successful. The local community and military installation may never have agreed on a future course of action and the result was less compatibility than before the J LUS. Typically all J LUS have positive results, yet there is never a guarantee. Second, and more critical, installations not near urban development have no need to perform a J LUS, yet they are rated as "high vulnerability" because they have not completed or pursued a J LUS. Thus, it is critical to read this data along with an understanding of the installation's proximity to Metropolitan Statistical Areas and other Urban Development sustainability issues. Any user of this data must have local knowledge to interpret the J LUS classifications.

\section{Replicable}

This indicator could be replicated every year based on material printed by the DoD, OEA concerning the J LUS program. The same material is often published on the DoD, OEA website. Current data may be found through URL: http://www.ngms.state.ms.us/cfmo/joint land.html. The last update made by the OEA was in 2003.

\section{Directions}

OEA J LUS constructs a map to chart the progress of JLUSs. That map is available from the OEA J LUS program and updated periodically (OEA 2003). The data from the map was synthesized to create the map and scale used for this indicator. Download the map data, import it into a GIS program, and join it with the installation boundary files to create a GISJ LUS indicator layer. 
Indicator Measure

The J LUS program identifies military installations where J LUS have been "completed," "underway," and where "technical assistance" has been given. Any installation with one of these characterizations was classified as very low vulnerability. All other installations were classified as high vulnerability. It is assumed that if a J LUS has been completed, is underway, or is expected to occur on a military installation, then the installation is concerned about land use compatibility and therefore received a "higher" rating. However, there are concerns in this logic with the success of the J LUS and the relative need for such a study to be made (refer to the section labeled "Logic" of this report). The following risk classifications were defined for J LUS:

Very Low Vulnerability (1): JLUS Completed, Underway, or Technical Assistance

Low Vulnerability (2): Not Applicable

Moderate Vulnerability (3): Not Applicable

Vulnerable (4): Not Applicable

High vulnerability (5): JLUS Not Completed, Underway, or no Technical Assistance

Overall, there are 33 installations that have completed a J LUS, 34 with a JLUS underway, and four installations receiving technical assistance.

Rules

Since this data is collected by installation, there is no calculation to determine installation classification.

\section{Indicator: Proximity to Metropolitan Statistical Areas (MSA) (UD7)}

Variables

MSA, Mile Buffers

Scale

Installation

Year

2000

\section{Data Source}

U.S. Bureau of the Census, U.S. Department of Commerce. 2000. About Metropolitan and Micropolitan Statistical Areas. Office of Management and Budget. Washington, DC: U.S. Bureau of the Census. Accessible through URL: http://www.census.gov/population/www/estimates/aboutmetro.html 
Logic

This indicator shows the proximity of Military installations to Metropolitan Statistical Areas (MSA), which indicates the potential for encroachment on military facilities. MSAs are a geographic entity designated by the Federal Office of Management and Budget for use by Federal statistical agencies (Bureau of the Census 2000). An MSA consists of one or more counties, except in New England, where MSAs are defined in terms of county subdivisions (primarily cities and towns) (Bureau of the Census 2000). Encroachment is a strong indicator of pressures on the future use and vulnerability of military installations. Encroachment places the military installation in a vulnerable state, affecting the type and intensity of training that could take place on the installation due to greater demands and limitations on military developments.

\section{Replicable}

This indicator could be replicated every year based on Census population estimates or every decade based on actual, verifiable counts. It is recommended that the data be replicated only once a decade due to the inaccuracy of census estimates. The GIS compatible layer containing MSAs can be found through URL: http://www.census.gov (Bureau of the Census 2000).

\section{Directions}

Download the GIS layer containing MSAs from the U.S. Census Bureau (Bureau of the Census 2000). Import the data into a GIS program to create a Proximity to MSA indicator layer. Create buffers at 20-miles from the edge of each MSA to show a level of risk.

\section{Indicator Measure}

Proximity to MSA is defined as the distance from the nearest MSA to an installation. All areas within an MSA were classified as highly vulnerable, while all areas not within an MSA, but within 20 miles of an MSA were classified as moderately vulnerable. All areas outside of the 20-mile buffer were considered not vulnerable. Proximity to MSA classifications were defined as follows: 
Very Low Vulnerability (1): Areas greater than 20 miles away from any MSA

Low Vulnerability (2): Not Applicable

Moderate Vulnerability (3): Areas not within an MSA, but within 20miles of one or more MSAs

Vulnerable (4): Not Applicable

High vulnerability (5): Within a Census designated MSA

Rules

This indicator measures an installations' proximity to an MSA. If only part of an installation is located within an MSA, then that region surrounding the installation takes on the highly vulnerable classification. The same follows if an installation straddles the 20 mile buffer-half of the installation within 20 miles the other half greater than 20 miles, the region takes on the "moderate" vulnerability classification.

\section{Sustainability Issue: Threatened and Endangered Species (TES)}

\section{Indicator: Number of TES per State (TE1)}

Variables

Number of TES per square mile

Scale

State

Year

2004

\section{Data Sources}

Bak, J.M., S. Sekscienski, and B. Woodson. 2002. FY 2000 Survey of Threatened and Endangered Species on Army Lands. Aberdeen Proving Ground, MD: U.S. Army Environmental Center. 21010-5401. SFIM-AEC-EQ-TR-20018. U.S. Navy HQ NAVFAC. U.S. Air Force AFCEE. Accessible through URL: http://clients.emainc.com/navfacl

DOD, USFWS, and USDOI. 2002. Integrated Natural Resources Management Plans. Washington, DC: DOD. Accessible through URL: http://endangered.fws.gov/DOD/inrmp.pdf

Sikes Act. 1960. 16 USC 670a-670o, 74 Stat. 1052. Accessible through URL: http://laws.fws.gov/lawsdigest/sikes.html

USFWS and USDOI. 2004. Threatened and Endangered Species System. The Endangered Species Program. (Species Information). Washington, DC: USFWS. Accessible through URL: http://endangered.fws.gov 
Logic

This indicator gives an indication of the comparative number of TES in each state. The presence of TES is highly sought after as a sustainability indicator due to the possible limitations they may put on certain land use actions, military or otherwise, in time or in space. In addition, other Federal requirements (e.g., Sikes Act) may require consideration and protection of state listed or other identified species identical or comparable to that required by the Endangered Species Act ("Sikes Act," 1960). Overall, the presence of TES on a military installation may result in legal and other requirements regarding the conservation and management of those species (USDoD et al. 2002).

\section{Replicable}

This information could be replicated daily based on updates from the United States Fish and Wildlife Service, Endangered Species Program (2004). It can be anticipated that the individual state lists will increase over time and that the removal of species from state lists will be uncommon and infrequent. However, changes in numbers can be anticipated to be relatively small and replication every day, or even year, should not be universally necessary.

\section{Directions}

Download the number of TES in each state from the United States Fish and Wildlife Service, Endangered Species Program (2004).

Import the resulting data into a GIS program and join it with state boundary files to create a Number of TES per State indicator layer.

\section{Indicator Measure}

Download the United States Fish and Wildlife Service's state listed TES data from their Species Information website and then divide by its respective state area (square miles) resulting in Number of TES per state per square mile. This distributes the data by area. Distributing the data by area allows for an equal comparison between large and small-area states. In other words, it protects against a large-area state from a more vulnerable classification because it naturally has more occurrences compared to a small-area state. The number TES per state per square mile were statistically classified by determining the mean ( 0.003298 species per square mile) and standard deviation (0.009745). Using this logic, the following classifications were defined: 


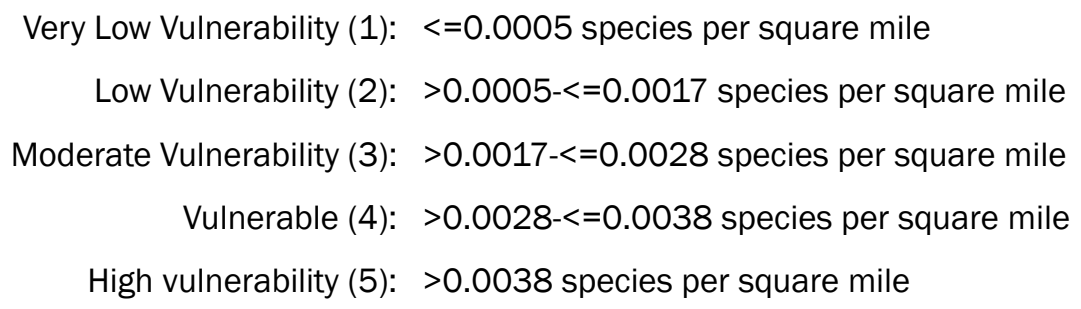

Rules

Every installation is located primarily in one state, although several installations do cross state boundaries. A region around an installation takes on the classification of the state in which the installation is primarily located.

\section{Indicator: Species at Risk (TE2)}

Variable

Number of Species

Scale

Watershed

Year

1997

Data Sources

16 USC 670a-670o, 74 Stat. 1052. Accessible through URL: http://laws.fws.gov/lawsdigest/sikes.html

Hurd, B., N. Leary, R. J ones, and J . Smith. 1999. "Relative Regional Vulnerability of Water Resources to Climate Change." J ournal of the American Water Resources Association. vol. 35 No. 6. pp. 1399-1409. Accessible through URL: http://www.awra.org

Sikes Act, 16 USC 670a-670o, 74 Stat. 1052 1960. Accessible through URL: http:/llaws.fws.gov/lawsdigest/sikes.html

USEPA. 1997. The Index of Watershed Indicators, EPA-841-R-97-010. Washington, DC: USEPA Office of Water. Accessible through URL: http://www.epa.gov/wateratlas/geo/maplist.html

Logic

This indicator measures the number of threatened and endangered aquatic and wetland species known to be in a watershed based on Federal Threatened and Endangered species (TES) counts as given by the USEPA in 1997 (USEPA 1997). This indicator characterizes the degree of relative stress that a watershed may be currently experiencing from a variety of sources, 
including habitat loss, pollution, predation, and disease by counting the number of at-risk, water-dependant species within a watershed (B. Hurd et al. 1999).

According to the Sikes Act, the DoD and Department of Interior (DoI) must cooperate with local state agencies for the planning, management, and maintenance of fish and wildlife populations and their associated habitat on military installations ("Sikes Act," 1960). Watersheds with a high number of TES will significantly increase the possibility of regulatory restrictions on the installation's mission. This would then place the military installation in a vulnerable state, possibly affecting the type and intensity of training that would take place on the installation. Reduction and or change in military training activities may result if state and Federal agencies question military training impacts on TES and associated habitat. Restrictions, reductions, and change of training could result, including the permanent removal of land parcels from training. Supplementary applicable laws and regulations can be found through URL:

\section{http://www.epa.gov/win/law.html}

A watershed is the area of land where all of the water that is under it or drains off of it goes into the same place. Watersheds are delineated by USGS using a nationwide system based on surface hydrologic features. This system divides the country into 21 regions, 222 subregions, 352 accounting units, and 2,262 cataloguing units. A hierarchical hydrologic unit code (HUC) consisting of 2 digits for each level in the hydrologic unit system is used to identify any hydrologic area. The 6-digit accounting units and the 8-digit cataloguing units are generally referred to as basin and sub-basin. There are many states that have defined down to 16-digit HUCs (USEPA 1997).

\section{Replicable}

Efforts are being made to replicate this analysis so it can be updated when new USEPA data is available using the methodologies generated by the original study. This data is found in the USEPA's Index of Water Quality Indicators through URL: http://www.epa.gov/wateratlas/geo/maplist.html (USEPA 1997). The USEPA intends to replicate the effort and produce new data, although the timeline is unclear at this point due to lack of funding. 


\section{Directions}

Download "species at risk" from the USEPA Index of Watershed Indicators through URL: http://www.epa.gov/wateratlas/geo/maplist.html (USEPA 1997). Import the data into a GIS program and join it with watershed boundary files to create a GIS Species at Risk indicator layer.

Indicator Measure

Number of aquatic and wetland species identified were defined as either threatened or endangered, at-risk, or water-dependant, as estimated by USEPA IWI (1997). A complete explanation of the USEPA, ranges is Accessible through URL: http://www.epa.gov/wateratlas/geo/maplist.html. The species at risk ratings were grouped into the following classifications based on definitions assigned by the USEPA (1997) as well as expert opinion:

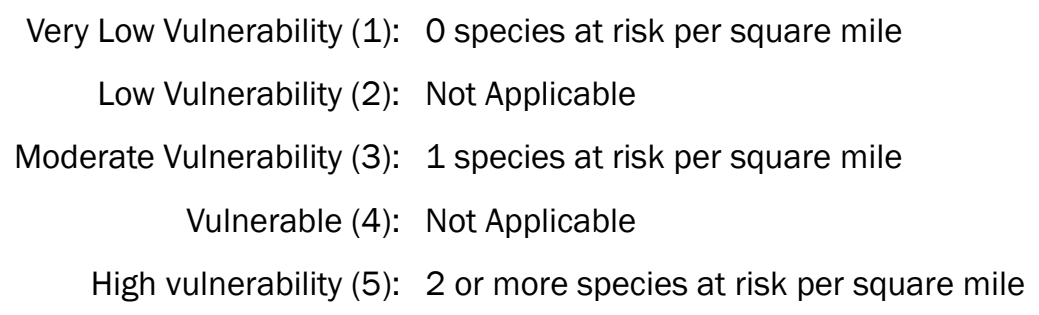

Rules

Every installation is located primarily in one watershed, although several installations do cross watershed boundaries. The area around an installation takes on the rating of the watershed where the installation is primarily located (area basis).

\section{Indicator: Federally Listed TES by Ecoregion (TE3)}

Variables

Year-round presence/ resident, Seasonal, Migratory, Contiguous, and Accidental per square mile

Scale

Ecoregion

Year

2004

Data Sources

Sikes Act. 1960. 16 USC 670a-670o, 74 Stat. 1052. Accessible through URL: http://laws.fws.gov/lawsdigest/sikes.html 
U.S. Department of Defense (DOD), and the U.S. Fish and Wildlife Service (USFWS), U.S. Department of the Interior (USDOI). 2002. Integrated Natural Resources Management Plans. Washington, DC: DOD. Accessible through URL: http:/lendangered.fws.gov/DOD/inrmp.pdf

NatureServe Central Databases. 2004. TNC Ecoregion Threatened and Endangered Species. Arlington, VA.

Logic

The species included in this analysis consist of all species with Federal status under the U.S. Endangered Species Act (USESA) for which NatureServe has associated Element Occurrence (EO) data. This indicator is important as a TES indicator because the presence of TES on or near a military installation may result in legal and other requirements regarding the conservation and management of those species (USDoD et al. 2002). The presence of TES may limit certain land use actions, military or otherwise, in time or in space. In addition, other Federal requirements (e.g., Sikes Act) may require consideration and protection of state listed or other identified species identical or comparable to that required by the Endangered Species Act ("Sikes Act," 1960). Reporting TES by ecoregions as opposed to States have certain advantages in naming species by habitat. In other words, classifying by state may result in the entire state classified as high TES vulnerability regardless of the characteristics of the majority of the state.

\section{Replicable}

Although this information could be replicated every year from the NatureServe Central Database there would be relatively little reason to do so. TES presence, once identified, would not be expected to change unless the species was extirpated, or its status changed. If the species were extirpated, other political and social concerns and considerations would raise themselves.

\section{Directions}

Data was ordered from the NatureServe Central Database (NatureServe 2004). Since data comes with a fee, it is recommended that the data be reproduced no more often than annually. The data will arrive in a spreadsheet format. Import the data into a GIS program and join with ecoregion boundary files to create a TES by Ecoregion indicator layer. 
Indicator Measure

NatureServe collects species occurrence data from local Natural Heritage Programs across the United States. It is important to note that the following data is missing in the NatureServe Central Databases and the dataset used for this analysis.

Most Washington animal data - with the exception of some select species, animal data in Washington is tracked by an agency outside the Washington Natural Heritage Program and the methodology of that animal location data is not currently compatible with Heritage EO Methodology.

Alaska animal data - NatureServe is unable to provide Alaska animal data until they complete their next data exchange with their Heritage program in the coming year.

Massachusetts data - NatureServe has an incomplete EO dataset for Massachusetts that is also a couple of years old. While these records were included in the crosstab tallies, the numbers for Ecoregions that intersect with Massachusetts may be low.

Arizona data - NatureServe does not currently store the coordinates for Arizona species location data in their Central Database. The crosstab tallies for Ecoregions that intersect with Arizona do not include counts of species locations within the state of Arizona.

NatureServe grouped the location of sited TES species by ecogregion. The number of TES per ecoregion was then divided by its respective ecoregion area (square miles) resulting in Federally listed TES by ecoregion per square mile. This distributes the data by area. Distributing the data by area allows for an equal comparison between large and small-area ecoregions. In other words, it protects against a large-area ecoregion from a more vulnerable classification because it naturally has more occurrences compared to a small-area ecoregion. Federally Listed TES by Ecoregion per square mile were statistically classified around natural breaks in the mean (0.0018) and standard deviation (0.0086) values: 


$$
\begin{aligned}
\text { Very Low Vulnerability (1): } & <=0.00016 \text { species per square mile } \\
\text { Low Vulnerability (2): } & >0.00016-<=0.00031 \text { species per square mile } \\
\text { Moderate Vulnerability (3): } & >0.00031-<=0.00086 \text { species per square mile } \\
\text { Vulnerable (4): } & >0.00086-<=0.0015 \text { species per square mile } \\
\text { High vulnerability (5): } & >0.0015 \text { species per square mile }
\end{aligned}
$$

Rules

Every installation is located primarily in one ecoregion, although several installations do cross ecoregion boundaries. The area around an installation takes on the rating of the ecoregion where the installation is primarily located (area basis).

\section{Indicator: Species of Concern (TE4)}

Variables

Species with a Global Conservation Status Rank of G1/T1 - G2/T2 and having no Federal Status per square mile

Scale

Ecoregion

Year

2004

\section{Data Sources}

Sikes Act 1960. 16 USC 670a-670o, 74 Stat. 1052 Accessible through URL: http:/llaws.fws.gov/lawsdigest/sikes.html

DOD, USFWS, and USDOI. 2002. Integrated Natural Resources Management Plans. Washington, DC: DOD. Accessible through URL: http:/lendangered.fws.gov/DOD/inrmp.pdf

NatureServe Central Databases. 2004. TNC Ecoregion Species of Concern. Arlington, VA.

Logic

The species included in this analysis consist of all species with a Global Conservation Status Rank of G1/T1 - G2/T2 and having no Federal status. In other words, the data only includes location records in the counts for which that status does NOT apply and those records do NOT have Federal protection. For example, if a species only has Federal status within 50 miles of a coastline, then only records for that species that are further then 50 miles from the coast would be included. This indicator is important as a TES indicator because the presence of TES on or near a military installa- 
tion may result in legal and other requirements regarding the conservation and management of those species (USDoD et al. 2002). The presence of TES may limit certain land use actions, military or otherwise, in time or in space. In addition, other Federal requirements (e.g., Sikes Act) may require consideration and protection of state listed or other identified species identical or comparable to that required by the Endangered Species Act ("Sikes Act," 1960). Reporting TES by ecoregions as opposed to States have certain advantages in naming species by habitat. In other words, classifying by state may result in the entire state classified as high TES vulnerability regardless of the characteristics of the majority of the state.

\section{Replicable}

Although this information could be replicated every year from the NatureServe Central Database there would be relatively little reason to do so. TES presence, once identified, would not be expected to change unless the species was extirpated, or its status changed. If the species were extirpated, other political and social concerns and considerations would raise themselves.

\section{Directions}

Data was ordered from the NatureServe Central Database (NatureServe 2004). Since data comes with a fee, it is recommended that the data be reproduced no more often than annually. The data will arrive in a spreadsheet format. Import the data into a GIS program and join with ecoregion boundary files to create a Species of Concern indicator layer.

\section{Indicator Measure}

NatureServe collects species occurrence data from local Natural Heritage Programs across the United States. It is important to note that the following data is missing in the NatureServe Central Databases and the dataset used for this analysis:

- Most Washington Animal Data. With the exception of some select species, animal data in Washington is tracked by an agency outside the Washington Natural Heritage Program and the methodology of that animal location data is not currently compatible with Heritage EO Methodology.

- Alaska Animal Data. NatureServe is unable to provide Alaska animal data until they complete their next data exchange with their Heritage program in the coming year.

- Massachusetts Data. NatureServe has an incomplete EO dataset for Massachusetts that is also a couple of years old. While these records 
were included in the crosstab tallies, the numbers for Ecoregions that intersect with Massachusetts may be low.

- Arizona Data. NatureServe does not currently store the coordinates for Arizona species location data in their Central Database. The crosstab tallies for Ecoregions that intersect with Arizona do not include counts of species locations within the state of Arizona.

NatureServe grouped the location of species of concern by ecogregion. The number of species of concern per ecoregion was then divided by its respective ecoregion area (square miles) resulting in species of concern by ecoregion per square mile. This distributes the data by area. Distributing the data by area allows for an equal comparison between large and small-area ecoregions. In other words, it protects against a large-area ecoregion from a more vulnerable classification because it naturally has more occurrences compared to a small-area ecoregion. Species of Concern by Ecoregion per square mile were statistically classified around natural breaks in the mean (0.0023) and standard deviation (0.0042) values:

$$
\begin{aligned}
\text { Very Low Vulnerability (1): } & <=0.0006 \text { species per square mile } \\
\text { Low Vulnerability (2): } & >0.0006-<=0.00195 \text { species per square mile } \\
\text { Moderate Vulnerability (3): } & >0.00195-<=0.0033 \text { species per square mile } \\
\text { Vulnerable (4): } & >0.0033-<=0.00466 \text { species per square mile } \\
\text { High vulnerability (5): } & >0.00466 \text { species per square mile }
\end{aligned}
$$

Rules

Every installation is located primarily in one ecoregion, although several installations do cross ecoregion boundaries. The area around an installation takes on the rating of the ecoregion where the installation is primarily located (area basis). 


\section{Sustainability Issue: Locational}

\section{Indicator: Federally Declared Floods (L01)}

Variable

Number of Federally declared floods per square mile

Scale

County

Year

12/ 24/ 1964 through 6/15/2004, totaled

Data Sources

Federal Emergency Management Agency (FEMA), U.S. Department of Homeland Security. 2004. Federally Declared Disasters by Calendar Year. Washington, DC: FEMA GIS and Data Solutions Branch. Accessible through URL: http://www.fema.gov/library/drcys.shtm

InterNational Federation of Red Cross and Red Crescent Societies (IRRCRCS). 2002. World Disasters Report: Focus on Reducing Risk 2002. Accessible through URL: http://www.ifrc.org/publicat/wdr2002/

Logic

Every year flood disasters cause damage amounting to billions of dollars world-wide. Floods inflict the greatest loss in money than any other Federally declared disaster in the United States. Floods are a threat to both built structures and human health and safety. Thus, the military must be sensitive to potential threats from the natural and built environment. The mission of the installation can be severely impacted by a flood if proper provisions are not in place.

This indicator measures the number of Federally Declared Floods occurring between 1964 and 2004. Federally Declared Floods are those floods declared by communities to the Federal government. Often times upon declaration, the Federal government offers some form of relief to the community (IFRCRCS 2002). Thus whether a flood is declared depends largely on the resources of the community and the aggressiveness of community leaders. Many floods of significant consequences are not declared while some of relatively little consequences are declared. In other words, declaration may have little to do with severity. Nonetheless, Federally Declared Floods offer the best indication of a community's flood risk reduction efforts. It is simply vital to use local knowledge in interpreting the Federally Declared Floods classifications. 


\section{Replicable}

This indicator can be updated annually based on Federally Declared Disasters by Calendar Year data, as collected in the National Emergency Management Information System (NEMIS) maintained by the Federal Emergency Management Agency (FEMA) (2004).

\section{Directions}

The FEMA database "declarations by type" is sorted by disaster type. Eliminate all disasters except flooding. Download and compile the data for all U.S. counties. Import the data into a GIS program and join it with county boundary files to create a Federally Declared Floods indicator layer.

\section{Indicator Measure}

The number of Federally declared floods for each county was summed to obtain a 38-year total for floods (FEMA 2004). This sum was then divided by its respective county area (square miles) resulting in Federally declared floods per square mile. This distributes the data by area. Distributing the data by area allows for an equal comparison between large and small-area counties. In other words, it protects against a large-area county from a more vulnerable classification because it naturally has more occurrences compared to a small-area county. Statistical analysis resulted in a mean of 0.0058 floods per square mile and a standard deviation of 0.0259 . The following classifications were defined using the mean and standard deviation values:

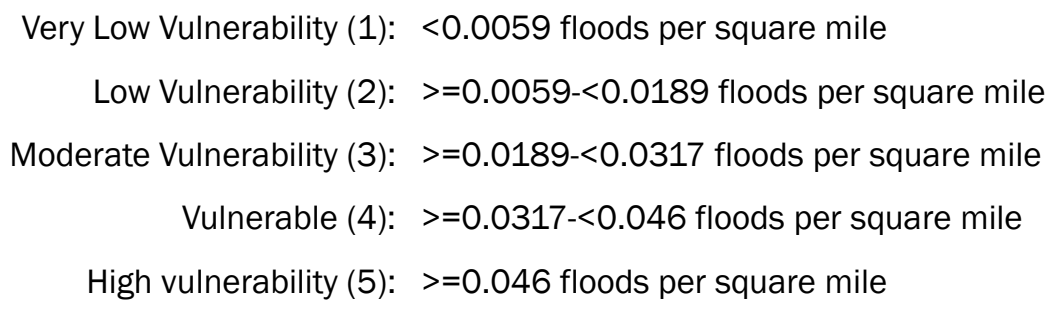

\section{Rules}

Installations are often in two or more counties. Therefore, regional classifications are determined by a weighted average. The weighted average calculation determines what percentage of the installation is in each county, and that percentage is multiplied by that county's value. The values for each county the installation lies in are then totaled to arrive at a value for the region. This value is then subject to the same metric that determined the classification for the individual counties. 
For example:

Indicator Value for the Installation =

(Percentage of Installation in County A* Indicator Value for County A) +

(Percentage of Installation in County $B *$ Indicator Value for County B)...etc.

\section{Indicator: Seismicity (LO2)}

Variables

Spectral acceleration for 0.2 second period with 2 percent probability of exceedance in 50 years

Scale

National

Year

2002

\section{Data Sources}

Frankel, Arthur, Charles Mueller, Theodore Barnhard, David Perkins, E.V. Leyendecker, Nancy Dickman, Stanley Hanson, and Margaret Hopper. 2002. Seismic-Hazard Maps for the Conterminous United States: Document for 2002 Update of National Seismic Hazard Map, U.S. Geological Survey Open-File Report 02-420 (Map F - Horizontal spectral response acceleration for 0.2 second period ( $5 \%$ of critical damping) with $2 \%$ probability of exceedance in 50 years) Reston, VA: U.S. Geological Survey Bureau, U.S. Department of the Interior. Accessible through URL: http:/learthquake.usgs.gov/hazmaps/

Sweeney, Steven. 2002. Structural Engineer, U.S. Army Engineer Research and Development Center, Construction Engineering Research Laboratory. In Adam Sagert (Ed.). Champaign, IL.

Logic

Earthquakes are a threat to both built structures and human health and safety. Thus, the military must be sensitive to potential threats from the natural environment. The mission of the installation can be severely impacted by an earthquake.

Replicable

This indicator can be replicated as often as the USGS updates their Seismic Risk data. The trend seems to be that these maps are updated every 5 or 6 years. 


\section{Directions}

GIS data concerning seismicity is (A. Frankel et al. 2002) is accessible through URL: http:/learthquake.usgs.gov/hazmapsl. Download the horizontal spectral response acceleration for 0.2 second period ( $5 \%$ of critical damping) with $2 \%$ probability of exceedance in 50 years. Import the data into a GIS program to create a Seismicity Risk area indicator layer.

\section{Indicator Measure}

The values found on the map are the horizontal spectral response acceleration for 0.2 second period ( $5 \%$ of critical damping) with $2 \%$ probability of exceedance in 50 years. USGS documentation (A. Frankel et al. 2002) separates the data into various seismic classifications, which were then translated into a vulnerability scale with the assistance of seismic expert and structural engineer, Steven Sweeney, at CERL (2002):

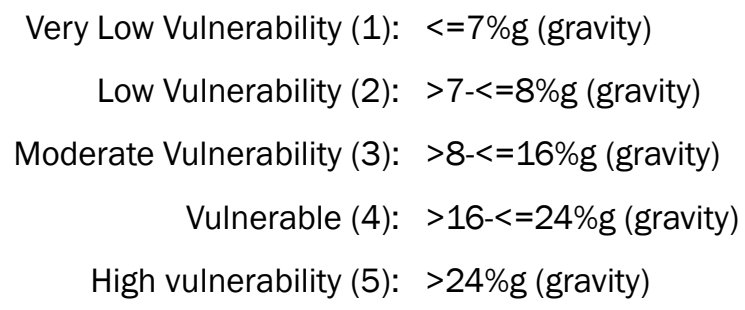

\section{Rules}

This indicator measures seismicity for a certain location. The region around an installation takes on the rating of the highest seismicity classification area that the installation touches. For instance, if an installation is partly in a moderate vulnerability classified area, and partly in a high vulnerability classified area, then the region around the installation has a high vulnerability classification.

\section{Indicator: Weather Related Damage (L03)}

Variable

Damage in dollars due to weather (crop and property) per square mile Scale

State Year

1995-2004 data, totaled 


\section{Data Source}

National Oceanographic and Atmospheric Administration (NOAA): National Weather Service, U.S. Department of Commerce. 2005. Summary of Natural Hazard Statistics in the United States. Silver Spring, MD: Office of Climate, Water, and Weather Services. Accessible through URL: http://www.nws.noaa.gov/om/hazstats.shtml

Logic

The United States suffered nearly $\$ 200$ billion in economic losses due to extreme weather in the 1990s, including \$14 billion in damage in 1999 (NOAA 2005). The insurance industry is worried about the soaring costs of severe weather damage and is already refusing to cover various weather events in certain regions. The DoD lost an installation with Hurricane Andrew's destruction of Homestead AFB in Florida in August 1992. By examining historical weather-related damage trends, one can see the vulnerability of the military mission to extreme weather. Thus, the military must be sensitive to potential threats from the natural environment. Weather conditions are a threat to built structures, human health and safety, and the mission of the installation. This indicator provides a measurement of the cost of the loss of crops and damage due to natural disasters for the past 7 years.

\section{Replicable}

This indicator could be updated annually as new data is posted to the National Weather Service website (NOAA 2005).

\section{Directions}

From the NOAA website, select a year from the "State Summaries" pulldown menu (NOAA 2005). This opens an Adobe acrobat document for that year containing fatalities, injuries, property damage, and crop damage for each state and U.S. territory. Download and compile the data into a spreadsheet for 1995 through 2004 for all U.S. counties. Import the totals into a GIS program and join it with county boundary files to create a Weather Related Damage indicator layer.

\section{Indicator Measure}

The damage in dollars due to weather for each state and territory was summed to obtain a 7-year total for weather-related crop and property damage (NOAA 2005). This sum was then divided by its respective state area (square miles) resulting in weather damage in dollars per square mile. This distributes the data by area. Distributing the data by area allows 
for an equal comparison between large and small-area states. In other words, it protects against a large-area state from a more vulnerable classification because it naturally has more occurrences compared to a smallarea state. Statistical analysis resulted in a median of $\$ 25,730$ per square mile and a standard deviation of 33,506. Using these statistics, the following classification were determined:

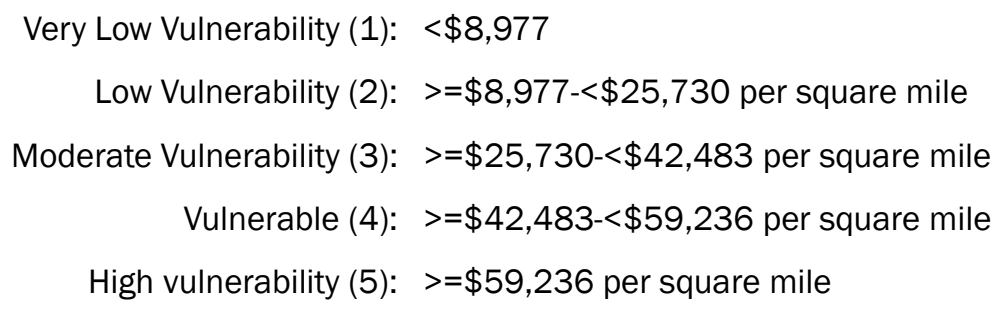

Rules

Every installation is located primarily in one state, although several installations do cross state boundaries. The region around an installation takes on the classification of the state in which the installation is primarily located.

\section{Indicator: Federally Declared Disasters (LO4)}

Variables

Number of Federally declared natural disasters in the categories of tsunami, coastal storm, drought, earthquake, flood, freezing, hurricane, typhoon, dam/levee break, mud/landslide, severe ice storm, fire, snow, tornado, volcano, and severe storm per square mile

Scale

County

Year

24 December 1964 through 15J une 2004, totaled Data Sources

FEMA. 2004. Federally Declared Disasters by Calendar Year. Washington, DC: FEMA GIS and Data Solutions Branch. Accessible through URL: http://www.fema.gov/library/drcys.shtm

InterNational Federation of Red Cross and Red Crescent Societies (IRRCRCS). 2002. World Disasters Report: Focus on Reducing Risk 2002. Accessible through URL: http://www.ifrc.org/publicat/wdr2002/ 
Logic

In the 1990s, some 2 billion people were affected by disasters world-wide (IFRCRCS 2002). No one is immune from disasters. Everyone is vulnerable, but some are more vulnerable than others. By examining historical disaster trends, one can see that it is not only weather-related damage causing disasters. Flawed development patterns (e.g., rapid unplanned urbanization, deforestation, installation of non-flood-proof dykes, no early warning systems, etc.) are also exposing more people to disasters (IFRCRCS 2002). For example, earthquake fatalities are not necessarily the result of an earthquake but rather ineffective building codes. Tornados sweeping away homes may not be a sign of strong winds as much as poorly sited housing. There is no doubt disasters are a threat to both built structures and human health and safety. Thus, the military must be sensitive to potential threats from the natural and built environment. The mission of the installation can be severely impacted by disasters if proper provisions are not in place.

This indicator measures the number of Federally Declared Disasters occurring between 1964 and 2004. Federally declared disasters are those disasters declared by communities to the Federal government. Often times upon declaration, the Federal government offers some form of relief to the community (IFRCRCS 2002). Thus whether a disaster is declared depends largely on the resources of the community and the aggressiveness of community leaders. Many disasters of significant consequences are not declared while some of relatively little consequences are declared. In other words, declaration may have little to do with severity. Nonetheless, Federally declared disasters offer the best indication of a community's disaster vulnerability reduction efforts. It is simply vital to use local knowledge in interpreting the Federally Declared Disasters classifications.

\section{Replicable}

This indicator can be updated annually based on Federally Declared Disasters by Calendar Year data, as collected in the National Emergency Management Information System (NEMIS) maintained by FEMA (FEMA 2004).

\section{Directions}

The "declarations by type" database is sorted by disaster type (FEMA 2004). Eliminate those disasters that are not in the categories of tsunami, coastal storm, drought, earthquake, flood freezing, hurricane, typhoon, 
dam/ levee break, mud/ landslide, severe ice storm, fire, snow, tornado, volcano, or severe storm. Download and compile the data by U.S. counties. Import the data into a GIS program and join it with county boundary files to create a Federally Declared Disasters indicator layer.

\section{Indicator Measure}

The number of Federally declared natural disasters in the categories of tsunami, coastal storm, drought, earthquake, flood, freezing, hurricane, typhoon, dam/levee break, mud/ landslide, severe ice storm, fire, snow, tornado, volcano, and severe storm for each county was summed to obtain a 38-year total for natural disasters (FEMA 2004). This sum was then divided by its respective county area (square miles) resulting in Federally declared disasters per square mile. This distributes the data by area. Distributing the data by area allows for an equal comparison between large and small-area counties. In other words, it protects against a large-area county from a more vulnerable classification because it naturally has more occurrences compared to a small-area county. Statistical analysis resulted in a mean of 0.0239 disasters per square mile and a standard deviation of 0.1136 . Using these statistics along with natural breaks in the data, the following classifications were determined:

$$
\begin{aligned}
& \text { Very Low Vulnerability (1): }<0.0245 \text { disasters per square mile } \\
& \text { Low Vulnerability (2): }>=0.0245-<0.0183 \text { disasters per square mile } \\
& \text { Moderate Vulnerability (3): }>=0.0183-<0.1375 \text { disasters per square mile } \\
& \text { Vulnerable (4): }>=0.1375-<0.1945 \text { disasters per square mile } \\
& \text { High vulnerability (5): } \quad>=0.1945 \text { disasters per square mile }
\end{aligned}
$$

Rules

Installations are often in two or more counties. Therefore, regional classifications are determined by a weighted average. The weighted average calculation determines what percentage of the installation is in each county, and that percentage is multiplied by that county's value. Those values for each county around the installation are then totaled to arrive at a regional value. This value is then subject to the same metric that determined the classification for the individual counties.

For example:

Indicator Value for the Installation =

(Percentage of Installation in County A* Indicator Value for County A) +

(Percentage of Installation in County $B *$ Indicator Value for County B)...etc. 


\section{Indicator: Tornado Occurrences (L05)}

Variable

Tornado county-segments per square mile

Scale

County

Year

$1992-2002$

Data Source

National Oceanic and Atmospheric Administration (NOAA). 2004. Tornados. Washington, DC: U.S. Department of Commerce. Accessible through URL: http://www.noaa.org/tornadoes.html

Logic

Tornadoes are one of nature's most violent storms. In an average year, about 1,000 tornadoes are reported across the United States, resulting in 80 deaths and over 1,500 injuries. A tornado is a violently rotating column of air extending from a thunderstorm to the ground. The most violent tornadoes are capable of tremendous destruction with wind speeds of 250 mph or more. Damage paths can be in excess of 1 mile wide and 50 miles long (NOAA 2004). Thus, the military must be sensitive to potential threats from tornadoes. Tornadoes, just as any other severe weather conditions, are a threat to built structures, human health and safety, and the mission of the installation.

This indicator measures the number and strength of tornadoes segments that passed through a county in a given year. It is not a measure of the number of total tornadoes by strength. If a tornado stays in one county, then a "tornado" is the same as a "segment." However, if a tornado that passes through two counties, it is then counted twice. If a tornado passes through three counties, it is then counted three times, and so forth. Tornadoes come in all shapes, sizes, and strengths and can occur anywhere in the United States at any time of the year. Yet, there are several geographic and climatic characteristics that may increase the probability of experiencing a tornado. For instance, in the southern states, peak tornado season is March through May, while peak months in the northern states are during the summer (NOAA 2004).

Tracking the occurrence and strength of tornadoes provides an indication of the likelihood of similar tornado damage re-occurring in the area. Yet 
there is an inherent inaccuracy in attempting to summarize expectations about what will happen in the future--weather forecasting. When predicting tornadoes, forecasters look for the development of temperature and wind flow patterns in the atmosphere that can cause enough moisture, instability, lift, and wind shear for tornadic thunderstorms. Those are the four needed ingredients. But it is not as easy as it sounds. "How much is enough" of those is not a hard fast number, but varies significantly from situation to situation - and is sometimes unknown. A large variety of weather patterns can lead to tornadoes; and often, similar patterns may produce no severe weather at all. To further complicate it, the various computer models can have major biases and flaws when the forecaster tries to interpret them on the scale of thunderstorms. In other words, what may have caused several tornadoes 1 year may not result in any tornadoes the next year, or vice versa (NOAA 2004). The best anyone can do is to make an educated guess where the most favorable combination of ingredients tends to occur and classify the vulnerability.

Lastly, it is important to note this data is on the county level. Tornadoes typically only hit a relatively small portion of land, especially compared at the county level. Yet, to name that specific piece of land more than several hours in advance is impossible. Thus, it is often an area much greater than county borders that are highly vulnerable to tornado occurrences. In other words, if a neighboring county to the study county has a high occurrence of tornadoes; it may be wise to regard the study county as a higher potential county. Because of the inaccuracy of forecasting and large high-potential areas, it is important to use local knowledge in interpreting the tornado classifications.

\section{Replicable}

This indicator is updated annually by the NOAA Storm Prediction Center through URL: http://www.spc.noaa.gov/software/svrplot2l (NOAA 2004).

\section{Directions}

Query tornado occurrences for 1992-2002 from the NOAA Storm Prediction Center's SeverePlot system available online through URL:

http://www.spc.noaa.gov/software/svrplot2l. Download the file in a tabular format and import it into a GIS program. The file should contain an "ID" for each tornado occurrence and a latitude/ longitude for the beginning of the event and latitude/ longitude for the end. Single touchdowns have the same beginning and ending latitude/ longitude. Use the GIS software to 
form a polyline shapefile from the beginning to the end of the tornado's path. Finally, intersect the tornado paths with county boundary files to note which counties the path crossed through, and use the GIS count function to get a number of tornadoes per county.

\section{Indicator Measure}

The number of tornado segments for each county was summed to obtain the total number of tornado segments occurring within a county from 1992 to 2002 (NOAA 2004). This sum was then divided by its respective county area (square miles) resulting in tornado segments per square mile. This distributes the data by area. Distributing the data by area allows for an equal comparison between large and small-area counties. In other words, it protects against a large-area county from a more vulnerable classification because it naturally has more occurrences compared to a small-area county. Statistical analysis resulted in a mean of 0.0072 tornadoes per square mile and a standard deviation of 0.0112. Using these statistics along with natural breaks in the data, the following classifications were determined:

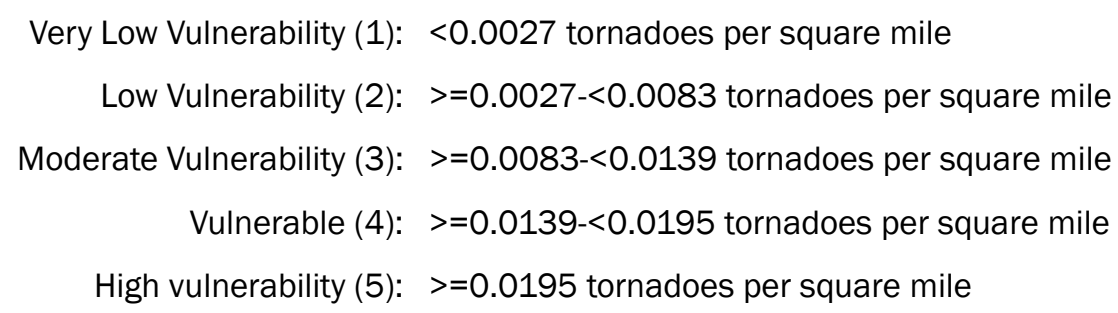

Rules

Installations are often in two or more counties. Therefore, regional classifications are determined by a weighted average. The weighted average calculation determines what percentage of the installation is in each county, and that percentage is multiplied by that county's value. The values for each county around the installation are then totaled to arrive at a regional value. This value is then subject to the same metric that determined the classification for the individual counties.

For example:

Indicator Value for the Region around an Installation =

(Percentage of Installation in County A* Indicator Value for County A) + (Percentage of Installation in County B* Indicator Value for County B) ... etc. 


\section{Sustainability Issue: Water}

\section{Indicator: Level of Development (WA1)}

Variables

Water withdrawal, Stream flow levels

Scale

Watershed

Year

1990

Data Sources

USEPA. 1997. The Index of Watershed Indicators, EPA-841-R-97-010. Washington, DC: Office of Water. Accessible through URL: http://www.epa.gov/wateratlas/geo/maplist.html

Hurd, B., N. Leary, R. J ones, and J . Smith. 1999. "Relative Regional Vulnerability of Water Resources to Climate Change." J ournal of the American Water Resources Association. Vol. 35. No. 6. pp. 1399-1409. Accessible through URL: http://www.awra.org

Logic

This indicator measures the ratio of current water withdrawal to mean annual unregulated streamflow. Watersheds with low water availability and high demand are vulnerable, i.e., in areas of development intensive use of off-stream water generally occurs resulting in decreased water availability (B. Hurd et al. 1999). With a reduction in streamflow, either via seasonal or dramatic climatic change, an increase in both in-stream and off-stream uses will occur, especially in areas of high development and high irrigation (B. Hurd et al. 1999). This indicator has an impact on the military mission if and when an installation is in an area with vulnerable watersheds. Water availability could be compromised resulting in a negative impact on soldiers, training, carrying capacity, and threatened and endangered species.

A watershed is the area of land where all of the water that is under it or drains off of it goes into the same place. Watersheds are delineated by USGS using a nationwide system based on surface hydrologic features. This system divides the country into 21 regions, 222 subregions, 352 accounting units, and 2,262 cataloguing units. A hierarchical hydrologic unit code (HUC) consisting of 2 digits for each level in the hydrologic unit system is used to identify any hydrologic area. The 6-digit accounting units 
and the 8-digit cataloguing units are generally referred to as basin and sub-basin. There are many states that have defined down to 16-digit HUC.

\title{
Replicable
}

The USEPA, Watershed Atlas is no longer available. Current watershed information is being made available from the USEPA, through the Watershed Information Network through URL: http:/lwww.epa.gov/winl. Efforts are being made to replicate this analysis with updated data.

\section{Directions}

Download "level of development" from the USEPA, Index of Watershed Indicators through URL: $\underline{\text { http://www.epa.gov/wateratlas/geo/maplist.html }}$ (USEPA 1997). Import the data into a GIS program and join it with watershed boundary files to create a GIS Level of Development indicator layer.

Indicator Measure

Ranges were defined as the ratio of total annual surface and groundwater withdrawals in $1990\left(\mathrm{Q}_{\mathrm{w}}\right)$ to unregulated mean annual streamflow (Qs):

Level of Development $=\left(Q_{w} / Q_{s}\right)$

The level of development ratings were grouped into the following classifications based on definitions created by the USEPA, Watershed Atlas (USEPA 1997):

\author{
Very Low Vulnerability (1): Low Level of Development ( $<20$ percent) \\ Low Vulnerability (2): Not Applicable \\ Moderate Vulnerability (3): Average Level of Development (20 to 85 percent) \\ Vulnerable (4): Not Applicable \\ High vulnerability (5): High Level of Development (>85 percent)
}

\section{Rules}

Every installation is located primarily in one watershed, although several installations do cross watershed boundaries. The area around an installation takes on the rating of the watershed where the installation is primarily located (area basis). 


\section{Indicator: Groundwater Depletion (WA2)}

Variables

Groundwater Outflow, Groundwater Withdrawals (annual) Scale

Watershed

Year

1990

Data Sources

USEPA. 1997. The Index of Watershed Indicators, EPA-841-R-97-010. Washington, DC: Office of Water. Accessible through URL: http://www.epa.gov/wateratlas/geo/maplist.html

Hurd, B., N. Leary, R. J ones, and J . Smith. 1999. "Relative Regional Vulnerability of Water Resources to Climate Change." J ournal of the American Water Resources Association. vol. 35 No. 6. pp. 1399-1409. Accessible through URL: http://www.awra.org

Logic

This indicator shows the level of groundwater withdrawal within watersheds of the continental U.S. Groundwater depletion characterizes the extent to which rates of groundwater withdrawals exceed long-run average recharge rates, resulting in overdraft and a condition referred to as "groundwater mining" (B. Hurd et al. 1999). Average groundwater withdrawals in excess of natural baseflows indicate an unsustainable rate of groundwater use. Excessive groundwater withdrawals suggest that increased groundwater use may not be a viable adaptation to changes in surface water supply or increases in water demand (B. Hurd et al. 1999).

A watershed is the area of land where all of the water that is under it or drains off of it goes into the same place. Watersheds are delineated by USGS using a nationwide system based on surface hydrologic features. This system divides the country into 21 regions, 222 subregions, 352 accounting units, and 2,262 cataloguing units. A hierarchical hydrologic unit code (HUC) consisting of 2 digits for each level in the hydrologic unit system is used to identify any hydrologic area. The 6-digit accounting units and the 8-digit cataloguing units are generally referred to as basin and sub-basin. There are many states that have defined down to 16-digit HUC. 


\section{Replicable}

The USEPA, Watershed Atlas is no longer available. Current watershed information is being made available from the USEPA, through the Watershed Information Network through URL: http://www.epa.gov/winl. Efforts are being made to replicate this analysis with updated data.

Directions

Download "groundwater outflow" and "annual groundwater withdrawals" from the USEPA, Index of Watershed Indicators through URL: http://www.epa.gov/wateratlas/geo/maplist.html (USEPA 1997). Import the data into a GIS program and join it with watershed boundary files to create a GIS Ground Water Depletion indicator layer.

Indicator Measure

Ranges were defined as the ratio of average groundwater withdrawals (QGW) in 1990 to annual average baseflow (QBase), reflecting the extent that groundwater use rates may exceed recharge:

Ground Water Depletion $=\left(\mathrm{Q}_{\mathrm{GW}} / \mathrm{Q}_{\text {Base }}\right)$

The groundwater depletion ratings were grouped into the following classifications based on definitions created by the USEPA, Watershed Atlas (USEPA 1997):

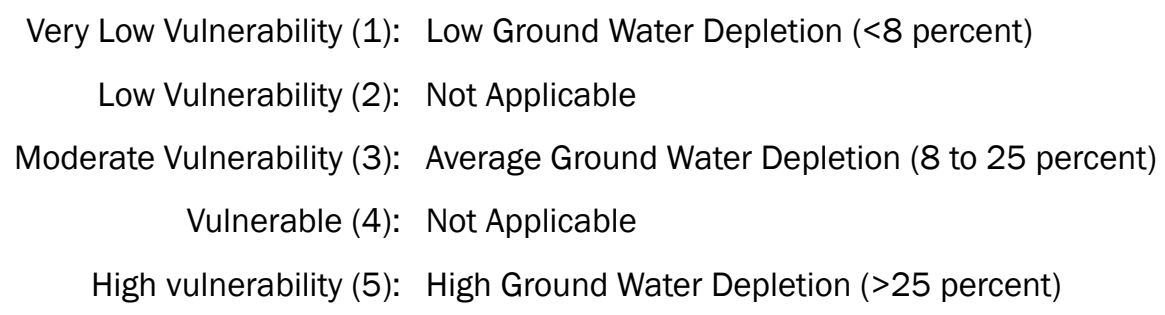

Rules

Every installation is located primarily in one watershed, although several installations do cross watershed boundaries. The area around an installation takes on the rating of the watershed where the installation is primarily located (area basis).

\section{Indicator: Flood Risk (WA3)}

Variable

Population 
Scale

Watershed

Year

1990

Data Source

USEPA. 1997. The Index of Watershed Indicators, EPA-841-R-97-010. Washington, DC: USEPA Office of Water. Accessible through URL: http://www.epa.gov/wateratlas/geo/maplist.html

Hurd, B., N. Leary, R. J ones, and J . Smith. 1999. "Relative Regional Vulnerability of Water Resources to Climate Change." J ournal of the American Water Resources Association. vol. 35 No. 6. pp. 1399-1409. Accessible through URL:

http://www.awra.org

Logic

This indicator is based on the current population living within a 500-Year flood plain. The flood risk indicator characterizes the extent to which lives and property are at risk of flood damages. The 500-Year Floodplain was selected over the more commonly used 100-Year standard because most, if not all, zoning standards and building practices have been based on the 100-Year standard (B. Hurd et al. 1999). This means that those living within the 100-Year Flood plain have generally taken the necessary precautions to mitigate flood risks. There is more concern and risk for populations and property that lie just beyond the margin of the 100-Year Floodplain, where people have not had regulations that have required modifications to properties to mitigate flood risks generally (B. Hurd et al. 1999). This takes into consideration the pressures on the future of negative impacts on water quality and availability. Training mission and carrying capacity would be negatively impacted as a result of a 500-Year flood. This would then place the military installation in a vulnerable state, possibly affecting the type and intensity of training that would take place on the installation. Applicable laws and regulations can be found through URL:

\section{http:/lwww.epa.gov/win/law.html}

\section{Replicable}

The USEPA, Watershed Atlas is no longer available. Current watershed information is being made available from the USEPA, through the Watershed Information Network through URL: http://www.epa.gov/winl. Efforts are being made to replicate this analysis with an analysis of an installation's proximity to the 100 and 500-Year Floodplain once that data is released in its entirety by FEMA. 


\section{Directions}

Download "flood risk" from the USEPA, Index of Watershed Indicators through URL: http://www.epa.gov/wateratlas/geo/maplist.html (USEPA 1997). Import the data into a GIS program and join it with watershed boundary files to create a GIS Flood Risk indicator layer.

Indicator Measure

Ranges were classified as an estimated number of people within the 500year 1990 defined floodplain. The flood vulnerability was grouped into the following classifications based on definitions created by the USEPA, Watershed Atlas (USEPA 1997):

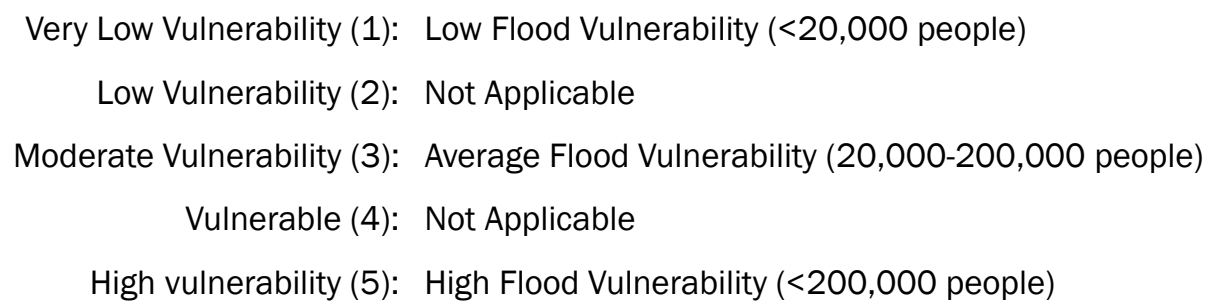

Rules

Every installation is located primarily in one watershed, although several installations do cross watershed boundaries. The area around an installation takes on the rating of the watershed where the installation is primarily located (area basis).

\section{Indicator: Low Flow Sensitivity (WA4)}

Variables

Streamflow in cubic feet squared per second Scale

Watershed

Year

2002-2004

Data Sources

USEPA. 1997. The Index of Watershed Indicators, EPA-841-R-97-010. Washington, DC: USEPA Office of Water. Accessible through URL: http://www.epa.gov/wateratlas/geo/maplist.html 
Hurd, B., N. Leary, R. J ones, and J . Smith. 1999. "Relative Regional Vulnerability of Water Resources to Climate Change." J ournal of the American Water Resources Association. vol. 35 No. 6. pp. 1399-1409. Accessible through URL: http://www.awra.org

U.S. Geological Survey (USGS). 2004. National Water Information System (NWIS): Surface-Water Data for the Nation, Daily Streamflow for the Nation. Washington, DC. UDSGS. Accessible through URL: http://nwis.waterdata.usgs.gov/usa/nwis/discharge

Logic

Streamflows are critical to many riparian areas, and falling below safe threshold levels can threaten individual species or potentially endanger entire aquatic ecosystems. Riparian ecosystems where seasonal periods of extreme low flow occur are the most vulnerable to climatic and hydrologic changes. This further diminishes streamflows during the low flow seasons, since there is less capacity for enduring additional stresses (B. Hurd et al. 1999).

Impacts to the military mission would include diminished or stressed threatened and endangered species (TES) habitat and population, which in turn could negatively impact the ability for certain training and other missions. Diminished carrying capacity across training may result due to the increased erosion, as a result. Finally, the availability of water would significantly decrease resulting in resource vulnerability.

A watershed is the area of land where all of the water that is under it or drains off of it goes into the same place. Watersheds are delineated by USGS using a nationwide system based on surface hydrologic features. This system divides the country into 21 regions, 222 subregions, 352 accounting units, and 2,262 cataloguing units. A hierarchical hydrologic unit code (HUC) consisting of 2 digits for each level in the hydrologic unit system is used to identify any hydrologic area. The 6-digit accounting units and the 8-digit cataloguing units are generally referred to as basin and sub-basin. There are many states that have defined down to 16-digit HUC.

\section{Replicable}

USGS surface-water data includes more than 850,000 stations recording time-series data that describe stream levels, streamflow (discharge), reservoir and lake levels, surface-water quality, and rainfall. The data is collected by automatic recorders and manual measurements by field personnel and relayed through telephones or satellites to offices where it is stored and processed. The data relayed through the Geostationary Operational 
Environmental Satellite (GOES) system are processed automatically in near real time, and in many cases, real-time data are available online within minutes. Annually, the USGS finalizes and publishes the daily data in a series of water-data reports. Daily streamflow data and peak data are updated annually following publication of the reports.

Due to extensive downloading and numerous calculations of streamflow data to create the Low Flow Sensitivity indicator, it is recommended that this indictor be updated annually or every other year.

\section{Directions}

Download average annual streamflow by hydrologic region for 2002 through 2004 from USGS NWIS through URL: http://nwis.waterdata.usgs.gov/usa/nwis/discharge

Save files as tab-separated data. Import and join all files into a spreadsheet program. Average streamflows for each data station for 2002 through 2004. Group all data stations by HUC. Average streamflows for 2002 through 2004 by HUC. Since not all basin and sub-basin HUC have data stations, compute averages for the largest HUC units first then for smaller HUC units as data allows. Import the HUC streamflow averages from 2002-2004 into a GIS program and join them with watershed (HUC) boundary files to create a GIS Low Flow Sensitivity indicator layer.

Note, downloading average annual streamflow measurements for over 850,000 stations over 2 years results in millions of data points. Due to query limitation of the NWIS webserver, it is recommended to contact USGS Surface-Water Data Department for assistance in these queries.

\section{Indicator Measure}

This indicator measures the unregulated mean streamflow in cubic feet squared per second. Streamflow is defined as the mean value of discharge that occurs in a natural channel. This measurement is mostly independent of levels and changes in surface runoff. A complete explanation of the USEPA, ranges is Accessible through URL: http:/lwww.epa.gov/winl. The low flow sensitivity indicator averages streamflows over a 2-year period. Ratings of low flow sensitivity were grouped into the following classifications based on definitions created by the USEPA (1997): 


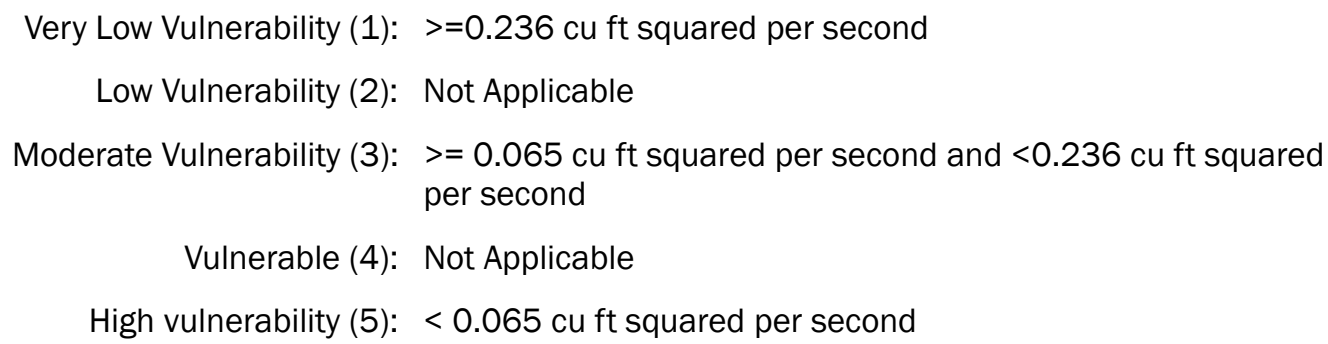

Rules

Every installation is located primarily in one watershed, although several installations do cross watershed boundaries. The area around an installation takes on the rating of the watershed where the installation is primarily located (area basis).

\section{Indicator: Water Quality Index (WA5)}

Variables

Waters meeting designated uses, Source water condition for drinking water systems, Fish \& wildlife consumption advisories, Indicators of source water condition, Contaminated sediments, Ambient water quality - toxics, Water quality - conventional, Wetlands loss, Aquatic and wetlands species at risk, Loads over limits - toxics, over limits - conventional, Urban runoff potential, Agriculture runoff potential, Population change, Hydrologic modification caused by dams, Estuarine pollution susceptibility, Deposition

Scale

Watershed

Year

1999

Data Source

USEPA. 1999. EPA Overall Watershed Characterization: September 1999 IWI Release. Washington, DC: Office of Water. Accessible through URL: http://www.epa.gov/iwi/1999sept/catalog.html

Logic

The Index of Watershed Indicators (IWI) characterizes the condition and vulnerability of aquatic systems in each of the 2,262 watersheds in the 50 states and Puerto Rico (USEPA 1999). This involves an assessment of condition, vulnerability, and data sufficiency. All variables taken into consideration are strong indicators of pressures in the future on water quality 
and vulnerability, leading to greater demands and risks to water supplies (USEPA 1999). This would then place the military installation in a vulnerable state, possibly affecting the type and intensity of training that would take place on the installation. Supplementary applicable laws and regulations can be found through URL: http://www.epa.gov/win/law.html.

A watershed is the area of land where all of the water that is under it or drains off of it goes into the same place. Watersheds are delineated by USGS using a nationwide system based on surface hydrologic features. This system divides the country into 21 regions, 222 subregions, 352 accounting units, and 2,262 cataloguing units. A hierarchical hydrologic unit code (HUC) consisting of 2 digits for each level in the hydrologic unit system is used to identify any hydrologic area. The 6-digit accounting units and the 8-digit cataloguing units are generally referred to as basin and sub-basin. There are many states that have defined down to 16-digit HUC.

\section{Replicable}

Efforts are being made to replicate this analysis so it can be updated when new data is available using similar methodologies of the original study. The USEPA intends to replicate the effort and produce new data, although the timeline is unclear at this point due to lack of funding. Replicability depends heavily on current and future monitoring programs.

\section{Directions}

Download "water quality" from the USEPA Overall Watershed Characterization: September 1999 IWI Release through URL:

http://www.epa.gov/iwi/1999sept/catalog.html (USEPA 1999). Import the data into a GIS program and join it with watershed boundary files to create a GIS Water Quality indicator layer.

\section{Indicator Measure}

This map combines 17 disparate data layers as listed above; layers were weighted and then combined by the USEPA. The approach taken by the USEPA (1999) can be found through URL:

http://oaspub.epa.gov/eims/direntrpt.report?p_deid=9996\&p_chk=9186

Indicators of the condition of the watershed were scored and assigned to one of three categories: better water quality, water quality with less serious problems, and water quality with more serious problems (USEPA 1999). It is important to note that the strength of monitoring programs varies 
across the country and is reflected in the map. Areas with strong monitoring programs may show more problems than those with weaker programs. The water quality IWI ratings were defined as follows by the USEPA (1999):

\author{
Very Low Vulnerability (1): Better Water Quality \\ Low Vulnerability (2): Not Applicable \\ Moderate Vulnerability (3): Less Serious Water Quality Problems \\ Vulnerable (4): Not Applicable \\ High vulnerability (5): More Serious Water Quality Problems
}

Rules

Every installation is located primarily in one watershed, although several installations do cross watershed boundaries. The area around an installation takes on the rating of the watershed where the installation is primarily located (area basis). 


\section{Sustainability Issue: Economic}

Indicator: DoD Local Employment (EC1)

Variables

Military Employment, Total Employment

Scale

County

Year

2003

Data Sources

Bureau of Economic Analysis (BEA), U.S. Department of Commerce. 2005. Regional Economic Information System. (Detailed county annual tables of income and employment by SIC industry: CA25-Total Full-Time and Part-Time Employment by Industry). Washington, DC: BEA. Accessible through URL: http://www.bea.gov/bea/regional/reis/

National Governors Association Center for Best Practices. 2003. State Strategies to Address Encroachment at Military Installations. Natural Resources Policy Studies. Washington, DC: National Governors Association Center for Best Practices. Accessible through URL: http://www.nga.org/cda/files/032403MILITARY.PDF

Logic

DoD local employment provides a measurement of the economic impact of military installations on the local economy. Military installations are often critical to local economies, accounting for thousands of jobs and for generating billions of dollars in economic activity and tax revenue (NGA Center for Best Practices 2003).

Military installations provide many benefits to their local region in terms of economic impact. Installations in areas with a strong independent economy or significant resource constraints may be economically less important to the area. This indicator is a measure of the economic investment of military employment within each county's economy. The assessment is based on the percentage of military employment within a county's total employment. It is assumed that the higher the percentage of military employment within an economy, the more likely the DoD will be looked on as a friend and field fewer complaints pertaining to stationing and mission decisions. 


\section{Replicable}

Since 1969 REIS updates its datasets annually. Updated employment figures are downloadable through URL (BEA 2005):

\section{http://www.bea.gov/bea/regional/reis/}

\section{Directions}

Download the most recent military and total employment figures by county (BEA 2005). Import the data into a GIS program and join it with county boundary files to create a GIS DoD Local Employment indicator layer.

\section{Indicator Measure}

The DoD local employment indicator provides a measure of the percent of military employment at a county level. The indicator is calculated by dividing the total military employment within a county by its total employment then multiplying the result by 100 . This yields a percentage of military employment per county:

DoD Local Employment $=$

[(total military employment)/(total employment)]*100

This data has evident natural breaks that have been used to classify the data into vulnerability ranges:

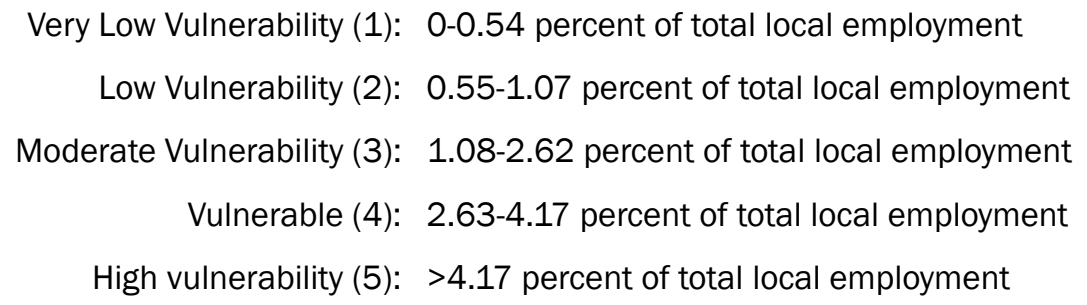

Very Low Vulnerability is the lowest level of military involvement, Moderate Vulnerability is the middle classification, and High Vulnerability indicates the highest level of military involvement, usually a major installation. Statistical analysis of the data reveals a county average of 1.15 percent of total local employment with a standard deviation value of 3.06.

\section{Rules}

Installations are often in two or more counties. Therefore, regional classifications are determined by a weighted average. The weighted average calculation determines what percentage of the installation is in each county and multiplies that percentage by that county's value. The values for each 
county surrounding the installation are then totaled to arrive at a value for the region. This value is subjected to the same metric that determined the classification for the individual counties.

For example:

Indicator Value for the Region Around an Installation =

(Percentage of Installation in County A* Indicator Value for County A) +

(Percentage of Installation in County $B *$ Indicator Value for County B)...etc.

\section{Indicator: Job Availability/Unemployment (EC2)}

Variables

Unemployment Rate

Scale

County

Year

2004

Data Sources

Bureau of Labor Statistics (BLS), U.S. Department of Labor. 2003. Employment

Situation Explanatory Note. Washington, DC: BLS. Accessible through URL:

http://www.bls.gov/news.release/empsit.tn.htm

BLS, U.S. Department of Labor. 2005. Local Area Unemployment Statistics. Washington, DC: BLS. Accessible through URL:

http://www.bls.gov/lau/home.htm

HQDA. 2002. FY03 Army Well-Being Action Plan. Washington, DC: Deputy Chief of Staff for Personnel, HQDA. Accessible through URL:

http://www.odcsper.army.mil/Directorates/wb/FY03 WBAP Vol 1.pdf

Logic

The most common measure of job availability is the unemployment rate. Theoretically, the unemployment rate characterizes the job-market in a particular area. However, the system for gathering employment data is not perfect. Unemployment surveys miss self-employed and discouraged job seekers. Other workers hold temporary jobs when they want permanent jobs, working part-time when they want to work full time, or holding jobs below their skill and education levels. Some workers counted as unemployed may be halfheartedly job-hunting to keep unemployment benefits (BLS 2003). Regrettably, there is no "quality of job" measure available to 
compare minimum-wage, living-wage, part-time, and full-time employment.

Unemployment rates do, however, characterize the quality of life. The Army has recognized in its Well-Being Action Plan that "Soldier and family satisfaction help to retain Soldiers" (USDoA 2002). Part of being "satisfied" is having the financial stability and employment needed to meet that. The military is beginning to move aggressively into addressing family member employment. Initial efforts are focused on establishing public partnerships with private corporations to provide training and career continuity to military spouses. A Spouse Telework Employment Program (STEP) is nearing completion and the Department of Defense is working with the Department of Labor to explore opportunities in the public sector. In the interim, the military's Spouse Employment Program is developing capabilities in the following areas: job search assistance, private sector job bank, and career counseling. Mid and long-term objectives focus on capturing lessons learned from the initial partnerships and expanding the program to more corporations (USDoA 2002).

Characteristics of the labor market reveal a lot about the economy and quality of life of a community. Although the job market may seem not to affect service members, it will affect their family members and the overall economic growth of the area. Like most economic news, a low unemployment rate is a mixed blessing. It is good news for workers and their families in terms of prosperity. But it means that employers must scramble to fill their openings, and prospective employers may be a bit wary about locating in areas where workers are hard to find and they have to offer higher wages to compete with other employers. Thus, economists have determined an ideal unemployment rate range of 4 to 5.6 percent (BLS 2003). Some level of unemployment is normal. Yet, too low or too high unemployment rates leads to problems.

\section{Replicable}

The U.S. Department of Labor, Bureau of Labor Statistics, provides unemployment statistics for the latest year available for download through URL: http://www.bls.gov/lau/home.htm.

\section{Directions}

Download unemployment rate county data from the U.S. Department of Labor, Bureau of Labor Statistics, Local Area Unemployment Statistic 
website available online through URL: http://www.bls.gov/lau/home.htm (BLS 2005). Import the data into a GIS program and join it with county boundary files to create a GISJ ob Availability/ Unemployment indicator layer.

\title{
Indicator Measure
}

The rationale for the legend is based on unemployment levels around the ideal or "natural" unemployment rate (4-5.6 percent). Scholars disagree about what the exact natural rate of unemployment is and how it should be derived. From data and papers accessible through the Bureau of Labor Statistics, most scholars commonly agree on 5.5 percent natural unemployment (BLS 2003). From this, levels of unemployment that are acceptable were designated Very Low Vulnerability, and outside of this range natural breaks occurred to designate Moderate and High Vulnerability classifications:

\author{
Very Low Vulnerability (1): $>=4$ and $<5.7$ percent \\ Low Vulnerability (2): Not Applicable \\ Moderate Vulnerability (3): $>=2.4$ and $<4$ or $>=5.7$ and $<9.1$ percent \\ Vulnerable (4): Not Applicable \\ High vulnerability (5): $>=0$ and $<2.4$ or $>9.1$ and $<=25$ percent
}

Rules

In the case where an installation is in two or more counties, regional classifications are determined by a weighted average. The weighted average calculation determines what percentage of the installation is in each county and multiplies that percentage by that county's classification value. The values for each county of the installation are then totaled to arrive at a value for the region around the installation. This value is subjected to the same metric that determined the classification for the individual counties.

For example:

Indicator Value for the Installation Region $=$

(Percentage of Installation in County A* Indicator Value for County A) +

(Percentage of Installation in County $B *$ Indicator Value for County B)...etc.

\section{Indicator: Housing Affordability (EC3)}

Variables

Net Rents, Net Income 
Scale

County

Year

1999

Data Sources

HQDA. 2002. FY03 Army Well-Being Action Plan. Washington, DC: Deputy Chief of Staff for Personnel, HQDA. Accessible through URL:

http://www.odcsper.army.mil/Directorates/wb/FY03 WBAP_Vol 1.pdf

National Association of Realtors. 2003. Housing Affordability. Chicago, IL: National Association of Realtors. Accessible through URL: http://www.realtor.org

U.S. Bureau of the Census, U.S. Department of Commerce. 2000. Summary File 3: Table H69, Gross Rent as a Percentage of Household Income. American FactFinder. Washington, DC: U.S. Bureau of the Census. Accessible through URL: http://factfinder.census.gov

U.S. Department of Housing and Urban Development. 2003. Buying a Home: Find out How Much Mortgage Can You Afford. Washington, DC: U.S. Department of Housing and Urban Development. Accessible through URL:

http://www.hud.gov/buying/index.cfm

Logic

Housing affordability is "the ratio of median family income to the income needed to purchase the median priced home based on current interest rates and underwriting standards, expressed as an index" (National Association of REALTORS 2003). The National Association of Realtors compiles such an index at the National level annually. The proportion of income spent on housing can be used as a broad measure of the ease (or difficulty) that people experience in meeting their housing commitments. However to the extent that higher housing payments may reflect discretionary savings among home purchasers, care should be exercised in the use of such a measure. In the rental sector, households may choose to pay a higher rent to live close to employment and so reduce travel time and cost. Nevertheless, a comparison of the proportion of income spent on housing for different types of households and levels of income provides insight into those groups most likely to be under financial pressure through housing costs.

Housing affordability is also a characteristic of the overall cost of living. Referenced from the United States Department of Housing and Urban Development (DoHUD 2003), people typically allocate 30 percent of their income to housing. This is the largest amount allocated to any one good or 
service. In other words, it is a large portion of a households' spending. If housing costs are high, it detracts from an individual's ability to afford other goods and services. People living where housing costs are high are more likely to not be able to afford a standard of living as high as those living where housing costs are lower. If standard of living is lower, quality of life is lower-cannot afford the social and cultural aspects of personal enrichment (USDoA 2002). More specifically to the military are DoD housing allowances. With many military employees forced to choose off-base housing, local cost of living is an important indicator in determining the DoD housing allowance.

Housing costs are determined based on gross rent within a community due to their high flexibility to change with rapidly changing market conditions.

\section{Replicable}

The U.S. Census provides housing statistics every decade reported in Summary File 3 available for download through URL: http://www.census.gov (Bureau of the Census 2000). Housing statistics are also replicated every 5 years in a Decennial Supplementary Survey. It is recommended that the data is replicated only once a decade due to the non-comprehensiveness of the supplementary surveys.

\section{Directions}

Download table H69 Gross Rent as Percentage of Household Income: 1999 from the U.S. Census 2000 Summary File 3 at the county level available online through URL: http:/lfactfinder.census.govl (Bureau of the Census 2000). Import the data into a GIS program and join with county boundary files to create a GIS Housing Affordability indicator layer.

\section{Indicator Measure}

Gross rent as a percentage of household income in 1999 is a computed ratio of monthly gross rent to monthly household income (total household income in 1999 divided by 12). The ratio is computed separately for each unit and is rounded to the nearest tenth. Units for which no rent is paid and units occupied by households that reported no income or a net loss in 1999 comprise the category "Not computed." The sample is assumed to be relatively normal; the classifications were configured around HUD's recommended 30 percent allocation (the National average is 29.86 percent): 


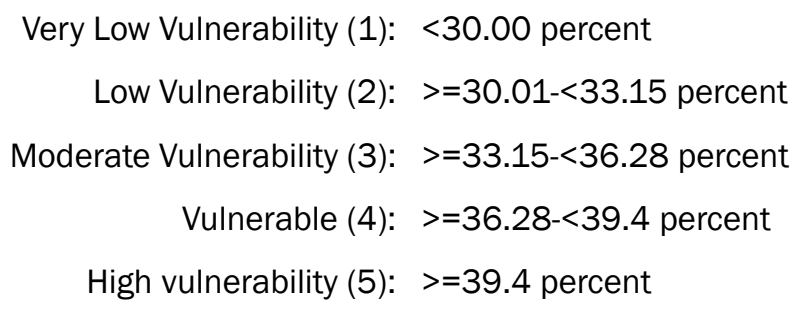

Rules

Installations are often in two or more counties. Therefore, the region around an installation is classified by a weighted average. The weighted average calculation determines what percentage of the installation is in each county and multiplies that percentage for each county by that county's classification value. The values for each county are then totaled to arrive at a value for the installation. This value is subjected to the same metric that determined the classification for the individual counties.

For example:

Indicator Value for the Installation =

(Percentage of Installation in County A* Indicator Value for County A) + (Percentage of Installation in County $B *$ Indicator Value for County B)...etc.

\section{Indicator: Poverty (EC4)}

Variables

Population Under 18 Years Below Poverty, Population 18-65 Years Below Poverty, Population Above 65 Years Below Poverty, Total Population

Scale

County

Year

2000

\section{Data Sources}

Kids Count, Annie E. Casey Foundation. 2000. The High Cost of Being Poor: Another Perspective on Helping Low-Income Families Get By and Get Ahead. Kids Count Online Database. Baltimore, MD: Kids Count. Accessible through URL: http://www.aecf.org/kidscount/census/

U.S. Bureau of the Census, U.S. Department of Commerce. 2000. Glossary (Poverty). American FactFinder. Washington, DC: U.S. Bureau of the Census. Accessible through URL:

http://factfinder.census.gov/home/en/epss/glossary_p.html 
Logic

This indicator measures the economic sustainability in a particular county based on the economic indicator of income. The amount of disposable income a household or individual has to provide the basic needs determine the extent to which economic development is either self-undermining or self-renewing. Many military installations depend on the economic resources of the surrounding community. Thus, it is important that current economic practices occurring around military installations focus on providing positive options and choices of future generations. Economic development thrives when there is sufficient income and stagnates without sufficient income.

Poverty rates measure the sufficiency of income to provide basic needs. Poverty rates are most easily accessible through the U.S. Census Bureau. The U.S. Census Bureau defines poverty by following the Office of Management and Budget's (OMB's) Directive 14. The Census Bureau uses a set of money income thresholds that vary by family size and composition to detect who is poor. If the total income for a family or unrelated individual falls below the relevant poverty threshold, then the family or unrelated individual is classified as being "below the poverty level" (Bureau of the Census 2000). The Kids Count project compiles these census figures into a comprehensive database addressing poverty for each U.S. County. By using these statistics, this study identifies areas with relatively high proportion of individuals without a sufficient disposable income to provide the basic needs and services (Kids Count 2000).

Lastly, it is important to note this data is on the county level, not community. Hence, it may be skewed by local "hotspots." In other words, if a county has one community ranking high in poverty, the entire county is classified as high poverty regardless of the characteristics of the remaining majority of the county. Because of this concern, it is important to use local knowledge in interpreting the poverty classifications.

\section{Replicable}

The Kids Count database is maintained by the Annie E. Casey Foundation. The database includes a comprehensive source of population poverty status at the state and county level obtained from the U.S. Census Bureau (Kids Count 2000). This indicator could be replicated every year from the U.S. Census Bureau small income and poverty estimates program based on population estimates, or every decade based on actual, verifiable counts. It 
is recommended that the data be replicated only once a decade due to the inaccuracy of census estimates. Poverty statistics may be obtained directly from the U.S. Census Bureau through URL: http:l/factfinder.census.gov, or a "cleaned" version downloaded from the Kids Counts through URL:

http://www.aecf.org/kidscount/data.htm

Directions

Download Population Under 18 Years Below Poverty, Population 18-65 Years Below Poverty, Population Above 65 Years Below Poverty, and Total Population for all U.S. counties from the Kids Count 2003 Database (Kids Count 2000). Import the data into a GIS program and join it with county boundary files to create a GIS Poverty indicator layer.

\section{Indicator Measure}

The poverty indicator provides a measure of the percent of the total population below the poverty level at a county level. The indicator is calculated by summing population under 18 years below poverty, population 18-65 years below poverty, and population above 65 years below poverty within a county and then dividing the total by the county's total population and finally multiplying the result by 100 . This yields a percentage of poverty within a county:

Poverty $=$

[(Population Under 18 Years Below Poverty +

Population 18-65 Years Below Poverty +

Population Above 65 Years Below Poverty) /

Total Population $]^{*} 100$

The data is assumed to be relatively normal and thus classification is statistically based on the standard deviation (6.33) and National mean (13.65 percent). The classes are as follows:

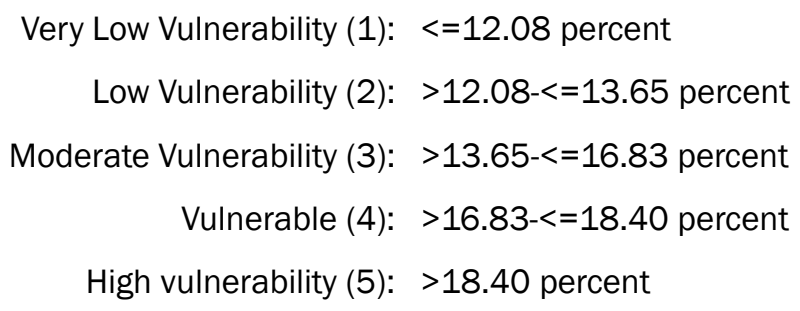

Rules

Installations are often in two or more counties. Therefore, the region around an installation is classified by a weighted average. The weighted 
average calculation determines what percentage of the installation is in each county and multiplies that percentage for each county by that county's classification value. The values for each county are then totaled to arrive at a value for the installation. This value is subjected to the same metric that determined the classification for the individual counties.

For example:

Indicator Value for the Installation =

(Percentage of Installation in County A* Indicator Value for County A) + (Percentage of Installation in County $B *$ Indicator Value for County B)...etc.

\section{Indicator: Residential Construction Value (EC5)}

Variables

Annual Average value per unit

Scale

County

Year

2004

Data Source

U.S. Bureau of the Census, U.S. Department of Commerce. 2005. New Residential Construction, Building Permits by County or Place. Manufacturing, Mining, and Construction Statistics. Washington, DC: U.S. Bureau of the Census. Accessible through URL: http://www.census.gov/const/www/permitsindex.html

\section{Logic}

This indicator along with Housing Affordability provides an idea of the overall cost of living. If housing costs are high, it detracts from an individual's ability to afford other goods and services. People living where housing costs are high are more likely to not be able to afford a standard of living as high as those living where housing costs are lower. If the standard of living is lower, the quality of life is lower and residents are less likely to afford the social and cultural aspects of personal enrichment. More specifically to the military are DoD housing allowances. With increasing numbers of military employees living off-base, local housing cost is an important indicator in determining the DoD housing allowance.

Additionally, the cost of local housing may be an indicator of the economic and political influence of the regional population. A more forceful and in- 
fluential regional population (accustomed to a higher standard of living) competing with the military installation for services, access, resources, and land can affect the type and intensity of training that can take place on the installation.

Lastly, it is important to note this data is on the county level, not community. Hence, it may be skewed by local "hotspots." In other words, if a county has one community with a high residential construction value, the entire county is classified as high vulnerability regardless of the characteristics of the remaining majority of the county. Because of these concerns, it is important to use local knowledge in interpreting the residential construction value classifications.

\section{Replicable}

The U.S. Census provides residential construction statistics by county on new privately-owned residential housing units authorized by building permits. Data items include number of buildings, units, and construction cost for monthly new privately-owned residential building permits. This data is updated monthly. County level data are totals provided for each county in which every permit office is requested to report monthly. Data is available for download through URL:

\section{http://www.census.gov/const/www/permitsindex.html}

It is recommended that this indicator be updated on an annual basis. The U.S. Census, Building Permits by County or Place webserver limits queries to one county or place at a time. Thus, it is more time effective to request annual county level residential building statistics directly from the U.S. Census for a minimal fee.

\section{Directions}

Request "Annual County Level Residential Building Permits" for 2004 in ASCII format from the U.S. Census through URL: http://www.census.gov/const/www/permitsindex.html.

Note that this file will include construction value. Import the data into a spreadsheet program and sum "value" and "units" columns for each county. Calculate the residential construction value as follows:

Residential Construction Value $=($ Total Value of Construction in 2004/Total Units for which permits were issued in 2004) 
Import the resulting math into a GIS program and join it with county boundary files to create a Residential Construction Value indicator layer.

\section{Indicator Measure}

This indicator provides a measure of the value of residential construction at a county level. The data is assumed to be relatively normal and thus classification is statistically based on the standard deviation $(50,089)$ and National mean (\$124,220 per unit) excluding 294 of 3,141 counties not reporting residential construction values in 2004 . The classes are as follows:

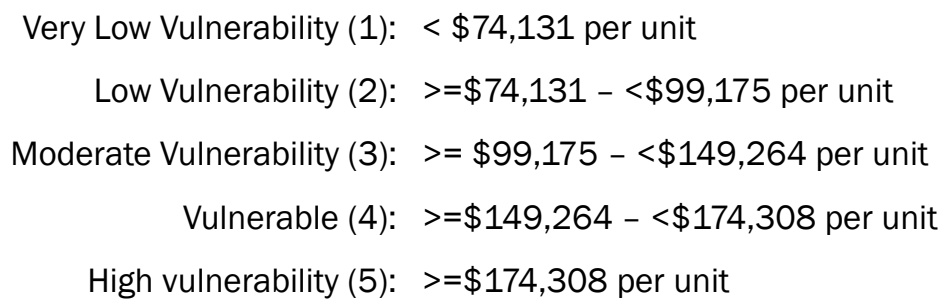

In random instances, the County permit office does not report the value or number of issued permits to the U.S. Census. These instances are rare but do occur

\section{Rules}

Installations are often in two or more counties. Therefore, the region around an installation is classified by a weighted average. The weighted average calculation determines what percentage of the installation is in each county and multiplies that percentage for each county by that county's classification value. The values for each county are then totaled to arrive at a value for the installation. This value is subjected to the same metric that determined the classification for the individual counties.

For example:

Indicator Value for the Installation =

(Percentage of Installation in County A Indicator Value for County A) + (Percentage of Installation in County $B *$ Indicator Value for County B)...etc.

\section{Indicator: Housing Permits Issue Rate (EC6)}

Variables

Annual Building Permits Issued in1995 and 2004 Scale

County 
Year

1995-2004

Data Source

U.S. Bureau of the Census, U.S. Department of Commerce. 2005. New Residential Construction, Building Permits by County or Place. Manufacturing, Mining, and Construction Statistics. Washington, DC: U.S. Bureau of the Census. Accessible through URL: http://www.census.gov/const/www/permitsindex.html

Logic

This indicator along with Rental and Housing Availability provides an idea of the availability of housing in a particular county. With an increasing number of military employees living off-base, local housing availability is an important indicator in determining DoD stationing attractiveness and quality of life for military employees and their family. Housing construction rates can directly impact a number of housing availability and quality of life indicators. For example, it may determine housing costs, commute times, access to schools or cultural amenities, or if a family may live with a service member.

Additionally, increasing residential construction may be an indicator of expected regional growth. The degree of regional population growth is a strong indicator of the demand for services, access, resources, and land in competition with the military installation. This can affect the type and intensity of training that can take place on the installation. This indicator assumes that fast growing human populations are less sustainable.

However, it is also important to note a National trend of decreasing household size (Bureau of the Census 2005). Thus, an increasing housing construction rate may be reflective of the local population consuming more housing as opposed to increasing regional population. In this case, local commercial and industrial land use would remain stable. Regardless, increasing land consumption for housing, commercial, and/or industrial uses is one of the leading causes of environmental degradation.

Lastly, it is important to note this data is on the county level, not community. Hence, it may be skewed by local "hotspots." In other words, if a county has one community with a high building permit issue rate, the entire county is classified as high vulnerability regardless of the characteristics of the remaining majority of the county. Because of these concerns, it is important to use local knowledge in interpreting the building permit issue rate classifications. 
Replicable

The U.S. Census provides building permit statistics by county on new privately-owned residential housing units authorized by building permits. Data items include number of buildings, units, and construction cost for monthly new privately-owned residential building permits. This data is updated monthly. County level data are totals provided for each county in which every permit office is requested to report monthly. Data is available for download through URL:

http://www.census.gov/const/www/permitsindex.html.

It is recommended that this indicator be updated on an annual basis. The U.S. Census, Building Permits by County or Place webserver limits queries to one county or place at a time. Thus, it is more time effective to request annual county level residential building permits directly from the U.S. Census for a minimal fee.

\section{Directions}

Request "Annual County Level Residential Building Permits" for 1995 and 2004 in ASCII format from the U.S. Census through URL:

\section{http://www.census.gov/const/www/permitsindex.html}

Import the data into a spreadsheet program and sum total units for each county in 1995 and 2004 separately. Calculate the housing permit issue rate from 1995 to 2004 as follows:

Housing Permit Issue Rate $=[$ (Total Issued Permits in 2004 -Total Issued

Permits in 1995)/Total Issued Permits in 1995]*100

Import the resulting math into a GIS program and join it with county boundary files to create a Housing Permit Issue Rate indicator layer.

\section{Indicator Measure}

This indicator provides a measure of residential construction growth rate at a county level. The data is assumed to be relatively normal and thus classification is statistically based on the standard deviation (407) and National mean (99.1 percent) excluding 263 of 3,141 counties not reporting permit data for 1995, 2004, or both years. The classes are as follows: 


$$
\begin{aligned}
\text { Very Low Vulnerability (1): } & <=0 \text { percent } \\
\text { Low Vulnerability (2): } & >0-<=100 \text { percent } \\
\text { Moderate Vulnerability (3): } & >100-<=200 \text { percent } \\
\text { Vulnerable (4): } & >200-<=300 \text { percent } \\
\text { High vulnerability (5): } & >300 \text { percent }
\end{aligned}
$$

In random instances, the County permit office does not report the number of issued permits to the U.S. Census. These instances are rare but do occur

Rules

Installations are often in two or more counties. Therefore, the region around an installation is classified by a weighted average. The weighted average calculation determines what percentage of the installation is in each county and multiplies that percentage for each county by that county's classification value. The values for each county are then totaled to arrive at a value for the installation. This value is subjected to the same metric that determined the classification for the individual counties.

For example:

Indicator Value for the Installation =

(Percentage of Installation in County A* Indicator Value for County A) + (Percentage of Installation in County $B *$ Indicator Value for County B)...etc.

\section{Sustainability Issue: Quality of Life}

\section{Indicator: Crime Rate (QL1)}

Variables

Murder, Rape, Robbery, Aggravated Assault, Burglary, Larceny, Auto

Theft, and Arson Counts, Population

Scale

County

Year

2002

\section{Data Sources}

Bureau of Investigation, U.S. Department of J ustice. 2005. Uniform Crime Reporting Program Data: County-Level Detailed Arrest and Offense Data. National Archive of Criminal J ustice Data/ Inter-university Consortium for Political and Social Research. Washington, DC/Ann Arbor, MI: U.S. Department of J ustice. Accessible through URL: http://www.icpsr.umich.edul 
Wilson, J ames Q., and George Kelling. 1982. "Broken Windows: The Police and Neighborhood Safety." The Atlantic Monthly. Boston, MA. Accessible through URL: http://www.theatlantic.com/politics/crime/windows.htm

Logic

For years, practitioners and experts in the field of law enforcement assert the crime rate as an indicator of the overall quality of life and level of public services offered in a particular area. The U.S. Department of J ustice supports the theory that higher incidences of crime tend to reflect economic stagnation, sprawl, and lack of community resources. If crime is prevalent in an area, people do not wish to live there, land is used inefficiently, and economic resources are spent fighting crime. The result is diverted resource away from other priorities such as protecting the environment. For these reasons, crime statistics are highly sought after as an indicator in the decisionmaking process for location of families and military development. The hosts of social and economic pressures that high crime incidences create result in large limitation on development potential of an area to military installations. These military installations are where soldiers and their families are housed. Thus, any installation must provide for their safe and secure future.

Supporting studies for these overall quality of life and level of public services assertions can be traced to a relatively simple theory referred to as "broken windows," which was first discussed by J ames Q. Wilson and George Kelling in 1982 (J.Q. Wilson et al. 1982). Wilson and Kelling prove that on a community level, disorder and crime are inextricably linked. Their analogy is simple-linking social disorder to the condition of windows in a vacant building. If a single window is broken and goes unrepaired, it is a symbol that no one cares and thus is an acceptable act within the community. It is then only a matter of time before all of the windows are broken. The failure to repair the broken window is evidence of a social failure that results in disorder and inevitably leads to more serious disorder and crime and overall lack of stability. People move to new areas excluding themselves from others, and public services decline as more resources are put into crime defense. The overall environment declines - decreased quality of life (J .Q. Wilson et al. 1982). Therefore, high incidences of crime should indicate a non-ideal location for military personnel, their families, and military operations.

The Uniform Crime Reporting Program Data: County-Level Detailed Arrest and Offense Data, 2002 reports counts of arrests and offenses for the Uniform Crime Reports (UCR) of the National Archive of Criminal J ustice 
Data (NACJ D) index (Part I) crimes: murder, rape, robbery, aggravated assault, burglary, larceny, auto theft, and arson (Bureau of Investigation 2005). The UCR County-level Arrest files also report arrests for additional (Part II) crimes such as forgery, fraud, vice offenses, and drug possession or sale. The Federal Bureau of Investigation (FBI) originally collected the data from reports submitted by agencies and states participating in the UCR Program. Detailed discussions of reporting procedures are found in the Uniform Crime Reporting Handbook (U.S. Government Printing Office 1980), and in the codebooks for the Inter-university Consortium for Political and Social Research (ICPSR) data collections Accessible through URL: http://www.icpsr.umich.edu/NACJD/ucr.html

The FBI maintains the data in the NACJ D, which is hosted by the ICPSR (Bureau of Investigation 2005).

Only Part I data-murder, rape, robbery, aggravated assault, burglary, larceny, auto theft, and arson-were used for this indicator. This data was summed by the ICPSR index and is a comprehensive list relevant to military installation quality of life assessment.

In one sense this crime data is complete because it accurately describes the accountancy of each event. Yet, in another sense, it is incomplete because it may not easily be used to explore circumstance patterns. Missing from this data is the day-to-day social context of crime, which may be understood more completely by community residents than by statistics because of the resident's expertise concerning neighborhood problems and activity patterns. For community residents, there is a wealth of information that affects their perceptions of the safety of their community. These perceptions are formed not only by crime data, but graffiti, rowdiness, public drunkenness, abandoned autos, and other such factors may be as influential in coloring perceptions and appear as threatening as murder, rape, robbery, aggravated assault, burglary, larceny, auto theft, and arson.

Lastly, it is important to note this data is on the county level, not community. Hence, it may be skewed by local "hotspots." In other words, if a county has one community ranking high in crime, the entire county is classified as high crime regardless of the characteristics of the remaining majority of the county. Because of these two concerns, it is important to use local knowledge in interpreting the crime classifications. 


\section{Replicable}

The FBI provides estimations of National reported crime activity and arrest statistics from law enforcement agencies periodically. These statistics are managed by the NACJ D, and are updated through the ICPSR. The NACJ D data are available from the ICPSR through URL: http://www.icpsr.umich.edu (Bureau of Investigation 2005).

\section{Directions}

Download Study No. 4009 Uniform Crime Reporting Program Data [United States]: County-Level Detailed Arrest and Offense Data, 2002 from the NACJ D/ICPSR website through URL: http://www.icpsr.umich.edul (Bureau of Investigation 2005). Import Dataset 4: Crimes Reported data into a GIS program and join it with county boundary files to create a GIS Crime Rate indicator layer.

\section{Indicator Measure}

The Crime indicator provides a measure of murder, rape, robbery, aggravated assault, burglary, larceny, auto theft, and arson arrests at a county level. The indicator is calculated by dividing the total number of the abovementioned arrests within a county by its population and then multiplying the result by 1,000 . This yields a rate of crime per 1,000 residents per county:

Crime Rate $=[$ (murder+rape+robbery+aggravated assault+burglary+larceny+auto theft+arson arrests)/population]*1,000

Crime data was statistically classified using the standard deviation around a relatively normal mean. The National average is 46 crimes per 1,000 persons, and the standard deviation is 31 . Thus, the scale is as follows:

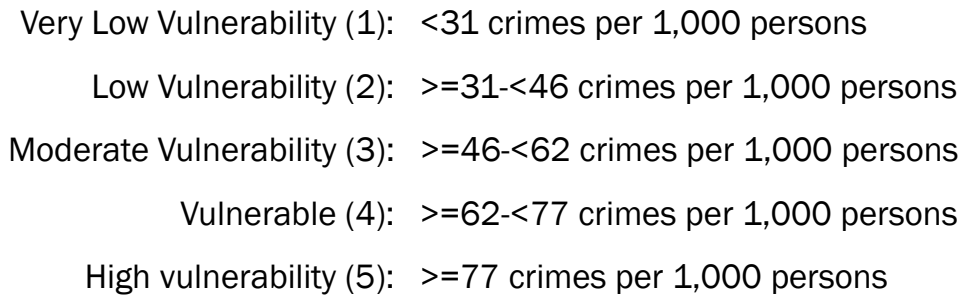

\section{Rules}

Installations are often in two or more counties. Therefore, regional rating around those installations is determined by a weighted average. The weighted average calculation determines the percentage of the installation 
in each county and multiplies that percentage by that county's value. The values for each county surrounding an installation are then totaled to arrive at a value for the region. This value is subjected to the same metric that determined the classification of the individual counties.

For example:

Indicator Value for the Region around an Installation =

(Percentage of Installation in County A* Indicator Value for County A) +

(Percentage of Installation in County $B *$ Indicator Value for County B)...etc.

\section{Indicator: Housing Availability (QL2)}

Variables

Homeowner Vacancy Rate

Scale

County

Year

2000

Data Sources

Heumann, Leonard F. 2002. Professor of Urban at Regional Planning and Psychology, University of Illinois at Urbana-Champaign. PhD, University of Pennsylvania, 1973. Adam Hall (ed.). Champaign, IL.

U.S. Bureau of the Census, U.S. Department of Commerce. 2000. Summary File 1: Homeowner Vacancy Rate. American FactFinder. Washington, DC: U.S. Bureau of the Census. Accessible through URL: http://factfinder.census.gov

Logic

This indicator along with Rental Availability provides an idea of the housing availability in a particular county and its neighboring area. Referenced in consultation with housing expert and professor at the University of Illinois Leonard Heumann, the homeownership and rental vacancy rate is relatively tight and small movements in one direction or another can have large effects in the surrounding economy. It is important to examine owner and rental availability separately to grasp a realistic picture of available housing in a given area (L.F. Heumann 2002).

With many service members required to use off base housing, housing availability is an important indicator in determining DoD stationing attractiveness and quality of life for the military and their families. Housing 
availability can directly impact a number of quality of life indicators. For example, it may determine commute times, access to schools or cultural amenities, or if a family may live with a service member.

\section{Replicable}

The U.S. Census provides vacancy statistics every decade reported in Summary File 1 available for download through URL: http:/lwww.census.gov (Bureau of the Census 2000). Vacancy statistics are also replicated as estimates annually. It is recommended that the data be replicated only once a decade due to the inaccuracy of census estimates.

\section{Directions}

Download Homeowner Vacancy Rate from the U.S. Census 2000 Summary File 1 at the county level. Available online through URL: http:/lfactfinder.census.govl (Bureau of the Census 2000). Import the data into a GIS program and join it with state boundary files to create a GIS Housing Availability indicator layer.

\section{Indicator Measure}

Housing Availability illustrates homeowner vacancy rate per county. It should be noted that some areas of high owner occupied vacancy might possibly be seasonal housing not occupied at the time of the census.

The rationale for the legend is that too high or too low of an owner vacancy rate can be an indicator of difficulty of obtaining housing (too low) or serious problems in the housing market and surrounding economy (too high). These rough classifications were provided from Leonard Heumann, a professor at the University of Illinois with expertise in housing issues, through a personal interview in 2002 (L.F. Heumann 2002):

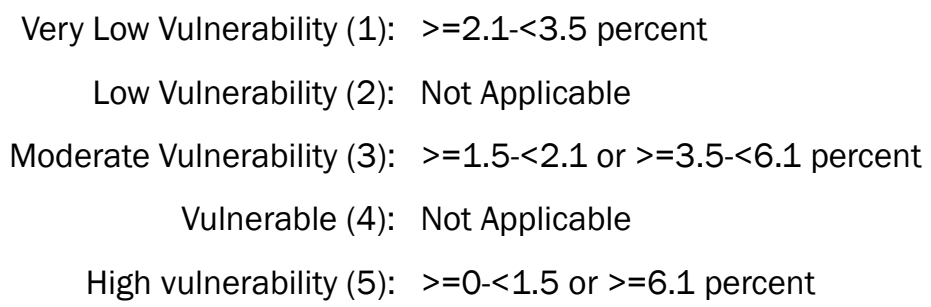

Rules

Installations are often in two or more counties. Therefore, the region around an installation is classified by a weighted average. The weighted average calculation determines what percentage of the installation is in 
each county and multiplies that percentage for each county by that county's classification value. The values for each county are then totaled to arrive at a value for the installation. This value is subjected to the same metric that determined the classification for the individual counties.

For example:

Indicator Value for the Installation =

(Percentage of Installation in County A* Indicator Value for County A) +

(Percentage of Installation in County $B *$ Indicator Value for County B)...etc.

\section{Indicator: Rental Availability (QL3)}

Variables

Rental Vacancy Rate

Year

2000

Data Sources

Heumann, Leonard F. 2002. Professor of Urban at Regional Planning and Psychology, University of Illinois at Urbana-Champaign. PhD, University of Pennsylvania, 1973. Adam Hall (Ed.). Champaign, IL.

U.S. Bureau of the Census, U.S. Department of Commerce. 2000. Summary File 1: Rental Vacancy Rate. American FactFinder. Washington, DC: U.S. Bureau of the Census. Accessible through URL: http://factfinder.census.gov

Logic

This indicator along with Homeowner Availability provides an idea of the rental availability in a particular county and its neighboring area. Referenced in consultation with housing expert and professor at the University of Illinois Leonard Heumann, the homeownership and rental vacancy rate is relatively tight and small movements in one direction or another can have large effects in the surrounding economy. It is important to examine owner and rental availability separately to grasp a realistic picture of available housing in a given area (L.F. Heumann 2002).

Many military members are required to choose off base housing. Rental availability is an important indicator in determining DoD stationing attractiveness and quality of life for military members and their families. Similar to housing availability, rental availability also directly impacts a number of quality of life indicators. For example, it may determine com- 
mute times, access to schools or cultural amenities, or if a family may live with a service member.

\section{Replicable}

The U.S. Census provides vacancy statistics every decade reported in Summary File 1 available for download through URL: http:/lwww.census.gov (Bureau of the Census 2000). Vacancy statistics are also replicated as estimates annually. It is recommended that the data be replicated only once a decade due to the inaccuracy of census estimates.

\section{Directions}

Download Rental Vacancy Rate from the U.S. Census 2000 Summary File 1 at the county level through URL: http:/lfactfinder.census.govl (Bureau of the Census 2000). Import the data into a GIS program and join it with county boundary files to create a GIS Rental Availability indicator layer.

\section{Indicator Measure}

Map rental vacancy rate per county. It should be noted that some areas of high rental occupied vacancy might possibly be seasonal housing not occupied at the time of the census.

The rationale for the legend is that too high or too low a rental vacancy rate can be an indicator of difficulty of obtaining housing (too low) or serious problems in the housing market and surrounding economy (too high). These rough classifications were provided from Leonard Heumann, a professor at the University of Illinois with expertise in housing issues, through a personal interview in 2002 (L.F. Heumann 2002):

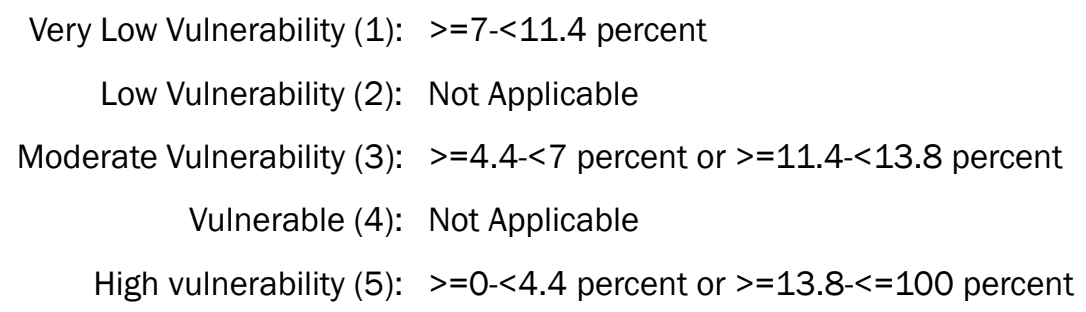

Rules

Installations are often in two or more counties. Therefore, the region around an installation is classified by a weighted average. The weighted average calculation determines what percentage of the installation is in each county and multiplies that percentage for each county by that county's classification value. The values for each county are then totaled to 
arrive at a value for the installation. This value is subjected to the same metric that determined the classification for the individual counties.

For example:

Indicator Value for the Installation =

(Percentage of Installation in County A* Indicator Value for County A) +

(Percentage of Installation in County $B *$ Indicator Value for County B)...etc.

\section{Indicator: Healthcare Availability (QL4)}

Variables

Health Professional Shortage Area (ratio of primary medical care physicians per 1,000 population)

Scale

ZIP Code

Year

2004

Data Sources

Health Resources and Services Administration (HRSA), U.S. Department of Health and Human Services. 2003. What We Do. Washington, DC: HRSA. Accessible through URL: http://www.hhs.gov/news/press/2002pres/profile.html

Health Resources and Services Administration, U.S. Department of Health and Human Services. 2005. HRSA Geospatial Data Warehouse: ZIP Code Tabulation Areas. Washington, DC: Health Resources and Services Administration. Accessible through URL: http://datawarehouse.hrsa.gov/pcsa.htm

HQDA. 2002. FY03 Army Well-Being Action Plan. Washington, DC: Deputy Chief of Staff for Personnel, HQDA. Accessible through URL: http://www.odcsper.army.mil/Directorates/wb/FY03 WBAP_Vol_1.pdf

Ringel, J eanne S., Susan D. Hosek, Ben A. Vollaard, and Sergej Mahnovski. 2002. The Elasticity of Demand for Health Care: A Review of the Literature and Its Application to the Military Health System. Washington, DC: National Defense Research Institute/ RAND Health. Accessible through URL:

http://www.rand.org/publications/MR/MR1355/MR1355.pdf

Logic

The U.S. Department of Health and Human Service (DoHHS) defines healthcare as an "essential human service" (HRSA 2005). Access to preventive healthcare and treatment for families and individuals can affect both their personnel and the region's quality of life. The Army's WellBeing Program acknowledges that low availability to healthcare can dimin- 
ish quality of life as populations go without preventive care such as immunizations, often leading to disease (USDoA 2002). Unfortunately, healthcare is not provided equally across the nation nor do all individuals use it similarly. DoD-paid healthcare differs in several important ways from the demand for healthcare services in general (J.S. Ringel et al. 2002). These differences derive from the unusual organization structure of the Military Health System (MHS). Three key differences exist. First, active duty personnel have less discretion in seeking care than their civilian counterparts and some military duties involve higher risk. Moreover, "to ensure that active duty personnel are healthy and fit for duty, they are provided more frequent preventive and routine care than would be typical for civilian the same age" (J .S. Ringel et al. 2002). Second, TRICARE, insurance provider to DoD, treats military treatment facilities (MTF) differently than civilian care. In other words, a recipient may receive more benefits if using a MTF instead of civilian care, thus allocation between the MTF and civilian providers is a factor. Third, military beneficiaries typically use substantially more healthcare service than comparable civilians do. Thus, increased demand for prescriptions and the like (J.S. Ringel et al. 2002).

Therefore, it is important to the well-being of military installations to identify areas where healthcare is underserved. Underservice is an indication of the current health status for military operations and the lives of military personnel and their families.

The DoHHS' indices of Health Professional Shortage Area (HPSA) and Medical Underservice (IMU) are currently the most comprehensive sources of secondary data to characterize the health and resource capacity of communities in the United States (HRSA 2005). Both indices are compiled by the HRSA, and are used to allocate resources for Federal and sometimes state programs including the assignment of National Health Service Corps Physicians or allowing InterNational Medical Graduates with J - 1 visas to practice in a community (HRSA 2005). An HPSA is a geographically defined area having an inadequate ratio of full-time primary care, mental health, and dental practitioners to total population. IMU designation weights HPSA calculations based on regional infant mortality rates, percentage of the population with incomes below the poverty level, and percentage of the population age 65 or older. The DoHHS' HPSA National dataset is more complete compared to the IMU National dataset. Thus, HPSA is the selected indicator. However, because differenced do exist between communities' healthcare needs, it is important to use local knowledge in interpreting healthcare availability. A complete definition of 
these measures and methods are published through URL: http://bhpr.hrsa.gov/shortage/muadatadict.htm

HPSA data is reported at the ZIP code level. Health analysis experts recognize that there are many potential geographic units to use in the monitoring of our health system, yet there is no agreement or evidence to suggest a preferred geography. The reason for mentioning the units is that significant disparities among neighbors and community groups exist. Health is not expressed by political boundary, gender, age, occupation, etc. In other words, there is no ideal standard for expressing the degree of need in a community or at what scale to address those needs. Therefore, it must be understood that the HPSA indicator is an aggregate measure of the availability ZIP codes have to healthcare. A particular ZIP code may have many designations, yet the map aggregates all designations within any given code. Therefore, with spatially large or populous ZIP codes, the data may be skewed by local "hotspots." Again, user knowledge of an area should be applied to the use of healthcare measurements.

\section{Replicable}

HRSA updates HPSA designations quarterly and is accessible through the DoHHS website through URL: $\underline{\text { http://datawarehouse.hrsa.gov/pcsa.htm }}$

\section{Directions}

Download HPSA designations from the DoHHS website. After downloading the data, "clean" the data by aggregating (averaging) rankings for ZIP codes with more than one HPSA designation. It should be noted that some ZIP codes have insufficient data. Import the cleaned data set into a GIS program and join it with ZIP code boundary files to form a Healthcare Availability indicator layer.

\section{Indicator Measure}

This indicator identifies areas (ZIP codes) where populations are medically underserved. To be designated as an HPSA, an area must exceed a population to full-time provider ratio of 3,000 to 3,500 or more people per primary care, mental health, and dental practitioners. The lower threshold ideally apples to areas with unusually high need for providers (HRSA 2005).

The indicator was calculated as a ratio of primary medical care physicians per 1,000 population as follows: 
Health Professional Shortage Area $=($ Number of full-time primary care, mental health, and dental practitioners/total population) $* 1,000$

Using the HRSA's recommendations, the following classifications were defined:

\author{
Very Low Vulnerability (1): >2.01 physicians per 1,000 population \\ Low Vulnerability (2): <=2.01->0.53 physicians per 1,000 population \\ Moderate Vulnerability (3): $<=0.53->0.33$ physicians per 1,000 population \\ Vulnerable (4): $<=0.33->0.28$ physicians per 1,000 population \\ High vulnerability (5): $>=0.28$ physicians per 1,000 population
}

\title{
Rules
}

Installations are often in two or more counties. Therefore, the region around an installation is classified by a weighted average. The weighted average calculation determines what percentage of the installation is in each county and multiplies that percentage for each county by that county's classification value. The values for each county are totaled to arrive at a value for the region around the installation. This value is subjected to the same metric that determined the classification for the individual counties.

For example:

Indicator Value for the Installation =

(Percentage of Installation in County A* Indicator Value for County A) + (Percentage of Installation in County $B *$ Indicator Value for County B)...etc.

\section{Indicator: Educational Attainment (QL5)}

Variables

Persons 25 years of age and older, Percent high school graduate or higher

Scale

County

Year

2000 
Data Sources

HQDA. 2002. FY03 Army Well-Being Action Plan. Washington, DC: Deputy Chief of Staff for Personnel, HQDA. Accessible through URL:

http://www.odcsper.army.mil/Directorates/wb/FY03 WBAP Vol 1.pdf

National Center for Educational Statistics, U.S. Department of Education. 2003. Condition of Education. Washington, DC: National Center for Educational Statistics. Accessible through URL: http://nces.ed.gov/programs/coel

U.S. Bureau of the Census, U.S. Department of Commerce. 2000. Summary File 3: Geographic Comparison Table P-11, Language, School Enrollment, and Educational Attainment. American FactFinder. (Population 25 years and over: Percent High School Graduate or Higher). Washington, DC: U.S. Bureau of the Census. Accessible through URL: http://factfinder.census.gov

Logic

Educational opportunities allow individuals to grow and enrich their life. The Army places high priority on the well-being - the "personal, physical, material, mental, and spiritual state of soldiers, civilians, and their families that contributes to their preparedness to perform the Army's mission" (USDoA 2002). Each year the Army updates an Army Well-Being Action Plan. This plan is dedicated to providing resources to meet the well-being needs of the Army as well as the entire U.S. military. These needs include the personal needs and aspirations of military personnel and family members to which education is a significant factor. The FY03 Army Well-Being Action Plan focuses on education and academic excellence for its personnel and their families (USDoA 2002). Thus, educational attainment is a highly sought after indicator for the sustainability of military installations.

The U.S. military provides all necessary education to its members. Currently, through the Education Transition Study Memorandum of Agreement, the military education focus in now shifting to nurturing relationships between civilian institutions and military institutions to ensure swift implementation of agreements for their personnel and their families (USDoA 2002). The military recognizes that it is easier to provide for education when there are resources to build off from within the surrounding community (USDoA 2002). Therefore, for this indicator, the quality of an educational environment is determined by the overall educational attainment of the surrounding community. It is assumed that the percentage of the population with a high school diploma or higher is an indicator of societal support for education (including the parental and community support). With strong support, it is then assumed the educational system will be strong and have a large amount of resources put into it. 
In addition to having the framework for educational opportunities for military employees, a high percentage of the population with a high school diploma or higher creates a strong pool of qualified employees for military operations.

\section{Replicable}

The U.S. Census provides educational attainment statistics every decade reported in Summary File 3 available for download through URL: http://www.census.gov (Bureau of the Census 2000). Every year the U.S. Census provides estimated educational attainment statistics available for download through URL: http:/lfactfinder.census.govl through the American Community Survey Summary Tables (PCT-034). However, due to the inaccuracy of U.S. Census estimates, it is recommended that the data be replicated only once a decade.

\section{Directions}

Download Geographic Comparison Table P-11. Language, School Enrollment, and Educational Attainment: 2000 from the U.S. Census website through URL: http://factfinder.census.govl (Bureau of the Census 2000). Import Population 25 years and over: Percent High School Graduate or Higher into a GIS program and join it with county boundary files to create a GIS Educational Attainment indicator layer.

\section{Indicator Measure}

Educational Attainment measures the percent of the population 25 years or older with a high school degree or higher (as calculated by the U.S. Census), and is available through URL: http:/lfactfinder.census.govl (Bureau of the Census 2000).

The sample is assumed to be relatively normal. Therefore, the National average of 69.5 percent was used to figure class breaks. The classifications for percent population with a high school diploma or higher are as follows:

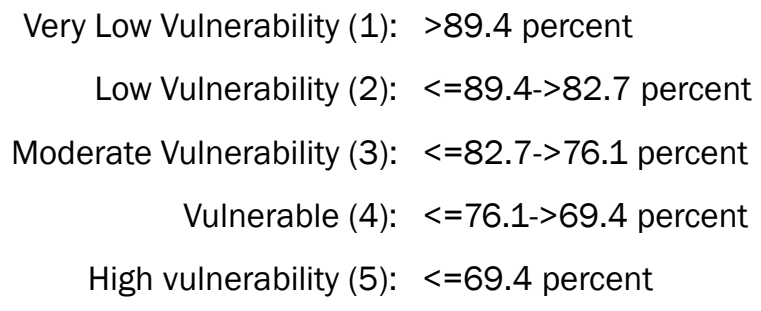


Rules

Installations are often in two or more counties. Therefore, regional classifications are determined by a weighted average. The weighted average calculation determines what percentage of the installation is in each county and multiplies that percentage for each county by that county's classification value. The values for each county are then totaled to arrive at a value for the region around the installation. This value is subjected to the same metric that determined the classification for the individual counties.

For example:

Indicator Value for the Installation =

(Percentage of Installation in County A* Indicator Value for County A) + (Percentage of Installation in County $B *$ Indicator Value for County B)...etc.

\section{Indicator: Commute Time (QL6)}

Variables

Commute Time

Scale

County

Year

2000

\section{Data Sources}

HQDA. 2002. FY03 Army Well-Being Action Plan. Washington, DC: Deputy Chief of Staff for Personnel, HQDA. Accessible through URL: http://www.odcsper.army.mil/Directorates/wb/FY03 WBAP Vol 1.pdf

Surface Transportation Policy Project. 2003. Transportation and Economic Prosperity. Washington, DC: Surface Transportation Policy Project. Accessible through URL: http://www.transact.org/library/Fact Sheets/transportation\%20and\%20economic\%20prosperity\%20.doc

U.S. Bureau of the Census, U.S. Department of Commerce. 2000. Summary File 3: Geographic Comparison Table P-12, Employment Status and Commuting to Work. American FactFinder. (Workers 16 years and over: Who did not work at home-Mean travel time to work [minutes]). Washington, DC: U.S. Bureau of the Census. Accessible through URL: http://factfinder.census.gov

Logic

Commute time relates to congestion of the local road network surrounding a military installation. Road congestion is an indicator of potential problems using the highway near installations. This addresses traffic from the 
military operations standpoint. Commute time addresses traffic from the quality of life standpoint. Individuals demand the conveniences of easy access between home and work with minimal time "wasted." Commute time also indicates the lag time in an off-post service member's ability to respond to alerts and emergencies. The natural tendency of a city is to prosper, grow, and expand outward. By nature, transportation improvements often do not keep pace with rapid population growth. Thus, commute time is a strong indicator of local quality of life. It is a measure of the inefficiency of the transportation system, which makes for happy or unhappy users (Surface Transportation Policy Project 2003).

The Surface Transportation Policy Project is a non-for-profit organization that advocates transportation systems as a component of quality of life (Surface Transportation Policy Project 2003). They cite:

The transportation system should provide for the efficient and reliable delivery and distribution of goods and services to all markets, serve employer needs for recruitment and retention of a high-quality workforce, and be redundant, resilient, reliable, and resistant to service and system disruptions. In addition, transportation investments should support local and regional economic objectives and recognize efficient activity centers as the drivers of economic prosperity and sustainable growth. (Surface Transportation Policy Project 2003)

In terms of the military, installations and their environs are where the military personnel and their families live. Excessive commute times may negatively impact re-enlistment rates (USDoA 2002). Thus commute times are sought after as an indicator of the local quality of life.

\section{Replicable}

The U.S. Census provides commuter statistics every decade reported in Summary File 3 available for download through URL: http://www.census.gov (Bureau of the Census 2000). Commuter statistics are also replicated annually based on Census of Population estimates. It is recommended that the data be replicated only once a decade due to the inaccuracy of the census estimates.

\section{Directions}

Download GCT-P12 Employment Status and Commuting to Work: 2000 from the U.S. Census 2000 Summary File 3 at the county level available online through URL: http:/lfactfinder.census.govl (Bureau of the Census 2000). Import Workers 16 years and over: Who did not work at home- 
Mean travel time to work (minutes) data into a GIS program and join it with county boundary files to create a GIS Commute Time indicator layer.

\section{Indicator Measure}

The U.S. Census Bureau reports average commute-time in minutes for each county (Bureau of the Census 2000). The National average was reported at 23 minutes for 2000 . Since the sample is assumed to be relatively normal, the classifications were statistically configured using the standard deviation (1.5) around the National average:

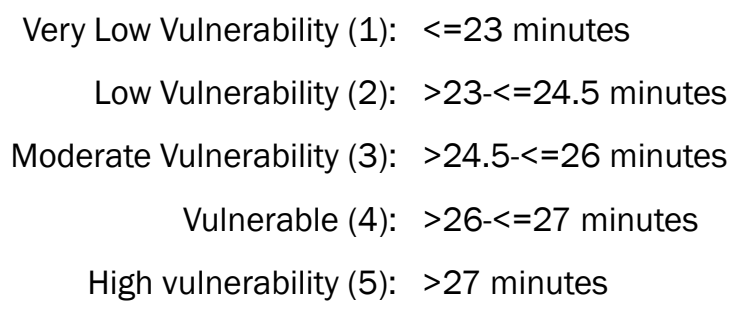

Rules

Installations are often in two or more counties. Therefore, installation classifications are determined by a weighted average. The weighted average calculation determines what percentage of the installation is in each county and multiplies that percentage for each county by that county's classification value. The values for each county are then totaled to arrive at a value for the installation. This value is subjected to the same metric that determined the classification for the individual counties.

For example:

Indicator Value for the Installation =

(Percentage of Installation in County A* Indicator Value for County A) +

(Percentage of Installation in County $B^{*}$ Indicator Value for County B)...etc.

\section{Sustainability Issue: Transportation}

\section{Indicator: Airport Capacity (TR1)}

Variables

Total Enplanement, Mile Buffers Scale

Airport 
Year

2003

Data Sources

AirNav.Com. 2004. "Airports." (complete list of airport codes). Accessible through URL: http://www.airnav.coml

Digital Aeronautical Flight Information File, National Imagery and Mapping Agency. 2005. DAFIF Edition 7. Bethesda, MD: National Imagery and Mapping Agency. Accessible through URL: https://164.214.2.62/products/digitalaero/index.cfm

Terminal Area Forecast System, Federal Aviation Administration (FAA). 2005. Air Mobility Command, Scott AFB. Unclassified Corporate Database. Accessible through URLs: http://www.apo.data.faa.gov/faatafall.HTM https://www.afd.scott.af.mil

U.S. General Accounting Office (GAO), Report to Congressional Committees. 1995. C-17 Aircraft: Cost and Performance Issues. National Security and InterNational Affairs Division. Washington, DC: GAO. Accessible through URL: http://www.fas.org/man/gao/gao9526.htm

Logic

This indicator provides a measurement of the amount of access available to the military at commercial airports. The DoD has identified a need to augment military airfields with access to commercial airports (USGAO 1995). Often it is unnecessary to duplicate the provisions of a nearby civilian airport on a military airfield. Thus, identification of commercial airport capacity is a highly sought after indicator in the decisionmaking process for military development. Air space pressures created from high use levels result in large limitation on development potential of an area to military installations' air space missions. Airport operations (take-offs and landings) are often reported for regions verses specific airports. Annual enplanements (persons boarding an airplane including certified, commuter, air-taxi, foreign, and in-transit planes) are reported at the airport level. Therefore, for the purposes of this study, total enplanements were used to measure airport capacity.

Total enplanements, however, have some limitations. Because it is a measure of the number of people using the airspace and not the number of planes using the airspace, it is not an adequate representation of the airspace capacity. For instance, two identical airports may both enplane 400 persons per day, but one airport enplanes all 400 persons onto one plane while the other airport enplanes the 400 persons among three planes. The airport enplaning three planes theoretically should have a lower availabil- 
ity to support military air operations, yet within this system both airports are rated equally. Although, this is a critical limitation of the data, the limitations of using available aircraft operation data are greater. Aircraft operations are not reported Nationally at the airport level. The lowest level available is at the state level (TAF 2005). Because of this, airport capacity ratings are heavily skewed by local "hotspots." In other words, if a state has one community ranking low in airport capacity, the entire state is classified as low capacity regardless of the characteristics of the remaining majority of the state. Aircraft operations data additionally does not take into consideration that installations located near state boundaries use airports located in more than one state. Because of these two concerns, the amount of people using an airport (total enplanements) is the preferred method to measuring airport capacity as long as local knowledge of activity patterns is understood in interpreting the capacity classifications of commercial airports.

Total enplanement data is most readily and widely available from the Federal Aviation Administration's (FAA) Terminal Area Forecast System (TAF). TAF is the official aviation activity forecast of the FAA. It contains historical aviation activity data and FAA's forecasts for 474 airports receiving FAA contract tower and radar service. This database also includes projections for more than 3,000 other airports in the National Integrated Airport Plan. The forecasts, covering fiscal years 2000-2030, project activity of four major users of the U.S. air traffic system: air carriers, air taxi and commuters, general aviation, and the military (TAF 2005). The FAA uses these forecasts to meet its budget and planning needs. It may be useful to refer to these forecasts when interpreting local airport capacity ratings. Additionally, since the TAF does not track all U.S. commercial airports, it is recommended to have an understanding of which airports near the installation in question are not included in the TAF database.

Finally, this indicator may be used in conjunction with Airspace Demand indicators to provide a greater understanding of airspace availability in a particular region.

\section{Replicable}

This indicator could be replicated every year based on information updated in the TAF System (TAF 2005).

Directions: Download the GIS airport boundary files from the Digital Aeronautical Flight Information File (DAFIF) through URL: 
https://164.214.2.62/products/digitalaero/index.cfm (AVDAFIF>ARPT.ZIP) (DAFIF 2005). These boundary files include all active civil, military, joint (civil and military), and private airports for the world. Delete all non-U.S. airports for the purposes of this indicator - keeping only civil, joint, and private airports in the United States.

Download total annual enplanements for all commercial airports from the TAF System. Import the TAF commercial airport data into a GIS program and join it with the DAFIF airports boundary files by airport code to create an Airport Capacity indicator layer. Create "buffers" around these airports at 25 miles to form vulnerability-rating classifications.

\section{Indicator Measure}

This indicator provides insight into the ability of a commercial airport within 25 miles of an installation and receiving FAA contract tower and radar service to supplement military installation air operations. Not all U.S. commercial airports are tracked by total annual enplanements. Therefore, it is vital to have an understanding of which airports near to the installation in question are not included in the study. This information may be obtained from the DAFIF airport boundary files or AirNav.com through URL: http:/lwww.airnav.com/airports. AirNav.com provides the 3letter codes for all airports (e.g., ORD for Chicago O'Hare InterNational Airport) by airport type and/ or geographic location (AirNav.Com 2004).

Airport Capacity classifications were defined by natural breaks in the data:

$$
\begin{aligned}
\text { Very Low Vulnerability (1): } & <2,262,633 \text { Total Annual Enplanements } \\
\text { Low Vulnerability (2): } & >=2,262,633-<3005916 \text { Total Annual Enplanements } \\
\text { Moderate Vulnerability (3): } & >=3,005,916-<5,979,049 \text { Total Annual Enplanements } \\
\text { Vulnerable (4): } & >=5,979,049-<6,722,332 \text { Total Annual Enplanements } \\
\text { High vulnerability (5): } & >=6,722,332 \text { Total Annual Enplanements }
\end{aligned}
$$

The National average is 2,644,376 total annual enplanements and the standard deviation is 5,733.024. The logic remains that the more people using the airport; the less available it will be to the military.

\section{Rules}

Installations typically have only one commercial airport located within a 25-mile radius. However, several installations do have two or more airports located within 25 miles. In this instance, the region around an installation takes on the airport classification of the lowest vulnerability. For in- 
stance, if two airports are located within 25 miles of an installation and one is classified as high vulnerability and the other as moderate vulnerability, the region would be classified as moderate vulnerability.

\section{Indicator: Proximity to Airports Suitable for C-5 Aircraft (TR2)}

Variables

Suitability for C-5 Aircraft, Mile Buffers

Scale

Airports

Year

2001

Data Sources

AirNav.Com. 2004. "Airports." (complete list of airport codes). Accessible through URL: http://www.airnav.coml

Digital Aeronautical Flight Information File, National Imagery and Mapping Agency. 2005. DAFIF Edition 7. Bethesda, MD: National Imagery and Mapping Agency. Accessible through URL: https://164.214.2.62/products/digitalaero/index.cfm

Terminal Area Forecast System, Federal Aviation Administration (FAA). 2005. Air Mobility Command, Scott AFB. Unclassified Corporate Database. Accessible through URLs: http://www.apo.data.faa.gov/faatafall.HTM https://www.afd.scott.af.mil

U.S. General Accounting Office (GAO), Report to Congressional Committees. 1995. C-17 Aircraft: Cost and Performance Issues. National Security and InterNational Affairs Division. Washington, DC: GAO. Accessible through URL: http://www.fas.org/man/gao/gao9526.htm

Logic

Not all aircraft types have the capability to land at every airfield due to runway strength, runway size, and runway type. Landing requirements will also vary, whether it is based on wartime or peacetime criteria. According to the J uly 1994 General Accounting Office (GAO) Report to Congressional Committees, Military Airlift: Comparison of C-5 and C-17 Airfield Availability the C-5 aircraft can land on a paved runway 5,000 ft long by $90 \mathrm{ft}$ wide during wartime, while normal performance is defined as landing on a paved runway 6,000 ft long by $147 \mathrm{ft}$ wide (USGAO 1994).

Access to a C- 5 capable runway is typically a necessity for military shipments, mobilization, and training. If access is inadequate (measured by 
geographical distance), then it is a strong indicator of pressures on the future use and vulnerability of air space, leading to greater demands and limitations on Military development and missions. This would then place the military installation in a vulnerable state, affecting the type and intensity of training that could take place on the installation.

The DoD has identified a need to augment military airfields with access to commercial airports (USGAO 1994). Often it is unnecessary to duplicate the provisions of a nearby civilian airport on a military airfield. Thus, identification of commercial airports suitable for C- 5 aircraft is a highly sought after indicator. Specifically, this indicator provides suitability for C-5 aircraft at all commercial airports receiving Federal Aviation Administration (FAA) contract tower and radar service within a prescribed distance. Thus, not all U.S. commercial airports are tracked for C- 5 suitability. It is recommended to have an understanding of which airports near the installation in question are not included in the study.

\section{Replicable}

This indicator could be replicated every year based on information updated in FAA's Terminal Area Forecast (TAF) System and Scott AFB's Airport Search Database (TAF 2001).

\section{Directions}

Digital Aeronautical Flight Information File (DAFIF) boundary files include all active civil, military, joint (civil and military), and private airports for the world (DAFIF 2005). Download complete airport GIS boundary files from the DAFIF through URL: https://164.214.2.62/products/digitalaero/index.cfm

Delete all non-U.S. airports for the purposes of this indicator-keeping only civil, joint, and private airports in the United States.

Download C-5 suitability airport data from the TAF System through URL: https://www.afd.scott.af.mill (TAF 2001). As previously mentioned, TAF does not track all U.S. commercial airports. Therefore, it is critical to use local knowledge when interpreting this indicator. Further local information may be obtained from the DAFIF airport boundary files or AirNav.com through URL: http://www.airnav.com/airports. AirNav.com provides the 3-letter codes for all airports (e.g., ORD for Chicago O'Hare InterNational Airport) by airport type and/ or geographic location (AirNav.Com 2003). Airfield in- 
formation is obtainable from the Air Mobility Command (Scott AFB) to determine whether each airfield is suitable for specific types of aircraft (i.e., C-141B, C-5, C-130, C-17, KC-10, KC-135, and C-9) (TAF 2005).

Import the TAF commercial airport data into a GIS program and join it with the DAFIF airports boundary files by airport code to create an Airport Suitability for C-5 Aircraft indicator layer. Create "buffers" around these airports at 5 and 25 miles to form vulnerability classifications.

Indicator Measure

Airport Suitability for C-5 Aircraft classifications were defined as follows:

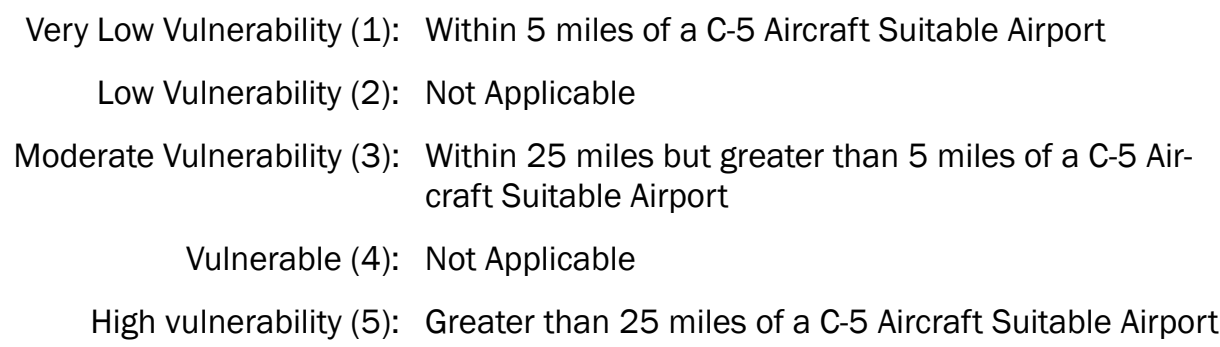

Rules

Installations typically have only one commercial airport located within a 25-mile radius. However, several installations do have two or more airports located within 25 miles. In this instance, an installation takes on the airport classification of the closest airport. For instance, if an installation were located within 5 miles of one airport and within 25 miles of another airport, the installation would be classified as very low vulnerability.

\section{Indicator: Proximity to Airports Suitable for C-141 Aircraft (TR3)}

Variables

Suitability for C-141 Aircraft, Mile Buffers

Scale

Airports

Year

2001

Data Sources

AirNav.Com. 2004. "Airports." (complete list of airport codes). Accessible through URL: http://www.airnav.coml 
Digital Aeronautical Flight Information File, National Imagery and Mapping Agency. 2005. DAFIF Edition 7. Bethesda, MD: National Imagery and Mapping Agency. Accessible through URL: https://164.214.2.62/products/digitalaero/index.cfm

Terminal Area Forecast System, Federal Aviation Administration (FAA). 2005. Air Mobility Command, Scott AFB. Unclassified Corporate Database. Accessible through URLs:

http://www.apo.data.faa.gov/faatafall.HTM https://www.afd.scott.af.mil

U.S. General Accounting Office (GAO), Report to Congressional Committees. 1995. C-17 Aircraft: Cost and Performance Issues. National Security and InterNational Affairs Division. Washington, DC: GAO. Accessible through URL: http://www.fas.org/man/gao/gao9526.htm

Logic

Not all aircraft types have the capability to land at every airport due to runway strength, runway size, and runway type. Landing requirements will also vary, whether it is based on wartime or peacetime criteria. According to a J anuary 1995 General Accounting Office (GAO) report entitled, C-17 Aircraft: Cost and Performance Issues, only the C-141 and C130 aircraft have the capability of routinely performing airdrop missions (USGAO 1995).

Access to a C-141 capable runway is typically a necessity for military shipments, mobilization, and training. If access in inadequate (measured by geographical distance), then it is a strong indicator of pressures on the future use and vulnerability of air space, leading to greater demands and limitations on Military development and missions. This would then place the military installation in a vulnerable state, affecting the type and intensity of training that could take place on the installation.

The DoD has identified a need to augment military airfields with access to commercial airports (USGAO 1995). Often it is unnecessary to duplicate the provisions of a nearby civilian airport on a military airfield. Thus, identification of commercial airports suitable for C-141 aircraft is a highly sought after indicator. Specifically, this indicator provides suitability for C141 aircraft at all commercial airports receiving Federal Aviation Administration (FAA) contract tower and radar service within a prescribed distance. Thus, not all U.S. commercial airports are tracked for C-141 suitability. It is recommended to have an understanding of which airports near to the installation in question are not included in the study. 


\title{
Replicable
}

This indicator could be replicated every year based on information updated in FAA's Terminal Area Forecast (TAF) System and Scott AFB's Airport Search Database (TAF 2001).

\section{Directions}

Download complete DAFIF airport GIS boundary files through URL: https://164.214.2.62/products/digitalaero/index.cfm (DAFIF 2005). This boundary files identify all active civil, military, joint (civil and military), and private airports for the world. Delete all non-U.S. airports for the purposes of this indicator-keeping only civil, joint, and private airports in the United States.

Download C-141 suitability airport data from the TAF System through URL: https://www.afd.scott.af.mill (TAF 2001). As previously mentioned, TAF does not track all U.S. commercial airports. Therefore, it is critical to use local knowledge when interpreting this indicator. Further local information may be obtained from the DAFIF airport boundary files or AirNav.com through URL: http://www.airnav.com/airports. AirNav.com provides the 3-letter codes for all airports (e.g., ORD for Chicago O'Hare InterNational Airport) by airport type and/ or geographic location (AirNav.Com 2003). Airfield information is obtainable from the Air Mobility Command (Scott AFB) to determine whether each airfield is suitable for specific types of aircraft (i.e., C-141B, C-5, C-130, C-17, KC-10, KC-135, and C-9) (TAF 2005).

Import the TAF commercial airport data into a GIS program and join it with the DAFIF airport boundary files by airport code to create an Airport Suitability for C-141 Aircraft indicator layer. Create "buffers" around these airports at 5 and 25 miles to form vulnerability classifications.

Indicator Measure

Airport Suitability for C-141 aircraft classifications were defined as follows:

\author{
Very Low Vulnerability (1): Within 5 miles of a C-141 Aircraft Suitable Airport \\ Low Vulnerability (2): Not Applicable \\ Moderate Vulnerability (3): Within 25 miles but greater than 5 miles of a C-141 Aircraft \\ Suitable Airport \\ Vulnerable (4): Not Applicable \\ High vulnerability (5): Greater than 25 miles of a C-141 Aircraft Suitable Airport
}


Rules

Installations typically have only one commercial airport located within a 25-mile radius. However, several installations do have two or more airports located within 25 miles. In this instance, an installation takes on the airport classification of the closest airport. For instance, if an installation were located within 5 miles of one airport and within 25 miles of another airport, the installation would be classified as very low vulnerability.

\section{Indicator: Railroad Capacity (TR4)}

Variables

Train Movements per Crossing per Day

Scale

County

Year

2004

Data Source

Federal Railroad Administration, U.S. Department of Transportation (USDOT). 2004. Highway-Rail Crossing Inventory by State. Washington, DC: USDOT Office of Safety Analysis. Accessible through URL:

http://safetydata.fra.dot.gov/OfficeofSafety/Downloads/Default.asp?page=d ownloaddbf.asp

Logic

This indicator provides a measurement of the number of trains passing through the terminal per day. The number of daily trains crossing the terminal is an indicator of potential availability problems and congestion on the rail system. The rail system may be required by the military for material shipment and mobilization. This would then place the installation in a vulnerable state, affecting mobilization or, possibly, the type and intensity of training that could take place.

It is important to note this data is on the county level, not community or installation. Hence, it may be skewed by local "hotspots." In other words, if a county has one railroad with numerous train movements, regardless of the movement characteristics, the entire county is classified as low available capacity (high vulnerability) regardless of the characteristics of the remaining majority of the county. Additionally, there are a limited number of counties that do not have a train crossing due to either a lack of railways or a lack of highways intersecting the rails. These counties may inappro- 
priately receive a low-vulnerability rating. Thus, it is critical to interpret data along with an understanding of local characteristics.

\title{
Replicable
}

This indicator could be replicated annually based on information updated in Federal Railroad Administration's Highway-Rail Crossing Inventory by State (FRA 2004).

\section{Directions}

Railroad capacity is defined as the number of trains per railroad crossing per day. A complete listing of railroad crossings at the state and county levels can be found using the Highway-Rail Crossing Inventory by State database (FRA 2004). Download county level trains per railroad per day and number of railroad crossings from the above-mentioned database. The calculation for determining the number of trains per crossing per day by county (or state) is as follows:

Number of Trains per Crossing per Day =

Grand Total Number of Trains per Day / Number of Railroad Crossings

A detailed example calculation for the state of Hawaii follows. Based on the information from Table A4, the State of Hawaii has a total of eight railroad crossings (six active, two non-active) for a grand total of 60 trains per day.

Compute the "number of trains per crossing per day" for each county. Import the resulting math into a GIS program and join it to county boundary files to create a Railroad Capacity indicator layer.

\section{Indicator Measure}

Railroad Capacity classifications were defined as follows based on definitions provided by the Federal Railroad Administration (FRA 2004):

\author{
Very Low Vulnerability (1): <10 Trains per Crossing per Day \\ Low Vulnerability (2): Not Applicable \\ Moderate Vulnerability (3): $>=10-<20$ Trains per Crossing per Day \\ Vulnerable (4): Not Applicable \\ High vulnerability (5): >=20 Trains per Crossing per Day
}


Table A4. List of railroad crossings in the state of Hawaii (USDoT. FRA 2003)

\begin{tabular}{|c|c|c|c|c|c|c|c|c|c|}
\hline $\begin{array}{c}\text { Railroad } \\
\text { Crossing \# }\end{array}$ & $\begin{array}{l}\text { Railroad } \\
\text { Line }\end{array}$ & Street & $\begin{array}{l}\text { No. of } \\
\text { Railroad } \\
\text { Tracks }\end{array}$ & $\begin{array}{c}\text { Average } \\
\text { Daily Traffic } \\
\text { through } \\
\text { Crossing }\end{array}$ & $\begin{array}{l}\text { No. of Day } \\
\text { Through } \\
\text { Trains } \\
\text { per Day }\end{array}$ & $\begin{array}{c}\text { No. of Day } \\
\text { Switch Trains } \\
\text { per Day }\end{array}$ & $\begin{array}{l}\text { No. of Night } \\
\text { Through } \\
\text { Trains } \\
\text { per Day }\end{array}$ & $\begin{array}{c}\text { No. of Night } \\
\text { Switch Trains } \\
\text { per Day }\end{array}$ & $\begin{array}{c}\text { Total No. of } \\
\text { Trains per } \\
\text { Day }\end{array}$ \\
\hline $311009 \mathrm{~V}$ & & KAPUNAKEA & 1 & 3,800 & 10 & 0 & 0 & 0 & 10 \\
\hline $311010 P$ & & FLEMING & 1 & 1,700 & 10 & 0 & 0 & 0 & 10 \\
\hline $311011 W$ & & WAHIKULI & 1 & 25 & 10 & 0 & 0 & 0 & 10 \\
\hline 311012D & & KANIAU & 1 & 950 & 10 & 0 & 0 & 0 & 10 \\
\hline 311013K & & CIVIC CENTER & 1 & 1,500 & 10 & 0 & 0 & 0 & 10 \\
\hline $311014 S$ & & PUUKOLII & 1 & 25 & 10 & 0 & 0 & 0 & 10 \\
\hline 918996X & HAWAIIAN RAILW & FT BARRETTE RD & 1 & 2,000 & 0 & 0 & 0 & 0 & 0 \\
\hline 918997E & HAWAIIAN RAILW & KALAELOA BLVD & 1 & 17,000 & 0 & 0 & 0 & 0 & 0 \\
\hline \multicolumn{5}{|c|}{ Grand Total No. of Trains per Day } & 60 & 0 & 0 & 0 & 60 \\
\hline
\end{tabular}


Number of Trains per Crossing per Day $=$

$60 / 6=10$ trains per railroad crossing per day for the state of Hawaii.

Rules

Installations are often in two or more counties and regional classifications are then determined by a weighted average. The weighted average calculation determines what percentage of the installation is in each county, and that percentage is multiplied by that county's value. The values for each county around the installation are then totaled to arrive at a value for the region around an installation. This value will then be subjected to the same metric that determined the classifications for the individual counties.

For example:

Indicator Value for the Installation =

(Percentage of Installation in County A* Indicator Value for County A) +

(Percentage of Installation in County $B *$ Indicator Value for County B)...etc.

\section{Indicator: Proximity to Interstate (TR5)}

Variables

Interstate Highways, Mile Buffers

Scale

Installation

Year

2002

Data Source

ESRI. 2002. GIS Data and Maps Media Kit. Accessible through URL:

http://www.esri.com

Logic

This indicator provides a measurement of the distance from the nearest interstate highway to an installation. The proximity of an interstate to an installation is an indicator of availability of transportation access. The interstate system is often required by the military for material shipment and mobilization. Lack of interstate access would place the military installation in a vulnerable state, affecting the type and intensity of training that could take place on the installation. 


\section{Replicable}

This indicator could be replicated every year based on updated interstate highway maps as new construction occurs.

\section{Directions}

Download interstates boundary files through URL: http://www.esri.com. Create "buffers" around these interstates at 20 and 50 miles to develop a Proximity to Interstate indicator layer.

\section{Indicator Measure}

Proximity to interstates is defined as the distance from the nearest interstate highway to an installation. All areas within 20 miles of an interstate were considered to be well served (very low vulnerability), while all areas more than 20 miles, but less than 50 miles from an interstate were considered to be moderately served (moderate vulnerability). All areas outside of these buffers are considered underserved (high vulnerability). Proximity to Interstate classifications are defined as follows:

Very Low Vulnerability (1): Within 20 miles of an interstate

Low Vulnerability (2): Not Applicable

Moderate Vulnerability (3): Within 50 miles but greater than 20 miles from an interstate

Vulnerable (4): Not Applicable

High vulnerability (5): Greater than 50 miles from an interstate

Rules

This indicator rates the region around an installation by evaluating its proximity to interstate highways. The region around an installation takes on the lowest vulnerability classification depending on its proximity to an interstate. For instance, if an installation straddles the 20 mile buffer-half of the installation within 20 miles the other half greater than 20 miles, the region resource takes on the "low vulnerability" classification.

\section{Indicator: Roadway Congestion (TR6)}

Variables

Roadway Congestion Index (RCI) Scale

State 
Year

2003

Data Sources

Chen, Ciao, ZhanfengJ ia, Pravin Varaiya. 2001. Causes and Cures of Highway

Congestion.. Berkeley, CA: University of California at Berkeley. Accessible through URL:

http://paleale.eecs.berkeley.edu/ varaiya/papers_ps.dir/csmpaperv3.pdf

Federal Highway Administration (FHA), U.S. Department of Transportation. 2005. Highway Statistics 2003. (Table PS-1, Selected Measures for Identifying Peer States; Table VM-2, Functional System Travel Annual Vehicle-Miles; Table HM60, Functional System Lane-Length Lane-Miles). Washington, DC: FHA Office of Highway Policy Information. Accessible through URLs: http://www.fhwa.dot.gov/policy/ohim/hs03/ps1.htm http://www.fhwa.dot.gov/policy/ohim/hs03/vm2.htm http://www.fhwa.dot.gov/policy/ohim/hs03/hm60.htm

Pima Association of Governments. 2004. Roadway Congestion. Tucson, AZ. Accessible through URL:

http://www.pagnet.org/TPD/rsp/default.htm

Texas Transportation Institute (TIT). 2003. The Keys to Estimating Mobility. (Chapter 5: Recommended Mobility Measures). College Station, TX: Texas A\&M University. Accessible through URL: http://mobility.tamu.edu/ums/estimating_mobility/chapter5.pdf

TIT. 2004. 2003 Urban Mobility Study. (Methodology - Base UMS Calculations). College Station, TX: Texas A\&M University. Accessible through URL: http://mobility.tamu.edu/ums/report/methodology appB.pdf

Logic

This indicator provides a measurement of the congestion of the local road network surrounding a military installation. Road congestion is an indicator of potential problems using highway system near the installation. This addresses traffic from the military operations standpoint. Congestion problems would place the military installation in a vulnerable state, affecting the type and intensity of training that could take place on the installation. For instance, commute times for work-related travel for the local community surrounding and including the installation would be extended longer than normally expected as a result of congestion problems (TIT 2003). Heavy to severe congestion areas also impacts the quality of life for the local community (see Commute Times as a Quality of Life sustainability indicator). Highways and roads within the proximity of a large metropolitan statistical area (MSA) provide higher risks of congested travel and increasing potentials for vehicular accidents (C. Chen et al. 2001). 
Additionally, it is important to note this data is on the state level, not community or installation. Hence, it may be skewed by local "hotspots." In other words, if a state has one roadway with relatively high congestion rates, the entire state may be classified as high roadway congestion regardless of the characteristics of the remaining majority of the state. Because of this concern, it is important to use local knowledge in interpreting the roadway congestion classifications. Since congestion is more associated with urban development and sprawl, the proximate to MSA indicator may be considered in conjunction with this indicator to give a better picture of the overall situation.

\section{Replicable}

This indicator could be replicated every year based on information updated annually in Federal Highway Administration's Highway Statistics (FHA 2005).

\section{Directions}

Road congestion is defined by the Roadway Congestion Index (RCI), which is defined as the ratio of traffic volume to road capacity, based on the 2003 Urban Mobility Study published by the TIT (TIT 2004). The RCI, which varies from city to city, is a function of traffic volume (also defined as annual average daily traffic in vehicles/ day), road segment length, and number of lanes in the road segment (TIT 2004). The United States Department of Transportation's Federal Highway Administration provides annual highway statistics containing urban and rural data by state on annual vehicle miles traveled (AVMT) and lane-miles (FHA 2005). The calculations for determining the RCI by state are as follows:

Daily Vehicle Miles Traveled (DVMT) =

Annual Vehicle-Miles Traveled (AVMT) / 365

Freeway DVMT = Urban Freeway DVMT + Rural Freeway DVMT

Principal Arterial DVMT $=$ Urban Principal Arterial DVMT + Rural Principal Arterial DVMT

Freeway DVMT per Lane-Mile = (Urban Freeway DVMT / Urban Freeway Lane-Miles) + (Rural Freeway DVMT / Rural Freeway Lane-Miles) 
Principal Arterial DVMT per Lane-Mile $=$

(Urban Principal Arterial DVMT / Urban Principal Arterial Lane-Miles) + (Rural Principal Arterial DVMT / Rural Principal Arterial Lane-Miles)

Roadway Congestion Index $(\mathrm{RCl})=$

(((Freeway DVMT per Lane-Mile) * Freeway DVMT) +

((Principal Arterial DVMT per Lane-Mile) * Principal Arterial DVMT)) / $((14,000$ * Freeway DVMT $)+(5,500$ * Principal Arterial DVMT $))$

Download Annual Freeway Vehicle-Miles Traveled, by State, Annual Rural Principal Arterial Vehicle-Miles Traveled, by State, Annual Urban Principal Arterial Vehicle-Miles Traveled, by State, and Lane-Miles Traveled by State data from the Highway Statistics. Calculate Roadway Congestion based on the equations above. Import the resulting math into a GIS program and join it with state boundary files to create a Roadway Congestion indicator layer. A detailed example calculation follows for the state of New York.

First, Calculate the total freeway DVMT for the state of New York.

Table A5. Annual freeway vehicle-miles traveled, by state (USDoT. FHA 2002).

\begin{tabular}{|c|c|c|c|}
\hline & Interstate (Rural) & Interstate (Urban) & Other Freeways and Expressways \\
\hline$\ldots$ & & & \\
\hline New York & 7,558 & 17,568 & 15,982 \\
\hline$\ldots$ & & & \\
\hline
\end{tabular}

Using Table A5 for the state of New York:

Rural Freeway AVMT $=7,558$ million miles

Urban Freeway AVMT $=17,568+15,982=33,550$ million miles

Therefore:

Rural Freeway DVMT $=(7,558 * 1,000,000) / 365=20,706,849.32$ miles

Urban Freeway DVMT $=(33,550 * 1,000,000) / 365=91,917,808.22$ miles

Freeway DVMT $=20,706,849.32+91,917,808.22=112,624,657.54$ miles

Second, calculate the principal arterial Daily Vehicle Miles Traveled (DVMT) for the state of New York. 
Table A6. Annual rural principal arterial vehicle-miles traveled, by state

(USDoT. FHA 2002)

\begin{tabular}{|c|c|c|c|c|c|}
\hline & $\begin{array}{c}\text { Principal } \\
\text { Arterial (Rural) }\end{array}$ & $\begin{array}{c}\text { Minor Arterial } \\
\text { (Rural) }\end{array}$ & $\begin{array}{c}\text { Major Collector } \\
\text { (Rural) }\end{array}$ & $\begin{array}{c}\text { Minor Collector } \\
\text { (Rural) }\end{array}$ & Local (Rural) \\
\hline$\ldots$ & & & & & \\
\hline New York & 5,120 & 6,232 & 5,279 & 8,903 & 4,361 \\
\hline$\ldots$ & & & & & \\
\hline
\end{tabular}

Using Table A6 for the state of New York:

Rural Principal Arterial AVMT $=$

$5,120+6,232+5,279+8,903+4,361=29,895$ million miles.

Therefore:

Rural Principal Arterial DVMT $=$

$(29,895 * 1,000,000) / 365=81,904,109.59$ miles.

Table A7. Annual urban principal arterial vehicle-miles traveled, by state (USDoT. FHA 2002)

\begin{tabular}{|c|c|c|c|c|}
\hline & $\begin{array}{c}\text { Principal Arterial } \\
\text { (Urban) }\end{array}$ & $\begin{array}{c}\text { Minor Arterial } \\
\text { (Urban) }\end{array}$ & $\begin{array}{c}\text { Major Collector } \\
\text { (Urban) }\end{array}$ & $\begin{array}{c}\text { Minor Collector } \\
\text { (Urban) }\end{array}$ \\
\hline$\ldots$ & & & & \\
\hline New York & 16,888 & 21,646 & 7,691 & 13,494 \\
\hline$\ldots$ & & & & \\
\hline
\end{tabular}

Using Table A7for the state of New York:

Urban Principal Arterial AVMT $=16,888+21,646+7,691+13,494=59,719$

million miles.

Therefore:

Urban Principal Arterial DVMT $=$

$(59,719 * 1,000,000) / 365=163,613,698.63$ miles

The total principal arterial DVMT can now be calculated as:

Principal Arterial DVMT $=$

$81,904,109.59+163,613,698.63=245,517,808.22$ miles

Third, calculate the freeway DVMT per lane-mile and principal arterial DVMT per lane-mile. 
Table A8. Lane-miles traveled by state (USDoT. FHA 2002)

\begin{tabular}{|c|c|c|c|c|}
\hline State & Urban (Freeway) & $\begin{array}{c}\text { Urban (Principal } \\
\text { Arterial) }\end{array}$ & Rural (Freeway) & $\begin{array}{c}\text { Rural (Principal } \\
\text { Arterial) }\end{array}$ \\
\hline$\ldots$ & & & & \\
\hline New York & 7,543 & 84,876 & 3,875 & 143,114 \\
\hline$\ldots$ & & & & \\
\hline
\end{tabular}

Using Table A8 for the state of New York:

Urban Freeway Lane-Miles = 7,543 lane-miles

Rural Freeway Lane-Miles $=3,875$ lane-miles

Urban Principal Arterial Lane-Miles $=84,876$ lane-miles

Rural Principal Arterial Lane-Miles $=143,114$ lane-miles

Therefore:

Freeway DVMT per Lane-Mile =

(Urban Freeway DVMT / Urban Freeway Lane-Miles) +

(Rural Freeway DVMT / Rural Freeway Lane-Miles)

Freeway DVMT per Lane-Mile

$=(91,917,808.22 / 7,543)+(20,706,849.32 / 3,875)$

$=17,529.55$ DVMT per Lane-Mile for the State of New York.

Principal Arterial DVMT per Lane-Mile $=$

(Urban Principal Arterial DVMT / Urban Principal Arterial Lane-Miles) +

(Rural Principal Arterial DVMT / Rural Principal Arterial Lane-Miles)

Principal Arterial DVMT per Lane-Mile

$=(163,613,698.63 / 84,876)+(81,904,109.59 / 143,114)$

$=2,499.98$ DVMT per Lane-Mile for the State of New York.

Finally, calculate the RCI for the state of New York.

Roadway Congestion Index $(\mathrm{RCl})=$

$((($ Freeway DVMT per Lane-Mile) * (Freeway DVMT $))+$ ((Principal Arterial DVMT per Lane-Mile) * Principal Arterial DVMT)) / $((14,000$ * Freeway DVMT $)+(5,500$ * Principal Arterial DVMT $)))$ 
Therefore:

$$
\begin{aligned}
\mathrm{RCl} & =(((17,529.55 * 112,624,657.54)+(2,499.98 * 245,517,808.22)) / \\
& ((14,000 * 112,624,657.54)+(5,500 * 245,517,808.22))) \\
& =0.884 \text { for the State of New York. }
\end{aligned}
$$

\section{Indicator Measure}

Roadway Congestion classifications were defined as follows based on information from Pima Association of Governments (Pima Association of Governments 2004):

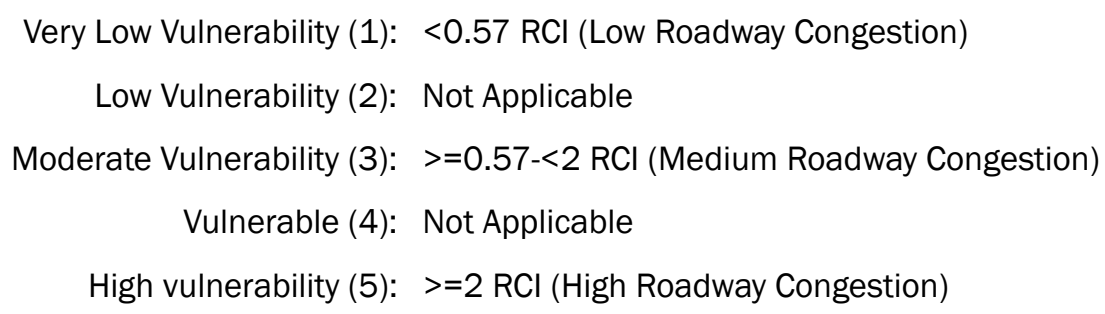

Rules

Every installation is located primarily in one state, although several installations do cross state boundaries. The region around an installation takes on the classification of the state in which the installation is primarily located.

\section{Indicator: Traffic Volume (TR7)}

Variables

Annual Average Daily Traffic per Lane (AADT)

Scale

State

Year

2003

\section{Data Sources}

Chen, Ciao, Zhanfeng Jia, Pravin Varaiya. 2001. Causes and Cures of Highway Congestion.. Berkeley, CA: University of California at Berkeley. Accessible through URL: http://paleale.eecs.berkeley.edu/ varaiya/papers ps.dir/csmpaperv3.pdf 
Federal Highway Administration (FHA), United States Department of Transportation. 2005. Highway Statistics 2003. (Table HM-62, Average Daily Traffic per Lane on Principal Arterials; Appendix B, Methodology for 2003 Annual Report). Washington, DC: FHA Office of Highway Policy Information. Accessible through URLs:

http://www.fhwa.dot.gov/ohim/hs01/aspublished/hm62.htm http://mobility.tamu.edu/ums/study/methods/entire methodology.pdf

TTI. 2002. Urban Mobility Study. Texas A\&M University. College Station, Texas. (Appendix A Exhibit A-17, 2000 Roadway Congestion Index). Accessible through URL: http://mobility.tamu.edu/ums/study/appendix A/exhibit A-17.pdf

TIT. 2003. The Keys to Estimating Mobility. (Chapter 5: Recommended Mobility Measures). College Station, TX: Texas A\&M University. Accessible through URL: http://mobility.tamu.edu/ums/estimating_mobility/chapter5.pdf

Logic

This indicator provides a measurement of the congestion of the local road network in the region surrounding a military installation in terms of annual average daily traffic per lane. Traffic volume is an indicator of potential problems using the local roads near the installation. This addresses traffic from the military operations standpoint. Congestion problems would place the military installation in a vulnerable state, affecting the type and intensity of training that could take place on the installation. For instance, commute times for work-related travel for the local community surrounding and including the installation would be extended longer than normally expected as a result of congestion problems (TTI 2003). Heavy to severe congestion areas also impacts the quality of life for the local community (see Commute Times as a Quality of Life sustainability indicator). Local roads within the proximity of a large metropolitan statistical area (MSA) provide higher risks of congested travel and increasing potentials for vehicular accidents (C. Chen et al. 2001).

Additionally, it is important to note this data is on the state level, not community or installation. Hence, it may be skewed by local "hotspots." In other words, if a state has one area with high local traffic volumes, it could skew the data for the entire state causing it to be classified as high traffic volumes regardless of the characteristics of the remaining majority of the state. Because of this concern, it is important to use local knowledge in interpreting the traffic volume classifications. This indicator should be taken in context and used in conjunction to proximity to MSA as a corroborating factor. 


\section{Replicable}

This indicator could be replicated every year based on information updated annually in Federal Highway Administration's Highway Statistics (FHA 2005).

\section{Directions}

Road access is defined by annual average daily traffic (AADT), which is the number of vehicles passing through a particular road segment (FHA 2005). The Federal Highway Administration provides annual highway statistics containing urban and rural data by state on AADT. Download the Highway Statistics data into a GIS program and join it with state boundary files to create a Traffic Volume indicator layer.

\section{Indicator Measure}

From a statistical analysis of the 2003 data, the National average AADT is 5,060 vehicles. Traffic Volume classifications were defined as follows based on definitions provided in the Texas Transportation Institute's 2002 Urban Mobility Study (TTI 2002):

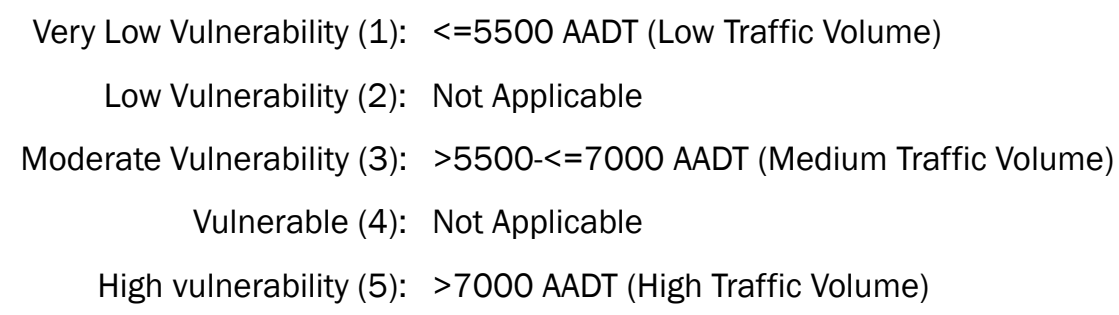

Rules

Every installation is located primarily in one state, although several installations do cross state boundaries. The region around an installation takes on the classification of the state in which the installation is primarily located. 


\section{Appendix B: Range Indicator Data}

See associated Excel file AppendixB.xls for range installation data and scoring information.<smiles>[111InH]</smiles> 


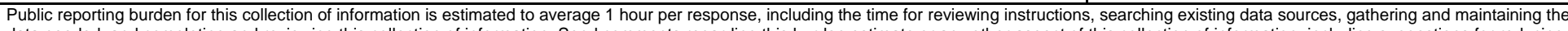

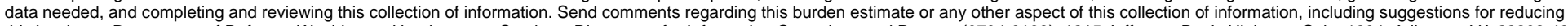

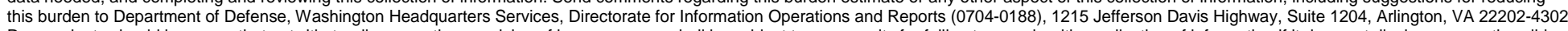

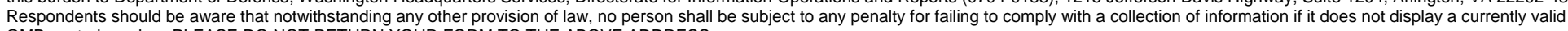
OMB control number. PLEASE DO NOT RETURN YOUR FORM TO THE ABOVE ADDRESS. 1. REPORT DATE (DD-MM-YYYY)
20-09-2006
Final

4. TITLE AND SUBTITLE

A Characterization of Land Use Trends Around the Perimeter of Military Ranges

6. AUTHOR(S)

Elisabeth M. J enicek, Donald F. Fournier, Natalie R.D. Myers, and Brad Boesdorfer
3. DATES COVERED (From - To)

5a. CONTRACT NUMBER

5b. GRANT NUMBER

5c. PROGRAM ELEMENT NUMBER

5d. PROJECT NUMBER

5e. TASK NUMBER

5f. WORK UNIT NUMBER

8. PERFORMING ORGANIZATION REPORT NUMBER

ERDC/ CERL TR-06-26

Construction Engineering Research Laboratory (CERL)

PO Box 9005,

Champaign, IL 61826-9005

9. SPONSORING I MONITORING AGENCY NAME(S) AND ADDRESS(ES)

Office of the Secretary of Defense

Range Sustainment Initiative

Arlington, VA
10. SPONSOR/MONITOR'S ACRONYM(S)

OSD

11. SPONSOR/MONITOR'S REPORT NUMBER(S)

12. DISTRIBUTION / AVAILABILITY STATEMENT

Approved for public release; distribution is unlimited.

13. SUPPLEMENTARY NOTES

\section{ABSTRACT}

A key concern for the Department of Defense (DOD) is the impact of urban encroachment on military installations and ranges. Regional competition for land, transportation, energy, water, and other resources may put the ability to use a range for essential activities at risk. The optimal use of ranges in the face of such urban encroachment, as well as changing missions, closures, and realignments requires an understanding of each range's capabilities. This research adapted the Sustainable Installations Regional Resource Assessment (SIRRA) methodology to provide a scientific, quantifiable, reliable, and data-sourced system of determining vulnerability to a set of sustainability issues based on data from the surrounding regions. This methodology can be used to identify range installations most vulnerable to encroachment issues identified by the DOD Senior Readiness Oversight Committee (SROC). The region surrounding each range installation is rated based on individual indicators organized by sustainability issue areas. Planners can then review those areas to identify ranges that would benefit from further study, intervention, and planning, and to develop strategic interventions to ensure the DOD's ability to sustain, change, or expand mission activities at the studied sites.

\section{SUBJECT TERMS}

encroachment

training lands

sustainable facilities

SIRRA military training

landuse planning ranges

\begin{tabular}{|c|c|c|c|c|c|}
\hline \multicolumn{3}{|c|}{ 16. SECURITY CLASSIFICATION OF: } & \multirow{2}{*}{$\begin{array}{l}\text { 17. LIMITATION } \\
\text { OF ABSTRACT } \\
\text { SAR }\end{array}$} & \multirow{2}{*}{$\begin{array}{l}\text { 18. NUMBER } \\
\text { OF PAGES } \\
172\end{array}$} & 19a. NAME OF RESPONSIBLE PERSON \\
\hline $\begin{array}{l}\text { a. REPORT } \\
\text { Unclassified }\end{array}$ & $\begin{array}{l}\text { b. ABSTRACT } \\
\text { Unclassified }\end{array}$ & $\begin{array}{l}\text { c. THIS PAGE } \\
\text { Unclassified }\end{array}$ & & & $\begin{array}{l}\text { 19b. TELEPHONE NUMBER (in- } \\
\text { clude area code) }\end{array}$ \\
\hline
\end{tabular}

